\title{
CATÁlOGO DOS PEIXES MARINHOS DA COLEÇÃO DA DIVISÃO DE ZOOLOGIA E GEOLOGIA DA PREFEITURA MUNICIPAL DE CURITIBA -- I.
}

\author{
* Marco Fábio Maia Corrêa \\ * Adelinyr Azevedo de Moura Cordeiro
}

*** Ivete Maria Justi

\section{INTRODUÇÃO}

0 presente trabalho relaciona, pela primeira vez, as espécies ícticas marinhas prorenientes dos Estados do Paraná e Santa Catarina e depositadas na coleção do Acervo Zoológico da Prefeitura Ýunicipal de Curitiba. surgido a partir de 1935, com o lançamento do plano de reorganização do antigo Museu Paranaense, inaugurado a 2.5 de setembro de 1876.

Os exemplares estudados compreendem material obtido por diversos pesquisadores. em coletas realizadas a partir de 1942 e sem metodologia pré-estabelecida.

Constam para cada espécie catalogada o nome vulgar, o correspondente em inglês, a procedência. a distribuição conhecida e os números de registro.

Referências são feitas ainda à ampliação, para o Sul, do registro de ocorrência. de algumas espécies. Breves discussões taxonômicas foram também fornecidas para espécies pouco referidas na literatura.

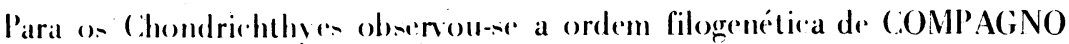
(19-3) " para (O) teichthy a atualmente proposta e especialmente preparada por (iREEVIIO(O) (1980).

Os exemplares de difícil identificação foram enviados ao especialista N. A. Menezes, do Museu de Zoologia da Universidade de São Paulo, sendo a autoria destas identificações sempre consignadas a este taxonomista.

Embora as epécies marinhas possuam, em sua maioria, habitat bem definido, verificou-se. não obstante, a ocorrência de permeio, de espécies dulcícolas. Todas estão incluídas no presente catálogo, inclusive as que habitam normalmente embocaduras de rios, uma vez que muitas delas são encontradas quer como habitantes permanente, quer como visitantes ocasionais em baías e/ou estuários.

Os locais de coleta e suas coordenadas geográficas encontram-se assinaladas respectivamente nos mapas 1,2 e tabela $\mathrm{I}$. Todas as espécies estão representadas por fotografias com suas respectivas escalas.

* Biólogo; Professor Assistente - Universidade Federal do Paraná - Centro de Biologia Marinha - Lab. Ictiologia.

* Bióloga; Pesquisadora - Divisão de Zoologia e Geologia da Prefeitura Municipal de Curitiba.

*** Bióloga; U. F. PR - Colaboradora junto ao Centro de Biologia Marinha - Lab. Ictiologia. 
Com o objetivo de compressão de espaço, os nomes dos coletores e as datas dr coleta são representados no catálogo através de código (númers letra cutre parênteses e após o número de registro), que correspondem aos registros abaixo relacionados em ordem numérica e alfabética crescentes.

1 - André Mayer

2 - Augusto \& Rolando

3 - Barão O. Fiori Di Caprani

4 - C. Gofferjé

5)- D. Pluge \& R. B. Lange

6 - Exc'ursão Zoológi'a

7 - Escola de Pesca
a) VIII/1946
b) $\mathrm{XII} / 1946$

a) VII/1951
a) $\mathrm{II} / 1945$
b) III/ 1946
c) $1 / 1950$
a) VII/1943
b) $\mathrm{I} / 1946$
c) $-/ 1948$
d) VII/1948
e) $I / 1949$
f) IX/1949
g) $I / 1950$
h) $V / 1950$
i) $s /$ data

IX/1952
a) XII/1942
j) IX/1963
b) $V / 1948$
k) II/1964
c) $-/ 1950$
l) II/1965
d) IV/1953
m) IV/1965
e) IX/1961
n) VII/1965
f) $\mathrm{XI} / 1961$
o) IX/1965
g) II/1963
p) $X I / 1966$
h) IV/1963
q) $\mathrm{V} / 1973$
i) $V / 1963$
r) s/data

8 - H. Ribeiro
a) IV/1960
b) $X / 1962$
c) $X I / 1962$
d) XII/1962
e) IX/1963

a) IX/1959

b) IV $/ 1960$
9 - Hirondino de Ramos
10 - J. Leprevost
11 - J. Loyola e Silva
- VIII/1982
- VII/1944
- I/1965


12 - M. H. Nogueira \& W. Esper
a) $\mathrm{XI} / 1962$
b) $I / 1964$
c) $X / 1964$
d) II/1966

13 - M. H. Nogueira
a) II/1962
b) $\mathrm{XI} / 1962$
h) VII/1967
c) XII/1962
i) III/1968
d) II/1964
j) IV/1971
e) III/1964
k) $\mathrm{XI} / 1971$
f) II/1966
l) XII/1971
g) III/1966
m) VII/ 1972
n) $\mathrm{XII} / 1972$

14 - M. Leal

IX/1981

15 - M. F.M. Corrêa
a) VII/1974
b) VIII/1980

16 - Pe. Jesus Moure
a) II/ 1945
b) IX/1945
c) XII/1945
d) II/1946

17 - P. Cerdeira \& M.F.M. Corrêa
a) V/1978
b) I/1979

18 - P. Cerdeira \& P. da Silva - V/1978

19 - R B. Lange \& Pe. Jesus Moure
a) II/1945
b) $V / 1951$

20 - R B. Lange
a) XII/1942
f) II/1951
k) VII/1957
b) VII/1944
g) $V / 1951$
l) IV/1964
c) $\mathrm{XI} / 1944$
h) IX/1952
d) II/ 1945
i) VII/1954
m) VII/1964
n) IX/1964
e) II/1946
j) $\mathrm{II} / 1957$
o) IV/1965

p) VII/1965

q) IX/1965

r) $X I I / 1965$

s) VI/ 1967

21 - R. Lange - VII/1972

22 - R. Saveau - II/1945

23 - Selly (sic) - VII/1965

24- R. Lange \& Zaide Alexandre - XI/1977

25 - Y. Saito Kuniyoshi

$\begin{array}{ll}\text { a) VI/1973 } & \text { b) VII/1973 }\end{array}$

26 - Z. Alexandre

VIII/1974

27 - W. Esper \& M. H. Nogueira
a) II/1962
b) IX/1962
c) $\mathrm{XI} / 1962$
d) XII/1971
03 
28 - W. Esper
a) $X / 1961$
d) $\mathrm{XI} / 1962$
f) V/1965
b) II/1962
e) IV/1963
g) IX/1965
c) $X / 1962$

29 - W. R. Agulhan

VII/1970

30 - S/coletor e s/data

31 - S/coletor
a) $-/ 1970$
d) VII/1944
f) II/1964
b) II/ 1945
e) $-/ 1956$
g) VII/1964
c) $\mathrm{VI} / 1944$

ABREVIAÇŌES UTILIZADAS

$\begin{array}{lll}\text { BR } & - & \text { Brasil } \\ \text { SC } & - & \text { Santa Catarina } \\ \text { PR } & - & \text { Paraná } \\ \text { E.U.A. } & - & \text { Estados Unidos da América } \\ \text { SP } & - & \text { São Paulo } \\ \text { B. } & - & \text { Baía } \\ \text { Ur } & - & \text { Uruguai } \\ \text { C.P. } & - & \text { Comprimento padrão } \\ \text { C.C. } & - & \text { Comprimento da cabeça } \\ \text { Alt. } & - & \text { Altura do (orpo } \\ \text { S/ } & -- & \text { Sem } \\ \text { Obs. } & - & \text { Observação } \\ \text { M.P. } & - & \text { Museu Paranaense } \\ \text { IAPAR } & - & \text { Instituto Agronômico do Paraná }\end{array}$




\begin{tabular}{|c|c|c|c|c|c|}
\hline Antonina/PR & $\left(25^{\circ}\right.$ & 26 'S & - & $48^{\circ}$ & $\left.43^{\prime} w\right)$ \\
\hline Baía de Paranaguá/PR & $\left(25^{\circ}\right.$ & 30 'S & - & 480 & $30 ' w)$ \\
\hline Barra Velha/SC & $\left(26^{\circ}\right.$ & 37 'S & - & 480 & $\left.41^{\prime} w\right)$ \\
\hline Cabeçudas/SC & $\left(26^{\circ}\right.$ & 56 'S & - & 480 & 38 'w) \\
\hline Caiobá/PR & $\left(25^{\circ}\right.$ & 51 'S & - & 480 & 32 'w) \\
\hline Canasvieiras/SC & $\left(27^{\circ}\right.$ & 25 'S & - & 480 & 29 'w) \\
\hline Guaraqueçaba/PR & $\left(25^{\circ}\right.$ & 18 'S & - & 480 & 20 'w) \\
\hline Guaratuba/PR & $\left(25^{\circ}\right.$ & 53 'S & - & 480 & 34 'w) \\
\hline Ilha das Cobras/PR & $\left(25^{\circ}\right.$ & 29 'S & - & 480 & $\left.25^{\prime} w\right)$ \\
\hline Ilha da Figueira/PR & $\left(25^{\circ}\right.$ & $21 ' S$ & - & 480 & 04'w) \\
\hline Ilha do Gastão/PR & \multicolumn{5}{|c|}{ (Ponto de coleta não localizado) } \\
\hline Ilha do Mel/PR & $\left(25^{\circ}\right.$ & 33 's & - & 480 & 17 'w) \\
\hline Ilha Rasa/PR & $\left(25^{\circ}\right.$ & 33 'S & - & 480 & $\left.26^{\prime} w\right)$ \\
\hline Ilha Rasa da Cotinga/PR & $(250$ & 32 'S & - & 480 & $\left.25^{\prime} w\right)$ \\
\hline Ipanema/PR & $\left(25^{\circ}\right.$ & $41, \mathrm{~S}$ & - & 480 & $\left.27^{\prime} \mathrm{w}\right)$ \\
\hline Itajaí/SC & $\left(26^{\circ}\right.$ & 55 'S & - & 480 & $\left.40^{\prime} w\right)$ \\
\hline Matinhos/PR & $\left(25^{\circ}\right.$ & $49 ' S$ & - & 480 & $32 ' w)$ \\
\hline Paranaguá/PR & $\left(25^{\circ}\right.$ & 31 's & - & 480 & 31 'w) \\
\hline Pontal do Sul/PR & $\left(25^{\circ}\right.$ & 35 's & - & 480 & 21 'w) \\
\hline Praia de Leste/PR & $\left(25^{\circ}\right.$ & $42 ' S$ & - & 480 & $28 ' w)$ \\
\hline Prainha, Caiobá/PR & $\left(25^{\circ}\right.$ & 51 's & - & 480 & $32 ' w)$ \\
\hline Rio Cachoeira/PR & $\left(25^{\circ}\right.$ & 34 'S & - & 480 & 37 'w) \\
\hline Rio Guanandi/PR & $\left(25^{\circ}\right.$ & 30 'S & - & 480 & $50 ' w)$ \\
\hline Serra Negra, Assungui/PR & $\left(25^{\circ}\right.$ & $11 ' s$ & - & 480 & $\left.25^{\prime} w\right)$ \\
\hline Ubatuba/SC & $\left(25^{\circ}\right.$ & $11 \mathrm{~s}$ & - & 480 & 33 'w) \\
\hline
\end{tabular}

TABELA I - Coordenadas geográficas dos locais de coleta referidos no texto. 


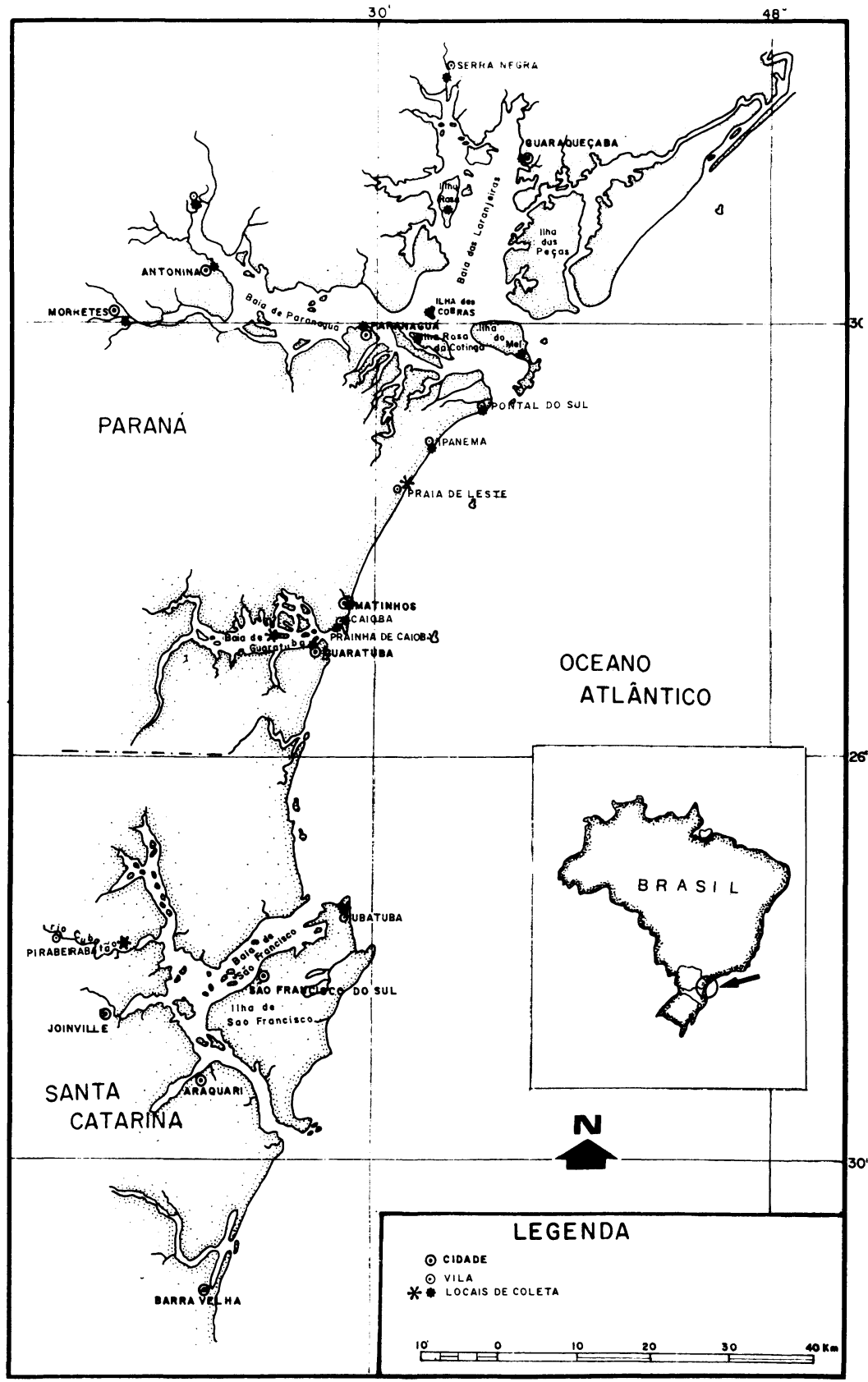

Mapa I - Locais de coleta para os Estados do Paraná e Santa Catarina.

06 


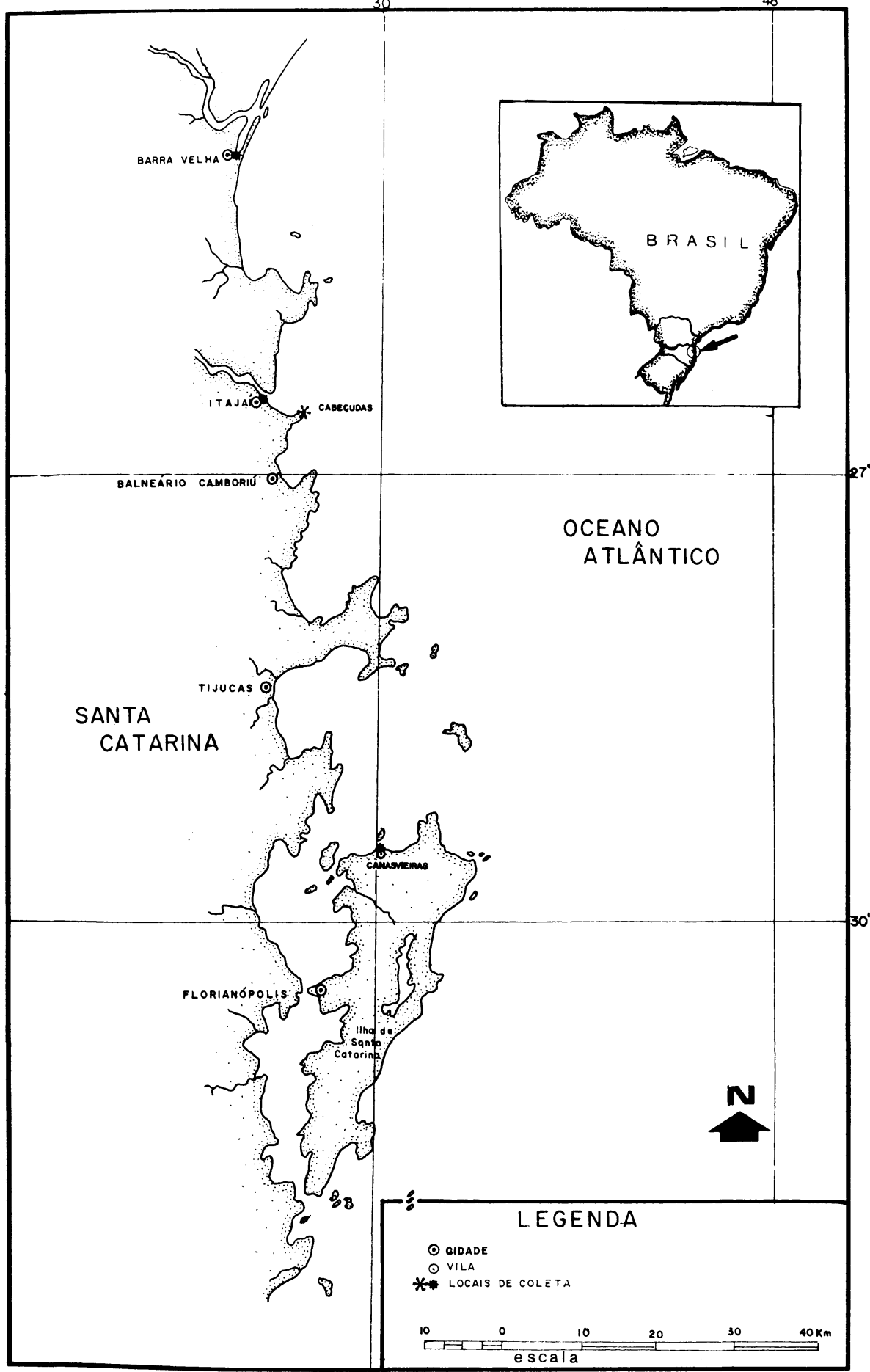

Mapa 2 - Locais de coleta para o litoral do Estado de Santa Catarina.

07 
CLASSE CHONDRICHTHYES (COMPAGNO, 1973)

SUBCLASSE ELASBRANCHII

COORTE EUSELACHII

SUPERORDEM BATOIDEA

ORDEM RAJIFORMES

SUBORDEM RHINOBATOIDEI

\section{FAMILIA RHINOBATIDAE}

Gênero: Rhinobatos Link, 1790.

Espécie-tipo: Raja rhinobatos Linnaeus

Rhinobatos percellens (Walbaum, 179:)

Fig. I.1

Nome vulgar: Raia-viola.

Correspondente em inglês: Guitar fish.

Distribuição: ambos os lados do Altêntico; do Caribe ao norte da Argentina.

Material Colecionado: Ilha das Cobras - B. de Paranaguá/PR, MP 0573, 0575, $0579,0580,0586(3 \mathrm{~b})$.

Matinhos/PR - MP 1195 (6o).

ORDEM TORPEDINIFORMES

SUPERFAMILIA TORPEDINOIDEA

2. FAMILIA NARCINIDAE

Gênero: Narcine Henle, 1834. 
Espécie-tipo: Torpedo brasiliensis Olfers.

Narcine brasiliensis (Olfers, 1831).

Fig. I.2

Nome vulgar: Raia elétrica, treme-treme.

Correspondente em inglês: Eletric rays, torpedos.

Distribuição conhecida: Carolina do Norte ao norte da Argentina.

Material colecionado: Guaratuba/PR - MP 770 (13L); 771, 772 (8a); 913, 914 $(13 b) ; 915,1042 ; 1043(13 a) ; 926(27 c)$

Prainha, Caiobá/PR - MP 355 (3a); 356, 560 (16a).

Pontal do Sul/PR - MP 602, 603 (6L); 1100 (6o).

Canasvieiras/SC - MP 230 (4d); 369 (4c).

ORDEM MYLIOBATIFORMES

SUPERFAMILIA DASYATOIDEA

\section{FAMILIA DASYATIDAE}

Gênero: Dasyatis Rafinesque, 1810.

Espécie-tipo: Dasyatis ujo Rafinesque.

Dasyatis say (Lesueur, 1817).

Fig. I.3

Nome vulgar: Raia chita.

Correspondente em inglês: Stingray.

Distribuição conhecida: de Massachusetts à Argentina.

Material colecionado: Guaratuba/PR - MP 2929, 2930, 2931 (8a).

\section{SUPERFAMILIA MYLIOBATIDEA}

\section{FAMILIA RHINOPTERIDAE}

Gênero: Rhinoptera (kuhl) Cuvier, 1829.

Espécie-tipo: Myliobatis marginatus Geoffroy.

Rhinoptera bonasus (Mitchill, 1815).

Fig. I.4

None vulgar: Ticonha.

Correspondente em inglês: Cownose ray.

Distribuição conhecida: da nova Inglaterra ao Rio de Janeiro.

Material colecionado: Prainha, Caiobá/PR - MP 769 (16a). 


\section{FAMILIA TRIAKIDAE}

Gênero: Mustelus Link, 1790.

Espécie-tipo: Squalus mustelus Linnaeus.

\section{Mustelus schimitti Springer, 1939.}

Fig. II.1

Nome vulgar: Cação.

Correspondente em inglês: Houndshark, Smooth-hounds.

Distribuição conhecida: do Rio de Janeiro(BR) ao norte da Argentina.

Material colecionado: Matinhos/PR - MP 1083, 1102 a 1105 (6L).

\section{FAMILIA CARCHARHINIDAE}

Gênero: Carcharhinus Blainville, 1816.

Espécie-tipo: Squalus commersonianus Blainville.

\section{Carcharhinus porosus Ranzani 1839.}

Fig. II. 2

Nome vulgar: Azeiteiro.

Correspondente em inglês: Smalltail shark.

Distribuição conhecida: da Costa Norte do México ao sudeste do Brasil.

Material colecionado: Caiobá/PR - MP 294 (6a).

Gênero: Rhizoprionodon Whithney, 1929.

Espécie-tipo: Carcharias (Scolidon) crenidens Klunziger.

$$
\begin{gathered}
\text { Rhizoprinodon lalandei (Valenciennes, 1841). } \\
\text { Fig. II.3 }
\end{gathered}
$$

Nome vulgar: Cação-frango.

Correspondente em inglês: Brazilian sharpnose shark.

Distribuição conhecida: do Panamá a Santa Catarina (BR).

Material colecionado: Praia de Leste/PR - MP 583, 646 (6b).

\section{FAMILIA SPHYRNIDAE}

Gênero: Sphyrna Rafinesque, 1810. 
Espécie-tipo: Sphyrna zygaena Linnaeus.

Sphyrna tudes (Valenciennes, 1822).

Fig. II.4

Nome vulgar: Martelo, cambeva, chapéu-armado.

Correspondente em inglês: Hammerhead, bonnethead shark.

Distribuição conhecida: Atlântico, do Gôlfo do México ao Uruguai e Mediterrâneo.

Material colecionado: Guaratuba/PR - MP 890 (28a).

CLASSE OSTEICHTHYES (GREENWOOD, 1980).

SUPERCOORTE ELOPOCEPHALA

COORTE ELOPOMORPHA

ORDEM ANGUILLIFORMES

SUBORDEM ANGUILLOIDEI

SUPERFAMILIA MURAENOIDEA

1. FAMILIA MURAENIDAE

Gênero: Gymnothoraz Bloch, 1795.

Espécie-tipo: Gymnothorax reticularis Bloch, por design. ult. Com. Int. Nom. Zool. (1926).

Gymnothorax ocellatus Agassiz, 1834.

Fig. III.1

Nome vulgar: Moreia-pintada.

Correspondente em inglês: Blackedge moray.

Distribuição conhecida: das Grandes Antilhas Ilhas ao sul do Brasil.

Material colecionado: Baía de Paranaguá/PR - MP 1847(26).

Canasvieiras/SC - MP332(4f).

\section{SUPERFAMILIA OPHICHTHYODEA}

\section{FAMILIA OPHICHTHYOIDEA}

Gênero: Ophichthus Ahl, 1787.

Espécie-tipo: Muraena ophis Linnaeus.

Ophichthus gomesii Castelnau, 1855."

Fig. III. 2

Nome vulgar: Muçum. 
Correspondente em inglês: Shrimp eel.

Distribuição conhecida: da Flórida ao sul do Brasil.

Material colecionado: Guaratuba/PR - MP 55l (6q); 904 (7d); 1000, 1001, $1002(7 \mathrm{c})$.

COORTE CLUPEOCEPHALA

SUBCOORTE CLUPEOMORPHA

ORDEM CLUPEIFORMES

SUBORDEM CLUPEOIDEI

\section{FAMILIA CLUPEIDAE}

Gênero: Opisthonema Gill, 1861.

Espécie-tipo: Clupanodon thrissa Lacépède (Não Clupea thrissa Osbeck) = Megalops oglina Lesueur, 1817.

Opisthonema oglinum (Lesueur, 1817).

Fig. IV.1

Nome vulgar: Sardinha-chata, sardinha-bandeira, sardinha-de-penacho.

Correspondente em inglês: Atlantic thread herring.

Distribuição conhecida: da Nova Inglaterra à Argentina.

Material colecionado: Prainha, Caiobá/PR - MP 224 e 238 (19a).

Ilha das Cobras/PR - MP 250 (3b).

Ilha do Gastão/PR - MP 963,964(28c).

Gênero: Harengula Cuvier \& Valenciennes, 1847.

Espécie-tipo: Harengula latulus Valenciennes, 1847 (Não Clupeola latulus Cuvier, 1829).

Harengula clupeola (Cuvier, 1829).

Fig. IV.2

Nome vulgar: Sardinha-cascuda.

Correspondente em inglês: False herring, false pilchard.

Distribuição conhecida: da Flórida (E.U.A.) a São Paulo (BR).

Material colecionado: Guaratuba/PR - MP 853 a 855 (8b); 883 (7a).

Guaraqueçaba/PR - MP 293 (10).

Ilha do Gastão/PR - MP 965 a 981, 991, 997 (28c).

Pontal do Sul/PR - MP 1086, 1087 (6o).

Canasvieiras/SC - MP 241, 249 (4e).

Gênero: Sardinella Cuvier \& Valenciennes, 1847.

Espécie-tipo: Sardinella aurita Valenciennes.

Sardinella brasiliensis (Steindachner, 1786).

Fig. IV.3 
Nome vulgar: Sardinha verdadeira.

Correspondente em inglês: Brazilian sardinella (Am. Fish.Soc.-Orange spot sardine). Distribuição conhecida: do Rio de Janeiro para o Sul (BR).

Material colecionado: Caiobá/PR - MP 289 (20e).

$$
\begin{aligned}
& \text { Matinhos/PR - MP 2639 a } 2649 \text { (6n). } \\
& \text { Ubatuba/SC - MP 2650, } 2651 \text { (13f). }
\end{aligned}
$$

Gênero: Pellona Valenciennes, 1847.

Espécie-tipo: Pellona orbignyana Valenciennes (por design. ult. de Gill, 1861).

$$
\text { Pellona horroweri (Fowler, 1917). }
$$

Fig. IV.4

Nome vulgar: Sardinha-mole.

Correspondente em inglês: American pellona.

Distribuição conhecida: do Panamá ao Rio Grande do Sul (BR).

Material colecionado: Guaratuba/PR - MP 1182 (6o); 2845 (13a).

Canasvieiras/SC - MP 199 (4e); 204 (4d).

Ubatuba/SC - MP 1414 a 1419, 1423 a 1425 (13f); 2807B (13a).

\section{FAMILIA ENGRAULIDAE}

Gênero: Anchoa Jordan \& Evermann, 1927.

Espécie-tipo: Engraulis compressus Girard.

$$
\text { Anchoa filifera (fowler, 1915). }
$$

Fig. V.1

Nome vulgar: Manjuba.

Correspondente em inglês: Anchovy.

Distribuição conhecida: Caribe, da Venezuela a Cananéia (SP - BR).

Material colecionado: Antonina/PR - MP 330 (4d).

$$
\text { Guaratuba/PR - MP } 1038 \text { a 1041, } 1044 \text { a } 1073 \text { (7c). }
$$

Canasvieiras/SC - MP 211, 229 (4e).

Ubatuba/SC - MP 1421, 1422 (13f).

Nota: Os exemplares representam uma extensão do limite de distribuição da espécie para o Sul.

$$
\text { Anchoa tricolor (Agassiz, 1829). }
$$

Fig. V.2

Nome vulgar: Manjuba.

Correspondente em inglês: Anchovy.

Distribuição conhecida: do Norte do Brasil à Argentina.

Material colecionado: Matinhos/PR - MP 1084A (13d). 
Gênero: Lycengraulis Günther, 1868.

Espécie-tipo: Engraulis grossidens Cuvier.

Lycengraulis grossidens (Cuvier, 1829).

Fig. V. 3

Nome vulgar: Manjuba.

Correspondente em inglês: Toothed anchovy.

Distribuição conhecida: Sudeste da Venezuela à Argentina.

Material colecionado: Prainha/Caiobá/PR - MP 256, 258 (16a); 596 (20f).

Ubatuba/SC - MP 1420 (13f).

Gênero: Cetengraulis Günther, 1868.

Espécie-tipo: Engraulis edentulus Cuvier.

Cetengraulis edentulus (Cuvier, 1829).

Fig. V. 4

Nome vulgar: Manjuba.

Correspondente em inglês: Atlantic anchoveta.

Distribuição conhecida: Caribe, Panamá e Santa Catarina (BR).

Material colecionado: Guaraqueçaba/PR - MP 1183 (6o).

Guaratuba/PR - MP 2859 (13i).

Canasvieiras/SC - 242 e 253 (4e).

Ubatuba/SC - MP 1426 (13f).

SUBCOORTE EUTELEOSTEI

DIVISÃO OSTARIOPHYSI

SUPERORDEM OTOPHYSI

ORDEM SILURIFORMES

5. FAMILIA ARIIDAE

Gênero: Bagre Öken, 1817.

Espécie-tipo: Silurus bagre Linnaeus por tautonomia.

Bagre bagre (Linnaeus, 1766).

Fig. VI. 1

Nome vulgar: Bagre-sari.

Corrrespondente em inglês: Coco sea catfish.

Distribuição conhecida: da Colômbia a Santa Catarina (BR).

Material colecionado: Guaratuba/PR - MP 625 (6q).

Paranaguá/PR - MP 1206 (28e).

Matinhos/PR - MP 1239 (20m). 
Gênero: Arius Cuvier \& Valenciennes, 1840.

Espécie-tipo: Pimelodus arius Buchanan.

Arius spixii (Agassiz, 1829).

Fig. VI.2

Nome vulgar: Bagre amarelo.

Correspondente em inglês: Madamango sea catfish.

Distribuição conhecida: Costas da América Central à América do Sul (de Belize ao sudeste do Brasil).

Material colecionado: Prainha, Caiobá/PR - MP 308, 313 (16a).

Caiobá/PR - MP 1214 a $1216(20 \mathrm{~m}) ; 1217$ (20o).

Guaraqueçaba/PR - MP 310 (20b).

Ilha das Cobras/PR - MP 584 (3b).

Guaratuba/PR - MP 622, 848 a 852, 932, 934 (8b); 949, 950(27c); 1036, $1037(7 \mathrm{c}) ; 1201$ a 1205 (6j).

Matinhos/PR - MP 872 (20r); 1238 (20s); 1242, 1244 $(20 \mathrm{~m})$.

Pontal do Sul/PR - MP 1167 a 1169 (6o).

Paranguá/PR - MP 1207 (28e).

Canasvieiras/SC - MP 234 (4e).

Nota: Os exemplares representam uma extensão do limite de distribuição da espécie para o Sul.

\section{DIVISÃO NEOGNATHI \\ SUBDIVISÃO NEOTELEOSTEI \\ ORDEM AULOPIFORMES \\ SUBORDEM ALEPOSAUROIDEI \\ SUPERFAMIILIA SYNODONTOIDEA}

\section{FAMILIA SYNODONTIDAE}

Gênero: Synodus Gronow, 1763.

Espécie-tipo: Esox synodus Linnaeus por tautonomia.

Synodus foetens (Linnaeus, 1766).

Fig. VII.1

Nome vulgar: Peixe-lagarto.

Correspondente em inglês: Lizardfish.

Distribuição conhecida: Nova Inglaterra a Santa Catarina (BR).

Material colecionado: Ilha do Mel/PR - MP $98(20 \mathrm{~h})$. 


\section{SUPERORDEM PARACANTHOPTERYGII}

\section{ORDEM BATRACHOIDIFORMES}

\section{FAMILIA BATRACHOIDIDAE}

Gênero: Porichthys Girard, 1854.

Espécie-tipo: Porichthys notatus Girard.

Porichthys pososissimus (Valenciennes, 1837).

Fig. VIII.1

Nome vulgar: Mamangá liso.

Correspondente em inglês: Toadfish.

Distribuição conhecida: do Rio de Janeiro (BR) à Argentina (limite norte ainda não definido).

Material colecionado: Caiobá/PR - MP 1089 (6o); 331 (20a).

Guaratuba/PR - MP 1079 (7c); 1237 (6h).

Matinhos/PR - MP 1084B (13d); 1277 (23).

Canasvieiras/SC - MP 203 (4d).

ORDEM GOBIESOCIFORMES

8. FAMILIA GOBIESOCIDAE

Gênero: Gobiesox Lacépède, 1800.

Espécie-tipo: Gobiesox cephalus Lacépède.

Gobiesox strumosus Cope, 1870.

Fig. IX.1

Nome vulgar: Piramangaba.

Correspondente em inglês: Clingfish.

Distribuição conhecida: de Nova Jérsei (E.U.A.) ao Rio Grande do Sul (BR).

Material colecionado: Ilha Rasa/PR - MP 267 (31e).

Caiobá/PR - MP 268 (31c).

\section{ORDEM LOPHIIFORMES}

SUBORDEM ANTENNAROIDEI

9. FAMILIA OGCOCEPHALIDAE

Gênero: Ogcocephalus Fischer, 1813. 
Espécie-tipo: Lophius vespertilio Linnaeus.

Ogcocephalus vespertilio (Linnaeus, 1758).

Fig. X.1

Nome vulgar: Peixe-morcego.

Correspondente em inglês: Batfish.

Distribuição conhecida: de New York (E. U. A.) ao Uruguai.

Material colecionado: Caiobá/PR - MP 63 (6c).

Prainha, Caiobá/PR - MP 322 (16a).

Barra Velha/SC - MP 94 (2).

Canasvieiras/SC - MP 185 (4d).

\section{ORDEM GADIFORMES}

SUBORDEM GADOIDEI

\section{FAMIILIA GADIDAE}

Gênero: Urophycis Gill, 1863.

Espécie-tipo: Blennius regius Walbaum = Urophycis regius.

\section{Urophycis brasiliensis (Kaup, 1858).}

Fig. XI.1

Nome vulgar: Abrótea, bacalhau brasileiro.

Correspondente em inglês: Brazilian codling.

Distribuição conhecida: da Argentina ao Rio de Janeiro (BR).

Material colecionado: Guaratuba/PR - MP 1033 a 1035 (7c); 930 (27c); 2851 (27a). Matinhos/PR - MP 2834 (20p).

\section{SUPERORDEM ACANTHOPTERYGII}

SERIE ATHERINOMORPHA

ORDEM ATHERINIFORMES

SUBORDEM EXOCOETOIDEI

\section{FAMILIA HEMIRAMPHIDAE}

Gênero: Hyporhamphus Gill, 1859.

Espécie-tipo: Hyporhamphus tricuspidatus Gill = Hemirhamphus unifasciatus Ranzani.

Hyporhamphus unifasciatus (Ranzani, 1842).

Fig. XII.1 
Nome vulgar: Agulha.

Correspondente em inglês: Common halfbeak.

Distribuição conhecida: Atlântico (Leste dos Estados Unidos ao sul do Brasil) e Pacífico (oeste das Indias).

Material colecionado: Antonina/PR - MP 196 (4d).

\section{FAMILIA BELONIDAE}

Gênero: Strongylura Van Hasselt, 1823.

Espécie-tipo: Strongylura caudimaculata Van Hasselt $=$ Belone strongylura Van Hasselt, 1823.

Strongylura timucu (Walbaum, 1792).

Fig. XII.2

Nome vulgar: Timucú, timbucú.

Correspondente em inglês: Timucu needlefish.

Distribuição conhecida: Costa leste da Fórida ao sul do Brasil.

Material colecionado: Antonina/PR - MP 193 (4d).

Guaratuba/PR - MP 2794 (13l).

\section{SUBORDEM ATHERINOIDEI}

\section{FAMILIA ATHERINIDAE}

Gênero: Xenomelaniris Schultz, 1948.

Espécie-tipo: Atherina brasiliensis Quoy \& Gaimard.

Xenomelaniris brasiliensis (Quoy \& Gaimard, 1824).

Fig. XII.3

Nome vulgar: Peixe-rei; manjuba.

Correspondente em inglês: Silverside.

Distribuição conhecida: da Venezuela ao Rio Grande do Sul (BR).

Material colecionado: Guaratuba/PR - MP 797 a $802 ; 804$ a $813,815,816$ e $858(8 \mathrm{~b})$.

SERRIE PERCOMORPHA

ORDEM GASTEROSTEIFORMES

SUBORDEM SYNGNATHOIDEI

\section{FAMIILIA SYNGNATHIDAE}

Gn̂ero: Hippocampus Rafinesque, 1810. 
Espécie-tipo: Hippocampus hippocampus Linnaeus.

Syngnathus hippocampus Linnaeus.

Hippocampus heptagonus Rafinesque por tautonomia absoluta.

Hippocampus erectus Perry, 1810.

Fig. XIII.1

Nome vulgar: Cavalo-marinho.

Correspondente em inglês: Sea-horse.

Distribuição conhecida: Atlântico Oriental e Ocidental (Nova Escócia e Argentina). Material colecionado: Canasvieiras/SC - MP 182, 183 (4d).

Hippocampus reidi Ginsburg, 1933.

Fig. XIII.2

Nome vulgar: Cavalho-marinho.

Correspondente em inglês: Sea-horse.

Distribuição conhecida: Bahamas, Bermudas, Caribe ao sul do Brasil.

Material colecionado: Illha do Mel/PR - MP 187 (31a).

Canasvieiras/SC - MP 181 (4d); 284 (4b).

Gênero: Syngnathus Linnaeus, 1758.

Espécie-tipo: Syngnathus acus Linnaeus.

Syngnathus folleti Herald, 1942.

Fig. XIII.3

Nome vulgar: Peixe-cachimbo.

Correspondente em inglês: Pipefish.

Distribuição conhecida: de São Paulo (BR) ao Uruguai.

Material colecionado: Canasvieiras/SC - MP 179, 189, 191, 194, 198, 210,296(4d).

ORDEM SCORPAENIFORMES

SUBORDEM SCORPAENOIDEI

\section{FAMILIA SCORPAENIDAE}

Gênero: Scorpaena Linnaeus, 1758.

Espécie-tipo: Scorpaena porcus Linnaeus.

Scorpaena brasiliensis Cuvier, 1829.

Fig. XIV.1

Nome vulgar: Peixe-pedra, mamangá, beatinha.

Correspondente em inglês: Scorpionfish, rockfish. 
Distribuição conhecida: da Virgínia (E.U.A.) a Santa Catarina (BR).

Material colecionado: Canasvieiras/SC - MP 180, 186, 200 (4d); 309 (4b).

\section{FAMILIA TRIGLIDAE}

Gênero: Prionotus Lacépède, 1802.

Espécie-tipo: Prionotus evolans Lacépède por monotipia.

Prionotus punctatus (Cuvier, 1829).

Fig. XIV.2

Nome vulgar: Cabrinha.

Correspondente em inglês: Bluewing searobin.

Distribuição conhecida: da América Central (Belize) à Argentina.

Material colecionado: Ilha do Mel/PR - MP 19 (20h).

Canasvieiras/SC - MP 166 (4e).

Itajai/SC - MP 2852, 2853 (14).

\section{ORDEM DACTYLOPTERIFORMES}

\section{FAMILIA DACTYLOPTERIDAE}

Gênero: Dactylopterus Lacépède, 1802.

Espécie-tipo: Dactylopterus pirapeda Lacépède = Trigla volitans Linnaeus.

Dactylopterus volitans (Linnaeus, 1758).

Fig. XV.1

Nome vulgar: Peixe-voador.

Correspondente em inglês: Flying gurnard.

Distribuição conhecida: Atlântico Oriental e Ocidental (das Bermudas a Argentina).

Material colecionado: Guaraqueçaba/PR - MP 270, 282 (10).

Ilha das Cobras/PR - MP 581 (3b).

Antonina/PR - MP 390 (19b).

Guaratuba/PR - MP 2795 (15a).

Canasvieiras/SC - MP 197 (4d); 207, 246, 255 (4e).

\section{ORDEM PERCIFORMES}

SUORDEM PERCOIDEI

\section{FAMILIA CENTROPOMIDAE}

Gênero: Centropomus Lacépède, 1803. 
Espécie-tipo: Sciaena undecimalis Bloch.

Centropomus parallelus Poey, 1860.

Fig. XVI.1

Nome vulgar: Robalo-peva.

Correspondente em inglês: Fat snook.

Distribuição conhecida: do sul da Flórida (E.U.A.) ao sul do Brasil.

Material colecionado: Prainha, Caiobá/PR - MP 263, 264, 311 (20d).

Caiobá/PR - MP 318 (20e).

Guaratuba/PR - MP 1078 (7c); 2796 (13i).

Antonina/PR - MP 1312, 1313, 1314, 1315 (24).

Rio Cachoeira/PR - MP 1992 (18).

Rio Guanandi/PR - MP 1993 e 1994 (17b); 1995 a 1998(17a)

\section{FAMILIA SERRANIDAE}

Gênero: Diplectrum Holbrook, 1855.

Espécie-tipo: Diplectrum fasciculares Holbrook.

Perca formosa Linnaeus.

Diplectrum radiale (Quoy \& Gaimard, 1824).

Fig. XVI.2

Nome vulgar: Michole da areia.

Correspondente em inglês: Sand seabass.

Distribuição conhecida: da Flórida (E.U.A.) ao Uruguai.

Material colecionado: Ilha das Cobras/PR - MP 297 (28e).

Ubatuba/SC - MP 2339 (13f).

Gênero: Mycteroperca Gill, 1862.

Espécie-tipo: Serranus olfax Jenyns.

Mycteroperca tigris (Valenciennes, 1833).

Fig. XVI.3

Nome vulgar: Badejo.

Correspondente em inglês: Tiger grouper.

Distribuição conhecida: da Flórida, Caribe, Venezuela a Ubatuba (SP-BR).

Material colecionado: Guaraqueçaba/PR - MP 1181 (6o).

Nota: $O$ exemplar corresponde a uma extensão do limite de distribuição da espécie para o Sul. 
20. FAMILIA GRAMMISTIDAE

Gênetro: Rypticus Cuvier, 1829.

Espécie-tipo: Anthias saponaceus Bloch.

Rypticus randalli Courtenay, 1967.

Fig. XVI.4

Nome vulgar: Peixe sabão.

Correspondente em inglês: Soapfish.

Distribuição conhecida: Atlântico Ocidental, da Jamaica até o litoral de São Paulo (BR).

Materirl colecionado: Guaratuba/PR - MP 928, 929 (27c).

Nota: 0 exemplar representa uma extensão do limite de distribuição da espécie para o Sul.

\section{FAMILIA PRIACANTHIDAE}

Gênero: Priacanthus Öken, 1817.

Espécie-tipo: Anthias macrophtalmus Bloch.

Priacanthus arenatus Cuvier, 1829.

Fig. XVII.1

Nome vulgar: Olho-de-boi, olho-de-cão.

Correspondente em inglês: Atlantic bigeye.

Distribuição conhecida: do Canadá ao norte da Argentina.

Material colecionado: Caiobá/PR - MP 604 (20f).

Guaratuba/PR - MP 909 (13i).

\section{FAMILIA POMATOMIDAE}

Gênero:Pomatomus Lacépède, 1802.

Espécie-tipo: Pomatomus skib Lacépède = Perca saltatrix Linnaeus.

Pomatomus saltator (Linnaeus, 1766).

Fig. XVII.2

Nome vulgar: Anchova, enchova.

Correspondente em inglês: Bluefish.

Distribuição conhecida: praticamente cosmopolita para o Oeste do Atlântico, da Nova Escócia à Argentina.

Material colecionado: s/procedência - MP 0298 (30). 
23. FAMILIA CARANGIDAE

Gênero: Parona Berg, 1895.

Espécie-tipo: Paropsis signata Jenyns.

Parona signata (Jenyns, 1842).

Fig. XVIII.1

Nome vulgar: Viúva.

Correspondente em inglês: Jack.

Distribuição conhecida: do Rio de Janeiro (BR) ao norte da Patagônia (Argentina).

Material colecionado: Pontal do Sul/PR - MP 1139, 1140 (6o).

Gênero: Oligoplites Gill, 1863.

Espécie-tipo: Scomber saurus Bloch \& Schneider = Oligoplites occidentalis Gill

Oligoplites saliens (Bloch, 1793).

Fig. XVIII.2

Nome vulgar: salteira, gaivira.

Correspondente em inglês: Atlantic leatherjack.

Distribuição conhecida: das Honduras ao Uruguai.

Material colecionado: Prainha, Caiobá/PR - MP 260 (16a); 592 (20f), 595 (20j).

Antonina/PR - MP 178 (4a).

Guaratuba/PR - MP 2616, 2617 (6q).

Rio Guanandi/PR - MP 2615 (17b).

Oligoplites saurus (Bloch \& Schneider, 1801).

Fig. XVIII.3

Nome vulgar: salteira, gaivira.

Correspondente em inglês: Atlantic leatherjack.

Distribuição conhecida: de Massachusetts (E.U.A.) ao Rio Grande do Sul (BR).

Material colecionado: Guaratuba/PR - MP $856(8 \mathrm{~b})$.

Pontal do Sul/PR - MP 1150 a 1153, 1155, 1160 e 1162 (6o).

Prainha, Caiobá/PR - MP 251 (20d).

Caiobá/PR - MP 299 (20f).

Gênero: Trachinotus Lacépède, 1802.

Espécie-tipo: Scomber falcatus Förskal.

Trachinotus carolinus (Linnaeus, 1766).

Fig. XIX.1

Nome vulgar: Sernambiguara, pampo.

Correspondente em inglês: Flórida pompano. 
Distribuição conhecida: de Massachusetts (E.U.A.) ao Rio Grande do Sul (BR). Material colecionado: Caiobá/PR - MP 278, 285, 291 (20e).

Illha das Cobras/PR - MP $563(3 \mathrm{~b})$.

Ilha do Gastão/PR - MP 994 (7b).

Pontal do Sul/PR - MP 1134 (28f); 1428 (28e).

Guaratuba/PR - MP 2797 (13i).

Guaraqueçaba/PR - MP 1178 a 1180 (6o).

Trachinotus goodei Jordan \& Evermann, 1826.

Fig. XIX.2

Nome vulgar: Pampo-malhado.

Correspondente em inglês: Palometa, pompano.

Distribuição conhecida: Massachusetts (E.U.A.) à Argentina.

Material colecionado: Guaratuba/PR - MP 2798, 2799 (13i).

Trachinotus falcatus (Linnaeus, 1758).

Fig. XIX.3

Nome vulgar: Pampo-galhudo.

Correspondente em inglês: Permit.

Distribuição conhecida: de Massachusetts (E.U.A.) ao Rio Grande do Sul (BR).

Material colecionado: Prainha, Caiobá/PR - MP 235 (16a).

Caiobá/PR - MP 2351 (20m).

Guaratuba/PR - MP 2800, 2801 (13i).

Gênero: Chloroscombrus Girard, 1859.

Espécie-tipo: Seriola cosmopolita Cuvier \& Valenciennes = Scomber chrysurus Linnaeus.

Chloroscombrus chrysurus (Linnaeus, 1766).

Fig. XX.1

Nome vulgar: Palombeta, palometa.

Correspondente em inglês: Atlantic bumper.

Distribuição conhecida: de Massachusetts (E.U.A.) à Argentina.

Material colecionado: Guaratuba/PR - MP 1016 e 1017, 1019 a 1025, 1027 a 1032,1081 (7c); 2855 e 2854 (13i);

825 a $831(8 b) ; 758,955$ a 962 (28c).

Matinhos/PR - MP 1107 (6o).

Caiobá/PR - MP 1225 (20p); 1443 e 1444 (20).

Pontal do Sul/PR - MP 1429, 1430, 1433, 1440, 1441(12c).

Ilha do Mel/PR - MP 2, 73 e 97 (5).

Prainha, Caiobá/PR - MP 254, 265 (16a).

Ubatuba/SC - MP 1434 a 1439 (12d). 
Gênero: Hemicaranx Bleeker, 1862.

Espécie-tipo: Hemicaranx marginatus Bleeker por design. original.

Hemicaranx amblyrhynchus (Cuvier, 1833).

Fig. XX.2

Nome vulgar: Vento-leste, catarro, rabo-azedo.

Correspondente em inglês: Bluntnose jack.

Distribuição conhecida: da Carolina do Norte (E.U.A.) à Santa Catarina (BR).

Material colecionado: Antonina/PR - MP 389 e 2859 (19b).

Guaraqueçaba/PR - MP 2856 a 2858, 1178 a 1180 (6o).

Gênero: Caranx Lacépède, 1802.

Espécie-tipo: Scomber carangus Bloch = Caranx hippos Linnaeus.

Caranx latus Agassiz, 1831.

Fig. XX.3

Nome vulgar: Xarelete, Xerelete

Correspondente em inglês: Horse-eye-jack.

Distribuiçção conhecida: de Nova Jérsei (E.U.A.) ao Rio Grande do Sul (BR).

Material colecionado: Guaratuba/PR - MP 877 e 878 (8b).

Gênero: Selene Lacépède, 1802.

Espécie-tipo: Selene argentea Lacépède = Zeus vomer Linnaeus.

Selene setapinnis (Mitchill, 1815).

Fig. XXI.1

Nome vulgar: Galo, galo verdadeiro.

Correspondente em inglês: Atlantic moonfish.

Distribuição conhecida: do Canadá ao norte da Argentina.

Material colecionado: Guaratuba/PR - MP 882 (7a); 908 (13d); 2861 (13i).

Pontal do Sul/PR - MP 1142 a $1149 ; 1151,1154$ (6o); 2632 e $2633(25 a)$.

Matinhos/PR - MP 1190 (6o); 2634 (20p).

Caiobá/PR - MP 1222, 1233 (20m); 1442 (20n).

Selene vomer (Linnaeus, 1758).

Fig. XXI.2

Nome vulgar: Galo de penacho.

Correspondente em inglês: Atlantic look down.

Distribuição conhecida: do Maine (E.U.A.) ao Uruguai.

Material colecionado: Caiobá/PR - MP 1220, 1221 e 1223 (20m). 
Prainha, Caiobá/PR - MP 239 (16a).

Guaraqueçaba/PR - MP 273 (10).

Guaratuba/PR - MP 823 (8b) e 2860 (13g).

Ubatuba/SC - MP 1427 (13f).

\section{FAMILIA GERREIDAE}

Gênero: Eucinostomus Baird \& Girard, 1857.

Espécie-tipo: Eucinostomus argenteus Baird \& Girard = Gerres gula Cuvier \& Valenciennes.

Eucinostomus melanopterus (Bleeker, 1863).

Fig. XXII.1

Nome vulgar: Carapeba, carapeva.

Correspondente em inglês: Flagfin mojarra

Distribuição conhecida: de Lousiana (E.U.A.) ao Rio Grande do Sul (BR).

Material colecionado: Prainha, Caiobá/SC - MP 225, 245 (16a).

Guaratuba/PR - MP 803, 832 e 833 (8b).

Serra Negra (Assungui)/PR - MP 568, 2863 a 2865 (1a).

Gênero: Diapterus Ranzani, 1840.

Espécie-tipo: Diapterus auratus Ranzani.

Diapterus rhombeus (Cuvier, 1829).

Fig. XXII.2

Nome vulgar: Escrivão.

Correspondente em inglês: Caitipa mojarra.

Distribuição conhecida: do Golfo do México ao sul do Brasil.

Material colecionado: Guaratuba/PR - MP 787 (8b).

Pontal do Sul/PR - MP 2348 e 2349 (13n).

Diapterus olithostomus (Goode \& Bean, 1822).

Fig. XXII.3

Nome vulgar: Escrivão.

Correspondente em inglês: Irish mojarra.

Distribuição conhecida: da Fórida ao sudeste do Brasil.

Material colecionado: Guaratuba/PR - MP 783, 784, 794 e 822 (8b); 2862 (13i).

Nota: Os exemplares representam uma extensão do limite da distribuição da espécie para o Sul.

Gênero: Eugerres Jordan \& Evermann, 1927.

Espécie-tipo: Gerres plumieri Cuvier. 


\section{Eugerres brasilianus (Cuvier, 1830).}

Fig. XXII.4

Nome vulgar: Caratinga vivóca.

Correspondente em inglês: Striped mojarra.

Distribuição conhecida: das Antilhas ao sul do Brasil.

Material colecionado: Caiobá/PR - MP 312 (20e).

Guaratuba/PR - MP 773 a 775, 777 a $782,785,786,788$, 790 a $792,795,796,834,835,2866(8 b)$.

\section{FAMILLIA POMADASYIDAE}

Gênero: Genyatremus Gill, 1862.

Espécie-tipo: Diagramma cavifrons Cuvier = Lutjanus luteus Bloch.

Genyatremus luteus (Bloch, 1795).

Fig. XXIII.1

Nome vulgar: Saguá.

Correspondente em inglês: Torroto grunt.

Distribuição conhecida: do Caribe ao sudeste do Brasil.

Material colecionado: Antonina/PR - MP 209 (4c).

Guaratuba/PR - MP 836 a $840(8 b)$.

Prainha, Caiobá/PR - MP 315 (16a).

Paranaguá/PR - MP 1082 e 1093 (6o).

Ilha das Cobras/PR - MP 562 (3b).

Ilha do Gastão/PR - MP 879, 880, 885 (7a).

Nota: Os exemplares representam uma extensão do limite da distribuição da espécie para o Sul.

Gênero: Boridia Cuvier \& Valenciennes, 1830.

Espécie-tipo: Boridia grossidens Cuvier \& Valenciennes, 1830 por monotipia.

Boridia grossidens (Cuvier, 1830).

Fig. XXIII.2

Nome vulgar: Corcoroca-sargo.

Correspondente em inglês: Grunt.

Distribuição conhecida: do Rio de Janeiro (BR) à Argentina.

Material colecionado: Guaratuba/PR - MP 2871 (6q).

Gênero: Pomadasys Lacépède, 1803.

Espécie-tipo: Sciaena argentea Förskal.

Pomadasys corvinaeformis (Steindachner, 1868).

Fig. XXIII.3 
Nome vulgar: Roncador.

Correspondente em inglês: Roughneck grunt.

Distribuição conhecida: da América Central ao sul do Brasil.

Material colecionado: Prainha, Caiobá/PR - MP 237 (16b), 248 e 307 (16a).

Pontal do Sul/PR - MP 1133 (12c).

Ipanema/PR - MP 2869 (12b).

Gênero: Orthopristis Girard, 1859.

Espécie-tipo: Orthopristis duplex Girard = Perca chrysopterus Linnaeus.

Orthopristis ruber (Cuvier, 1830).

Fig. XXIV.1

Nome vulgar: Corcoroca, corocoroca.

Correspondente em ingês: Corocoro grunt.

Distribuição conhecida: das Antilhas ao sul do Brasil.

Material colecionado: Antonina/PR - MP 177 (4i).

Ilha das Cobras/PR - MP 222 (3b).

Prainha, Caiobá/PR - MP 227 (16a).

Guaratuba/PR - MP 2870 (6i).

Gênero: Conodon Cuvier \& Valenciennes, 1830.

Espécie-tipo: Conodon antillanus Cuvier \& Valenciennes = Perca nobilis Linnaeus por monotipia.

Conodon nobilis (Linnaeus, 1758).

Fig. XXIV.2

Nome vulgar: Roncador de listra.

Correspondente em inglês: Barred grunt.

Distribuição conhecida: do Texas (E.U.A.) ao sul do Brasil.

Material colecionado: Guaratuba/PR - MP 954 a 1045 (27c); 1070 (7c); 2806B, 2867 e $2868(6 \mathrm{q})$.

Pontal do Sul/PR - MP 2337 (13n).

Ubatuba/SC - MP 2785A (13F).

\section{FAMILIA SCIAENIDAE}

Gênero: Menticirrhus Gill, 1861.

Espécie-tipo: Perca alburnus Linnaeus = Cyprinus americanus Linnaeus.

Menticirrhus americanus (Linnaeus, 1758). Fig. XXV.1

Nome vulgar: Betara, papa-terra. 
Correspondente em inglês: Southern kingcroacker, Southern kingfish.

Distribuição conhecida: do Cabo Cod (E.U.A.) à Argentina.

Material colecionado: Ilha das Cobras/PR - MP 220 e 585 (3b).

Caiobá/PR - MP 228 (31b).

Guaratuba/PR - MP 891 (28a); 916 (13b); 940 (27c); 1218, 2872 a 2876 (6j); 2831 e $2832(6 \mathrm{q})$.

Matinhos/PR - MP 1108 e 1109 (6o); 1251 (20m).

Pontal do Sul/PR - MP 1124(6o);1125 a $1127(28 \mathrm{~g}) ; 1128(6 \mathrm{o})$ 1129 (28g); 1130 e 1131 (6o).

Gênero: Micropogonias Bonaparte, 1831.

Espécie-tipo: Micropogonias lineatus Cuvier = Umbrina furnieri Desmarest, 1823

Micropogonias furnieri (Desmarest, 1823).

Fig. XXV.2

Nome vulgar: Corvina.

Correspondente em inglês: White mouth croaker.

Distribuição conhecida: Antilhas, América Central à Argentina.

Material colecionado: Prainha, Caiobá/PR - MP 244, 305 e 306 (16a).

Guaratuba/PR - MP 817 a 821 (8b).

Illha do Gastão, Baía da Guaratuba/PR - MP 998 (28c).

Pontal do Sul/PR - MP 931 (13c).

Gênero: Paralonchurus Bocourt, 1869.

Espécie-tipo: Paralonchurus petersi Bocourt.

Paralonchurus brasiliensis (Steindachner, 1875).

Fig. XXV.3

Nome vulgar: Maria luisa, camiseta, clariana.

Correspondente em inglês: Banded croacker.

Distribuição conhecida: do Panamá à Argentina.

Material colecionado: Prainha, Caiobá/PR - MP 213, 219, 243, 321 (16a) e 329 (16c).

Guaratuba/PR - MP 869 a 871, 1009, 1014, 1059 e 1199 (7c); 925, 905, 912 e $1200(13 \mathrm{~b}) ; 951$, 952 e 1015 (27c); 1198 (7e); 1208 (6j).

Pontal do Sul/PR - MP 2331 a 2334 (13m); 2335 e 2336 (13n).

Matinhos/PR - MP 2342 (20s); 2802, 2820 a 2823 (20p).

Ubatuba/SC - MP 2338 (13f).

Gênero: Nebris Cuvier \& Valenciennes, 1830. 
Espécie-tipo: Nebris microps Cuvier \& Valenciennes.

Nebris microps Cuvier, 1830.

Fig. XXV.4

Nome vulgar: Pescada banana.

Correspondente em inglês: Smalleye crocker.

Distribuição conhecida: da Venezuela ao sudeste do Brasil.

Material colecionado: Guaratuba/PR - MP 938 (27c).

Pontal do Sul/PR - MP 1101 e 2877 (6o).

Matinhos/PR - MP 2803 e 2804 (20p).

Nota: Os exemplares correspondem a extensão do limite de distribuição da espécie para o sul do Brasil.

Gênero: Larimus Cuvier \& Valenciennes, 1830.

Espécie-tipo: Larimus breviceps Cuvier \&Valenciennes, 1830.

Larimus breviceps Cuvier, 1830.

Fig. XXVI.1

Nome vulgar: Oveva.

Correspondente em inglês: Shorthead drum.

Distribuição conhecida: das Antilhas e América Central até o litoral de Santa Catarina (BR).

Material colecionado: Ilha das Cobras, Baía de Paranaguá/PR - MP 221 (3b).

Prainha, Caiobá/PR - MP 240 e 295 (16a).

Guaratuba/PR - MP 936 (27d); 2816 a 2818 (6q).

Pontal do Sul/PR - MP 1090 e 1091 (6o).

Matinhos/PR - MP 1184, 1186, 1189, 1191 a 1194 e 2878

(6o); $1240(20 \mathrm{~m}) ; 2879(6 \mathrm{k})$.

Ubatuba/SC - MP 2827 a 2830 (13f).

Gênero: Isopisthus Gill, 1862.

Espécie-tipo: Ancylodon parvipinnis Cuvier \& Valenciennes.

Isopisthus parvipinnis (Cuvier, 1830).

Fig. XXVI.2

Nome vulgar: Pescada malheira, cantadeira.

Correspondente em inglês: Shortfin corvina.

Distribuição conhedia: da Costa Rica ao sul do Brasil.

Material colecionado: Prainha, Caiobá/PR - MP 223 (3lb).

Guaraqueçaba/PR - MP 276 e 277 (10); 2882 (6o).

Guaratuba/PR - MP 1074 e 1075 (7c); 2824 e 2825 (13k); 2883 (6o); 2884 a 2897 e 2899 a 2912 (6r). 
Pontal do Sul/PR - MP 1172 (6o).

Matinhos/PR - 2826 (20p).

Ubatuba/SC - MP 2786A, 2787A e 2788A, 2880 e 2881 (13f).

Gênero: Cynoscion Gill, 1861.

Espécie-tipo: Johnius regalis Schneider = Otolithus regalis Cuvier \& Valenciennes.

Cynoscion acoupa (Lacépède, 1802).

Fig. XXVI.3

Nome vulgar: Pescada amarela.

Correspondente em inglês: Weakfish.

Distribuição conhecida: do Panamá à Argentina (rara).

Material colecionado: Guaraqueçaba/PR - MP 314 (31d); 2353 (20i).

Cynoscion leiarchus (Cuvier, 1830).

Fig. XXVII.1

Nome vulgar: Pescada branca.

Correspondente em inglês: Weakfish.

Distribuição conhecida: do Panamá ao sul do Brasil.

Material colecionado: Prainha, Caiobá/PR - MP 281 (16a).

Ilha das Cobras, Baía de Paranaguá/PR - MP 585 (3b).

Paranaguá/PR - MP 1092, 1094 a 1098 (6o).

Gênero: Stellifer Öken, 1817.

Espécie-tipo: Bodianus stellifer Bloch.

Stellifer rastrifer (Jordan, 1889).

Fig. XXVII.2

Nome vulgar: Canguá, Canganguá.

Correspondente em inglês: Rake stardrum.

Distribuição conhecida: da Colômbia a Santa Catarina (BR).

Material colecionado: Illa das Cobras, Baía de Paranaguá/PR - MP 216 (3b).

Prainha de Caiobá/PR - MP 233 (16a); 587 a 591; 594, $598,599,600$ e 601 (20f).

Guaratuba/PR - MP 911 (13b); 927 e 933 (27c); 935, 937 (27d); 1018, 1046 a 1058,1060 a 1069 , $1072,1076,1077,1080$ e 1210 (7c); 1226 $(6 \mathrm{j}) ; 2819$ (6q); $2898(13 \mathrm{~b})$.

Pontal do Sul/PR - MP 1088 (6o); 1139 (12c).

Matinhos/PR - MP 1106, 1110, 1114 a 1118, 1122 e 1185 
(6o); $1241(20 \mathrm{~m}) ; 2343$ a $2347(20 \mathrm{~s})$; $2789 \mathrm{~A}$ a 2793,2795 a 2812,2814 a 2815 (20p); 2833 (13d).

Caiobá/PR - MP 1234 (3lg).

Stellifer brasiliensis (Schultz, 1945).

Fig. XXVII.3

Nome vulgar: Canguá, canganguá.

Correspondente em inglês: Brazilian stardrum, stardrum.

Distribuição conhecida: encontrada até agora, somente nas costas brasileiras (da Bahia até Santa Catarina).

Material colecionado: Prainha, Caiobá/PR - MP 231 (31b).

Guaratuba/PR - MP 910 (13d); 1209 (6j); 1211 (13d);

1212 e $1213(6 \mathrm{j})$.

Matinhos/PR - MP 1112 e 1113 (6o).

Caiobá/PR - Mp 1219 (20m).

\section{FAMILIA EPHIPPIDAE}

Gênero: Chaetodipterus Lacépède, 1803.

Espécie-tipo: Chaetodipterus plumieri Lacépède = Zeus faber Gmelin por monotipia.

Chaetodipterus faber (Broussonet, 1782).

Fig. XXVIII.1

Nome vulgar: Parú.

Correspondente em inglês: Atlantic spadefish.

Distribuição conhecida: da Nova Inglaterra (E.U.A.) ao sul do Brasil.

Material colecionado: Ilha das Cobras, Baía de Paranaguá/PR - MP 226 (3b).

Guaratuba/PR - MP 814, 824 (8b); 884 e 886 (7a); 982 a 990, $992(28 \mathrm{c}) ; 2352(13 \mathrm{i})$.

Pontal do Sul/PR - MP 1135 a 1138 (6o); 2340 a 2341 (13c).

\section{FAMILIA POMACENTRIDAE}

Gênero: Abudefduf Förskal, 1775.

Espécie-tipo: Chaetodon sordidus Förskal.

Abudefduf saxatilis (Linnaeus, 1758).

Fig. XXVIII.2

Nome vulgar: Acará da pedra.

Correspondente em inglês: Sargeant major. 
Distribuição conhecida: da Carolina do Norte (E.U.A.) ao Rio Grande do Sul (BR). Material colecionado: Prainha, Caiobá/PR - MP 261 (16a).

\section{SUBORDEM MUGILOIDEI}

29. FAMILIA MUGILIDAE.

Gênero: Mugil Linnaeus, 1758.

Espécie-tipo: Mugil cephalus Linnaeus por monotipia.

Mugil curema Valencinnes, 1836.

Fig. XXVIII.3

Nome vulgar: Parati.

Correspondente em inglês: White mullet.

Distribuição conhecida: da Flórida (E.U.A.) até pelo menos ao Rio Grande do Sul (BR).

Material colecionado: Prainha, Caiobá/PR - MP 266 (19a); 320 (16a).

Guaraqueçaba/PR - MP 319 (10); 1174 a 1177 (6o).

Caiobá/PR - MP 371 (4h); $1232(20 \mathrm{~m})$.

Illa do Mel/PR - MP 561 (20c).

Matinhos/PR - MP 1250, 1252, 1253 a 1254 (20m); 2638D (23).

\section{SUBORDEM POLYNEMOIDEI}

\section{FAMIIIA POLYNEMIDAE}

Gênero: Polydactylus Lacépède, 1803.

Espécie-tipo: Polydactylus plumieri Lacépède = Plynemus virginicus Linnaeus.

Plydactylus virginicus (Linnaeus, 1758).

Fig. XXIX.1

Nome vulgar: Parati-barbudo.

Correspondente em inglês: Atlantic threadfin.

Distribuição conhecida: da Flórida (E.U.A.) ao Uruguai.

Material colecionado: Prainha, Caiobá/PR - MP 212 e 262 (16a).

\section{SUBORDEM BLENNIOIDEI}

\section{FAMIIIA BLENNIIDAE}

Gênero: Scartella Jordan, 1886. 
Espécie-tipo: Blennius microstomus Poey = Blennius cristatus Linnaeus por monotipia.

Scartella cristata (Linnaeus, 1758).

Fig. XXIX.2

Nome vulgar: Peixe macaco.

Correspondente em inglês: Combtooth blennie.

Distribuição conhecida: da Flórida (E.U.A.) até Santa Catarina (BR).

Material colecionado: Guaratuba/PR - MP 900 e 903 (28a).

Canasvieiras/SC - MP 279, 288 (4b); 2913 (4d).

Gênero: Hypleurochilus Gill, 1861.

Espécie-tipo: Blennius multifilus Girard = Blennius geminatus Wood.

Hypleurochilus sp.

Fig. XXIX.3

Nome vulgar: Peixe macaco.

Material colecionado: Illa das cobras/PR - MP $564(3 \mathrm{~b})$.

Cabeça - 10,2\% C.P.; Alt. - 268\% C.P.; Olho: - 9.3\% C.P.;

Dorsal - XII, 13; Anal - II, 14; Peitoral - 14/14.

Nota: $O$ exemplar se diferencia da espécie $H$. aequipinnis (descrita para o Brasil), por:

a) apresentar 3 manchas na região lateral posterior do corpo;

b) ausência, no exemplar examinado, da mancha negra na membrana entre o $1^{\circ}$. e $2^{\circ}$. espinho da dorsal; e

c) o comprimento da cabeça em relação ao comprimento padrão ser bem menor que em $H$. aequipinnis.

\section{SUBORDEM GOBIOIDEI}

\section{FAMILIA GOBIIDAE}

Gn̂ero: Bathygobius Bleeker, 1878.

Espécie-tipo: Gobius petrophilus Bleecker, 1863 por desig. ult.

Bathygobius soporator (Valenciennes, 1837).

Fig. XXXI.1

Nome vulgar: Amborê, amorê.

Correspondente em inglês: Gobie.

Distribuição conhecida: da Venezuela até o sul do Brasil.

Material colecionado: Ilha do Mel/PR - MP 78 e 89 (20h).

Ilha das Cobras/PR - MP 232, 576, 577 (3b); 700 a 702 (28e). 
Guaraqueçaba/PR - MP 269, 274, 275 e 303 (10).

Pontal do Sul/PR - MP 1173 (28g).

Caiobá/PR - MP 283, 292, 304 (20a); 1196 (28g).

Guaratuba/PR - MP 857 (8b); 893 a 895, 897 a 899, 901 e $902(28 a)$.

Cabeçudas/SC - MP 290 (4f).

\section{FAMILIA ELEOTRIDAE}

Gênero: Dormitator Gill, 1861.

Espécie-tipo: Sciaena maculata Bloch.

Dormitator maculatus (Bloch, 1792).

Fig. XXX.2

Nome vulgar: Barrigudo.

Correspondente em inglês: Sleeper.

Distribuição conhecida: Costa do Brasil e Indias Ocidentais.

Material colecionado: Illa do Mel/PR - MP 1, 59, 86, 387 e 388 (5).

Canasvieiras/SC - MP 2914 (4e).

\section{SUBORDEM ACANTHUROIDEI}

\section{FAMILIA ACANTHURIDAE}

Gênero: Acanthurus Förskal, 1775.

Espécie-tipo: Chaetodon sohal Förskal por design. ult.

\section{Acanthurus bahianus Castelnau, 1855.}

Fig. XXXI.1

Nome vulgar: Barbeiro, cirurgião.

Correspondente em inglês: Ocean surgeon.

Distribuição conhecida: do norte de Massachusetts (E.U.A.) a Santa Catarina (BR).

Material colecionado: Procedência desconhecida: MP 2607 (15b).

Ilha da Figueira/PR - MP 2932 (9).

\section{SUBORDEM SCOMBROIDEI}

\section{FAMILIA TRICHIURIDAE}

Gênero: Trichiurus Linnaeus, 1758.

Espécie-tipo: Trichiurus lepturus Linnaeus. 


\section{Trichiurus lepturus Linnaeus, 1758.}

Fig. XXXI.2

Nome vulgar: Espada.

Correspondente em inglês: Largehead hairtail, Atlantic cutlassfish.

Distribuição conhecida: do norte da Virgínia (E.U.A.) à Argentina.

Material colecionado: Prainha, Caiobá/PR - MP 214 e 215 (19a).

Guaratuba/PR - MP 2610 a 2614 (13l).

Ubatuba/SC - MP 2608 e 2609 (13f).

\section{ORDEM PLEURONECTIFORMES}

SUBORDEM PLEURONECTOIDEI

\section{FAMILIA BOTHIDAE}

Gênero: Citharichthys Bleeker, 1862.

Espécie-tipo: Citharichthys cayennensis Bleeker = Citharichthys spilopterus Günther.

Citharichthys spilopterus Günther, 1862.

Fig. XXXII.1

Nome vulgar: Linguado.

Correspondente em inglês: Lefteye flounder.

Distribuição conhecida: Costa dos E.U.A.; Antilhas e nas Costas da América do Sul até o Rio Grande do Sul (BR).

Material colecionado: Ilha do Gastão/PR - MP 996 (28c).

$$
\text { Guaratuba/PR - MP } 1013 \text { (7c). }
$$

Gênero: Etropus Jordan \& Gilbert, 1881.

Espécie-tipo: Etropus crossotus Jordan \& Gilbert.

\section{Etropus intermedius Norman, 1933.}

\section{Fig. XXXII.2}

Nome vulgar: Linguado.

Correspondente em inglês: Lefteye flounder.

Distribuição conhecida: Costa atlântica da América do Sul (de Trinidad ao Rio de Janeiro - BR).

Material colecionado: Guaratuba/PR - MP 1008 (7c): 2619 (6q).

\section{SUBORDEM SOLEOIDEI}

\section{FAMILIA SOLEIDAE}

Gênero: Achirus Lacépède, 1803. 
Espécie-tipo: Pleuronectes achirus Linnaeus.

Achirus sp.

Fig. XXXIII.1

Nome vulgar: Linguado da areia.

Correspondente em inglês: Sole.

Material colecionado: Pontal do Sul/PR - MP 1163 e 1166 (6o).

Guaratuba/PR - MP 892 (28a); 917 a 924, 939, 941 e 943 (12a); 945 e 946, 948, $953(27 \mathrm{c}) ; 944$, $947,1007,1010$ a 1012,1085 (7c); 1224, $1227(13 \mathrm{l}) ; 1229(6 \mathrm{~g}) ; 1230(6 \mathrm{j})$.

Matinhos/PR - MP 1245 a $1249(20 \mathrm{~m}) ; 2330$ (21); 2620 a 2626 (20p); 2915 (20l); 1119 a 1121 (6o).

Caiobá/PR - MP 1445 (20n).

Antonina/PR - MP 2627 (29).

Obs.: 0 presente gênero encontra-se atualmente em revisão sistemática.

\section{FAMILIA CYNOGLOSSIDAE}

Gênero: Symphurus Rafinesque, 1810.

Espécie-tipo: Symphurus nigriscens Rafinesque.

\section{Symphurus diomedanus (Goode \& Bean, 1886).}

Fig. XXXIII.2

Nome vulgar: Língua de mulato, língua de vaca.

Correspondente em inglês: Spottedfin tonguefish.

Distribuição conhecida: da Carolina do Norte ao litoral do Rio de Janeiro (BR.)

Material colecionado: Matinhos/PR - MP 2794A, 2813, 2916, 2917 (20p).

Nota: Os exemplares correspondem a ampliação do limite da espécie para o sul do Brasil.

Symphurus plagusia (Bloch \& Schneider, 1801).

Fig. XXXIII.3

Nome vulgar: Língua de mulato, língua de vaca.

Correspondente em inglês: Duskycheek tonguefish.

Distribuição conhecida: da América Central e Antilhas ao sul do Brasil.

Material colecionado: Guaratuba/PR - MP 906 e 907 (13c).

Pontal do Sul/PR - MP 1164 (6o).

Matinhos/PR - MP 2918 (20p) e 2919 (20l).

\section{ORDEM TETRAODONTIFORMES \\ SUBORDEM TETRAODONTOIDEI \\ SUPERFAMILIA BALISTOIDEA}




\section{FAMIILIA MONOCANTHIDAE}

Gênero: Stephanolepis Gill, 1861.

Espécie-tipo: Monacanthus setifer Bennett.

Stephanolepis hispidus (Linnaeus, 1766).

Fig. XXXIV.1

Nome vulgar: Peixe-porco.

Correspondente em inglês: Filefish.

Distribuição conhecida: da Escócia (Canadá); Bermudas (E.U.A.); Gôlfo do México até Maldonado (Ur.).

Material colecionado: Canasvieiras/SC - MP 205 (4e).

\section{SUPERFAMILIA TETRAODONTOIDEA}

Gênero: Lagocephalus Swainson, 1839.

Espécie-tipo: Tetrodon stellatus Donovan = Lagocephalus lagocephalus.

Lagocephalus laevigatus (Linnaeus, 1766).

Fig. XXXV.1

Nome vulgar: Baicú--arara.

Correspondente em inglês: Smooth-puffer.

Distribuição conhecida: da Nova Inglaterra (E.U.A.) à Argentina.

Material colecionado: Guaraqueçaba/PR - MP 272, 287 (10).

Guaratuba/PR - MP 841 a 844 (8b); 1003 (7c); 1228 (6h); 1236 (6p); 2635 (13e).

Pontal do Sul/PR - MP 1165 (6e); 2920 e 2021 (6o).

Caiobá/PR - MP 704 (22); 845 (20e); 1197 e $1235(20 \mathrm{~m})$.

Canasvieiras/SC - MP 117 (4e).

Gênero: Sphoeroides Lacépède, 1800.

Espécie-tipo: Tetrodon spengleri Bloch.

Sphoeroides tyleri Shipp, 1972.

Fig. XXXV.2

Nome vulgar: Baiacú.

Correspondente em inglês: Bearded puffer.

Distribuição conhecida: da Colômbia a Santa Catarina (BR).

Material colecionado: Guaraqueçaba/PR - MP 271 (10).

Serra Negra/PR - MP 552, 565 a 567 e 570 (1a).

Illha de Paranaguá/PR - MP 569 (lb).

Ilha Rasa da Cotinga/PR - MP 571 e 572 (lb). 
Guaratuba/PR - MP 1005 (7c).

Pontal do Sul/PR - MP 1132 (6o); 1170 (28e).

Canasvieiras/SC - MP 206 (4e).

Sphoeroides greeleyi Gilbert, 1900.

Fig. XXXV.3

Nome vulgar: Baiacú.

Correspondente em inglês: Caribbean puffer.

Distribuição conhecida: da Venezuela a Santa Catarina (BR).

Material colecionado: Matinhos/PR - MP 427 (23).

Guaratuba/PR - MP 1231 (7d).

Sphoeroides testudineus (Linnaeus, 1758).

Fig. XXXV.4

Nome vulgar: Baiacú-mirim, baiacú-malhado, baiacú-pintado.

Correspondente em inglês: Checkered puffer.

Distribuição conhecida: da Fórida (E.U.A.); América Central até Santa Catarina (BR).

Material colecionado: Ilha do Mel/PR - MP 77 e 88 (20h).

Antonina/PR - MP 195 e 201 (4d).

Matinhos/PR - MP 435 (23); 1187 (60).

Guaratuba/PR - MP 846, 847 e 859 (8b); 993, 995 (28c); 1004 (7c); 2923 (13j); 2925 (13l); $2924(7 a)$.

Pontal do Sul/PR - MP 1171 (28e).

Canasvieiras/SC - MP 171 e 2922 (4e); 202 (4d).

\section{FAMILIA DIODONTIDAE}

Gênero: Chilomycterus Bibron, 1846.

Espécie-tipo: Diodon reticulatus Linnaeus.

Chilomycterus spinosus (Linnaeus, 1758).

Fig. XXXVI.1

Nome vulgar: Baiacú-espinhoso.

Correspondente em inglês: Burrfish.

Distribuição conhecida: Indias, Costas do Brasil (Rio de Janeiro à Argentina).

Material colecionado: Caiobá/PR - MP 372 (16a).

Guaratuba/PR - MP 881 (7a); 1006 (7c); 2636 (13l).

Matinhos/PR - MP 2629 (11).

Pontal do Sul/PR - MP 2630 e 2631, 2926 a 2928 (25a).

Illha do Mel/PR - MP 217 (3b).

Antonina/PR - MP 1123 (6r).

Canasvieiras/SC - MP 574 e 578 (4d). 


\section{RESUMO}

Os autores relacionam, pela primeira vez, as espécies ícticas marinhas obtidas a partir de 1942 no litoral do Estado do Paraná e Santa Catarina, e depositadas na Coleção Ictiológica do Acervo Zoológico da Prefeitura Municipal de Curitiba.

0 presente trabalho corresponde ao resultado final da organização iniciada pelos autores em 1980. Foram examinados 935 peixes obtendo-se 48 famílias, 79 gêneros e 91 espécies identificadas.

Toda relação é apresentada em ordem filogenética a nível de família, proposta para Chondrichthyes por COMPAGNO (1973) e para Osteichthyes por GREENWOOD (1980).

São ainda citadas para cada exemplar o número de registro, local de coleta, coletor(es) e data. Todas as espécies estão representadas através de fotografias com suas respectivas escalas.

As regiões, em que as coletas foram realizadas, encontram-se assinaladas nos mapas anexos.

PALAVRAS-CHAVES - Peixes marinhos - Catálogo - Parıná e Santa Catarina. 


\section{SUMMARY}

The authors list, for the first time, the marine ichthyological specimens colected since 1942 along the litoral of the Paraná and Santa Catarina states, in Southern Brazil. The studied material belongs to the Ichthyological Collection of the Zoology and Geology Division of the Prefeitura Municipal de Curitiba.

The present paper is the final result the organization started by the authors in 1980. A total of 935 fishes, representing 48 families, 79 genera and 91 species, were identified.

The Catalogue follows the phylogenetic orders proposed, at family level, by COMPAGNO (1973) for Chondrichthyes and GREENWOOD (1980) for Osteichthyes.

Registration numbers, place and time of collecting and collectors names are given for each fish.

All the species are represented by photographies in corresponding scales. The regions in wich the collects were made are showed in maps.

KEY WORDS - Marine Fishes - Catalogue - Paraná e Santa Catarina. 


\section{AGRADECIMENTOS}

Ao Dr. Naércio A. Menezes do Museu de Zoologia da USP por sua incansável colaboração na identifcação dos exemplares enviados.

Ao Dr. Milton Mirá Vernalha, Diretor do Centro de Biologia Marinha, por seu incentivo, assim como pelas facilidades que nos foram concedidas na realização deste trabalho.

Ao Diretor do Museu Paranaense, Miguel A. Gaissler, por autorizar a permanência e uso do nome de sua instituição nas etiquetas de registro.

Ao Geógrafo Paulo C. R. Cerdeira, Líder do Projeto de Recursos Naturais Renováveis em 1980 (IAPAR), por sua autorização expressa para o acesso ao material colecionado.

Ao Engenheiro Agrônomo Pedro Scherer Neto, Chefe de Divisão de Zoologia da P.M.C., por sua permissão para divulgação dos resultados.

Em especial os autores agradecem ao fotógrafo e mergulhador colaborador junto ao Centro de Biologia Marinha - U.F.PR; Engenheiro Roberto Lachowski, por sua colaboração na execução das fotos aqui apresentadas. Ả Botânica Luiza T. Dombrowski, curadora do herbário Perl Karl Dusen, por suas contribuições na orientação das técnicas museológicas. À Bióloga Jussara S. Leprevost e ao Engenheiro Cart. Ernesto V. Bini por suas colaborações na confecção dos mapas anexos. Ao Biólogo Berndt E. Marterer pela revelação das fotos.

Ao Dr. Paulo Cunha Lana, Professor Rudolf B. Lange e Ruth Misiuta pela revisão e valiosas sugestões no tex to final.

Aos estagiários Márcia R Cury, Olga K. Maehama por suas colaborações na organização do texto final, assim como às datilógrafas Maria de Lourdes Fonseca Bueno, Rosana de Fátima Ferrando e Luiza Hollmann por sua paciência e dedicação. 


\section{ÍNDICE POR FAMÍLIAS}

Acanthuridae . . . . . . . . 35

Ariidae . . . . . . . . . . 14

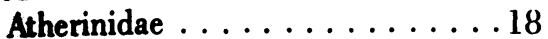

Batrachoididae . . . . . . . 16

Belonidae. . . . . . . . . . 18

Bleniidae . . . . . . . . . . 33

Bothidae . . . . . . . . . . 36

Carangidae............23

Carcharhinidae . . . . . . . . 10

Centropomidae.........20

Clupeidae. . . . . . . . . . . 12

Cynoglossidae. . . . . . . . . 37

Dactylopteridae . . . . . . . 20

Dasyatidae . . . . . . . . . . .09

Diodontidae. . . . . . . . . . 39

Eleotridae . . . . . . . . . . . 35

Engraulidae . . . . . . . . . . 13

Ephippidae. . . . . . . . . 32

Gadidae . . . . . . . . . . . 17

Gerreidae. . . . . . . . . . . 26

Grammistidae. . . . . . . . . . . 22

Gobiidae . . . . . . . . . . . . . 34

Gobiesocidae ........... 16

Hemiramphidae. . . . . . . 17
Monoacanthidae . . . . . . 38

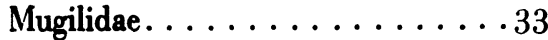

Muraenidae . . . . . . . . . 11

Narcinidae . . . . . . . . . . 08

Ogcocephalidae. . . . . . . . 16

Ophichthidae ...........11

Polynemidae. . . . . . . . . 33

Pomacentridae .......... 32

Pomadasyidae. . . . . . . . 27

Pomatomidae . . . . . . . . 22

Priacanthidae . . . . . . . 22

Rhinobatidae ...........08

Rhinopteridae. . . . . . . . 09

Sciaenidae . . . . . . . . . . 28

Scorpaenidae . . . . . . . . 19

Serranidae . . . . . . . . . 21

Soleidae. . . . . . . . . . . . 36

Sphyrnidae. . . . . . . . . 10

Syngnathidae . . . . . . . . 18

Synodontidae . . . . . . . . 15

Tetraodontidae . . . . . . . . 38

Triakidae . . . . . . . . . . 10

Triglidae ............20

Trichiuridae . . . . . . . . 35 


\section{INDICE POR GÊNERO E ESPÉCIE}

Abudefduf saxatilis . . . . . . . 32

Acanthurus bahianus .........35

Achirus sp . . . . . . . . . 37

Anchoa filifera . . . . . . . 13

Anchoa tricolor. . . . . . . . 13

Arius spixii . . . . . . . . 15

Bagre bagre . . . . . . . . . . 14

Bathygobius soporator . . . . . . . 34

Boridia grossidens . . . . . . . . 27

Caranx latus. . . . . . . . . 25

Carcharhinus porosus. . . . . . 10

Centropomus parallelus ....... 21

Cetengraulis edentulus . . . . . . 14

Chaetodipterus faber . . . . . . . 32

Chilomicterus spinosus. . . . . . . 39

Citharichthys spilopterus . . . . . 36

Chloroscombrus chrysurus ..... 24

Conodon nobilis . . . . . . . . 28

Cynoscion acoupa..........31

Cynoscion leiarchus. . . . . . . . 31

Dactylopterus volitans . . . . . . 20

Dasyatis say. . . . . . . . . . 09

Diplectrum radiale. . .......21

Dapterus rhombeus . . . . . . . . 26

Diapterus olithostomus. . . . . . 26

Dormitator maculatus . . . . . . 35

Etropus intermedius. . . . . . . 36

Eucinostomus melanopterus . . . . 26

Eugerres brasilianus . . . . . . 27

Genyatremus luteus. . . . . . . 27

Gobiesox strumosus. . . . . . . . 16

Gymnothorax ocellatus ....... 11

Harengula clupeola . . . . . . . 12

Hemicaranx amblyrhynchus . . . 2 25

Hippocampus erectus. . . . . . . 19

Hippocampus reidi. . . . . . . 19

Hypleurochilus sp . . . . . . . 34

Hyphoramphus unifasciatus. . . . . 17

Isopisthus parvipinnis. . . . . . 30

Lagocephalus laevigatus . . . . . . 38

Larimus breviceps . . . . . . . . 30

Lycengraulis grossidens. . . . . . . 14

Menticirrhus americanus. . . . . . 28

Micropogonias furnieri . . . . . . 29

Mugil curema ........... 33

Mustelus schimitti . . . . . . . . 10
Mycteroperca tigris .......21

Narcine brasiliensis . . . . . . . . 08

Nebris microps . . . . . . . . 30

Ophichthus gomesii . . . . . . 11

Ophistorema oglinum. . . . . 12

Ogocephalus vespertilio . . . . . 17

Oligoplites saliens . . . . . . . 23

Oligoplites saurus . . . . . . . 23

Orthopristis ruber . . . . . . 28

Paralanchurus brasiliensis . . . . . 29

Parona signata. . . . . . . . . 23

Pellona harroweri . . . . . . . . 13

Polydactilus virginicus . . . . . . 33

Pomatomus saltator. . . . . . . . 22

Pomadasys corvinaeformis. . . . . . 27

Porichthys porosissimus . . . . . 16

Prionotus punctatus. . . . . . . 20

Priacanthus arenatus . . . . . . 22

Rhinobatos percellens .......08

Rhinoptera bonasus. . . . . . . 09

Rhizoprionodon lalandei. . . . . 10

Rypticus randalli. . . . . . . . 22

Sardinella brasiliensis . . . . . . . 12

Scartella cristata . . . . . . . . . . 34

Scorpaena brasiliensis. . . . . . . 19

Selene vomer . . . . . . . . . 25

Selene setapinnis. . . . . . . 25

Stellifer brasiliensis . . . . . . . 32

Stellifer rastrifer . . . . . . . . 31

Stephanoleps hispidus . . . . . . 38

Strongylura timucu . . . . . . . 18

Sphoeroides greeleyi ........ 39

Sphoeroides testudineus. . . . . . . 39

Sphoeroides tyleri. . . . . . . . 38

Symphurus diomedanus . . . . . . 37

Symphurus plagusia . . . . . . . 37

Sphyrna tudes. . . . . . . . . . 11

Syngnathus folleti . . . . . . . . . 19

Synodus foetens . . . . . . . . 15

Trachinotus carolinus. . . . . . . 23

Trachinotus falcatus. . . . . . . 24

Trachinotus goodei . . . . . . . 24

Trichirius lepturus. . . . . . . . 36

Urophycis brasiliensis. . . . . . . 17

Xenomelaniris brasiliensis . . . . . 18 
Abrótea ............. 17

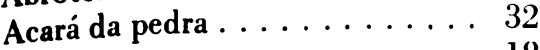

Agulha ............. 18

Amborê, amorê $\ldots \ldots \ldots \ldots 34$

Anchova . . . . . . . . . 22

Azeiteiro . . . . . . . . . 10

Bacalhau brasileiro . . . . . . 17

Badejo ............. 2]

Bagre amarelo .......... 15

Bagre-sari, bandeira . . . . . . . 14

Baiacú ............ 39

Baiacú-arara . . . . . . . . . 38

Baiacú-de-espinho . . . . . . . 39

Baiacú mirim . . . . . . . . 39

Baiacú pintado . . . . . . . . 39

Barbeiro . . . . . . . . . . 35

Barrigudo . . . . . . . . 35

Beatinha . . . . . . . . 19

Betara . . . . . . . . . 28

Cabrinha ............ 20

Cação . . . . . . . . . 10

Cação-frango . . . . . . . 10

Camiseta . . . . . . . . . . . 29

Canguá, canganguá $\ldots \ldots \ldots 31 / 32$

Cantadeira . . . . . . . . . 30

Carapeba, Carapeva . . . . . . . . 26

Caratinga vivóca . . . . . . 27

Catarro . . . . . . . . . . . 25

Cavalo marinho . . . . . . . . 19

Chapéu-armado/cambeva . . . . 11

Cirurgião . . . . . . . . . 35

Clariana . . . . . . . . . . 29

Corcoroca sargo . . . . . . . 27

Corcoroca, corocoroca . . . . . . 28

Corvina . . . . . . . . . . . . 29

Escrivão . . . . . . . . . 26

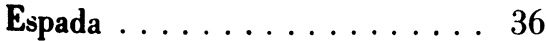

Gaivira . . . . . . . . . . . 23

Galo . . . . . . . . . . . . . . . 25

Galo verdadeiro . . . . . . . . . . 25

Galo-de-penacho . . . . . . . . . . 25

Lingua-de-vaca . . . . . . . . . . 37

Lingua-de-mulato . . . . . . . . 37

Linguado de areia . . . . . . . . 37

Linguado

Manjuba

$13 / 14 / 18$

Mamangá

Mamangá-liso . . . . . . . . . 16

Maria-luisa . . . . . . . . . . . . 29

Martelo
Michole d'areia .

Moréia pintada ..........11

Muçum ...............11

Olho de boi, olho de cão. . . . . . 22

Oveva . . . . . . . . . . . . 30

Palombeta, palometa . . . . . . 24

Pampo. . . . . . . . . . . . 23

Pampo-galhudo. . . . . . . 24

Pampo-malhado . . . . . . . 24

Papa-terra . . . . . . . . . 28

Parati .................33

Parati-barbudo . . . . . . . . 33

Parú ............... 32

Peixe-cachimbo. . . . . . . . 19

Paixe-lagarto. . . . . . . . . 15

Peixe-macaco . . . . . . . . . 34

Peixe-morcego . . . . . . . . 17

Peixe-pedra . . . . . . . . 19

Peixe-porco . . . . . . . . . 38

Peixe-rei . . . . . . . . . . 18

Peixe-sabão . . . . . . . 22

Peixe-voador. . . . . . . . . . 20

Pescada amarela . . . . . . . 31

Pescada branca . . . . . . . . 31

Pescada banana . . . . . . . . . 30

Pescada malheira . . . . . . . . . 30

Piramangaba. .........16

Raia chita . . . . . . . . . . 09

Raia elétrica . . . . . . . . 08

Raia viola. . . . . . . . . . . .08

Rabo azedo ...........25

Robalo-peva...........21

Roncador. . . . . . . . . . . .28

Roncador-de-listra . . . . . . . . 28

Saguá . . . . . . . . . . . 27

Salteira . . . . . . . . . . . . 23

Sardinha ............. 13

Sardinha-bandeira . . . . . . . 12

Sardinha-cascuda. . . . . . . . 12

Sardinha-chata . . . . . . . . 12

Sardinha de penacho . . . . . . 12

Sardinha verdadeira . . . . . . . 13

Sernambiguara . . . . . . . . 23

Ticonha.............. 09

Timucu, timbucu. . . . . . . . 18

Treme-treme. . . . . . . . . .09

Vento-leste. . . . . . . . . . .25

Viúva .............23

Xarelete. . . . . . . . . . . .25 


\section{ÍNDICE DE NOMES VERNACULARES EM INGLES}

American pellona . . . . . . 13

Anchovy ............. 13

Atlantic anchoveta . . . . . . 14

Atlantic bigeye . . . . . . . 22

Atlantic bumper . . . . . . . 24

Atlantic cutlassfish . . . . . . 36

Atlantic leatherjack . . . . . . . 23

Atlantic look down . . . . . . . 25

Atlantic moonfish . . . . . . . . 25

Atlantic spadefish . . . . . . . 32

Atlantic thread herring . . . . . 12

Atlantic threadfin . . . . . . . . 33

Banded croaker . . . . . . . 29

Barred grunt . . . . . . . . 28

Barred Puffer . . . . . . . . . . 38

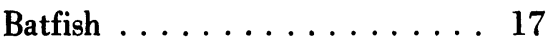

Blackedge moray . . . . . . 11

Bluefish. . . . . . . . . . 22

Bluewing searobin . . . . . 20

Bluntnose jack . . . . . . . . 25

Bonnethead shark . . . . . . . 11

Brazilian codling . . . . . . . 17

Brazilian sardinella. . . . . . . . 13

Brazilian sharpnose shark . . . . 10

Brazilian stardrum . . . . . . . . 32

Burrfish. . . . . . . . . . . 39

Caitipa mojarra . . . . . . . . 26

Caribbean puffer.......... . 39

Checkered puffer. . . . . . . . . 39

Clingfish . . . . . . . . . 16

Coco sea catfish . . . . . . . 14

Combtooth blenny . . . . . . 34

Common halfbeak. . . . . . . . 18

Corocoro grunt . . . . . . . . . 28

Cownose ray. . . . . . . . . 09

Duskysheek tonguefish. . . . . . 37

Eletric rays. . . . . . . . . . 08

False herring. . . . . . . . 12

False pilchard . . . . . . . 12

Fat snook ...........21

Filefish . . . . . . . . . 38

Flagfin mojarra . . . . . . . 26

Flying gurnard $\ldots \ldots \ldots \ldots 20$

Florida pompano. . . . . . . . 23

Gobie ... . . . . . . . . . 34

Grunt .............27

Guitarfish ........... 08
Hammerhead shark . . . . . . 11

Horse-eye-jack . . . . . . . . 25

Houndshark . . . . . . . 10

Irish mojarra. . . . . . . . 26

Jack . . . . . . . . . . . . . 23

Largehead hairtail . . . . . . . . . 36

Lefteye flounder. . . . . . . . 36

Lizard fish . . . . . . . . . . . 15

Madamango sea catfish . . . . . 15

Ocean surgeon . . . . . . . . 35

Orange spot sardine . . . . . . . 13

Palometa . . . . . . . . . . . 24

Permit. . . . . . . . . . . 24

Pipefish. . . . . . . . . 19

Pompano.............24

Rake stardrum . . . . . . . . 31

Rockfish . . . . . . . . . . . . 19

Roughneck grunt. . . . . . . . . . 28

Sand seabass. . . . . . . . 21

Sargeant major . . . . . . . . . 32

Scorpionfish. . . . . . . . . . 19

Sea horse . . . . . . . . . . . . 19

Shrimp eel . . . . . . . . . . 12

Shortfin corvina . . . . . . . 30

Shorthead drum . . . . . . . . 30

Silverside. . . . . . . . . . 18

Sleeper . . . . . . . . . . . 35

Smalltail shark . . . . . . . . 10

Smalleye croaker. . . . . . . . 30

Smooth-hounds. . . . . . . . . 10

Smooth puffer . . . . . . . . 38

Sole . . . . . . . . . . . 37

Soapfish . . . . . . . . . 22

Southern kingcroaker. . . . . . . . 29

Southern kingfish . . . . . . . . 29

Spottedfin tonguefish. . . . . . 37

Stardrum. . . . . . . . . 32

Stingray. . . . . . . . . . 09

Striped mojarra. . . . . . . . 27

Tiger grouper . . . . . . . 21

Timucu needlefish. . . . . . . 18

Toadfish ............. 16

Toothead anchovy. . . . . . . . 14

Torroto grunt . . . . . . . . 27

Weakfish .............. 31

White mullet. . . . . . . . . . 33

Whitemouth croaker . . . . . . 29 


\section{REFERÊNCIAS BIBLIOGRÁFICAS}

CARVAlHo, N. R; TOMMASI, L. R \& NOVELli, M. P. Lista dos Linguados do Brasil. Contr. Inst. Oceanog. São Paulo, 14: 1-26p., 1968.

CERvigÓN M., F. Los Peces Marinos de Venezuela I. Fund. La Salle de Cienc. Nat., Estac. Mar. Margarita, Caracas. Monografia. $11: 436$ p., 1966.

Los Peces Marinos de Venezuela II. Fund. La Salle de Cienc. Nat., Estac. Mar. Margarita, Caracas. Monografia. $12: 449-951$ p., 1966.

Los Peces Marinos de Venezuela. Complemento I. Fund. La Salle de Cienc. Nat., Estac. Mar. Margarita, Caracas. Contrib. 31: 117-218p., 1967.

Las Especies de los Generos Anchovia y Anchoa (Pisces-Engraulidae) de Venezuela y Areas Adyacentes del Mar Caribe y Atlantico Hasta $23^{\circ} \mathrm{S}$. Fund. La Salle de Cienc. Nat. Estac. Mar. Margarita, Caracas. Contrib. $39: 193-215 p, 1975$.

COMPAGNO, L. J. V. Phyletic Relationships of Living Sharks : and Rays. In: Recent Advances in the biology of sharks. Ed. R. G. North Cutt. American Zoologist. 17(2): 303-322p., 1977.

FGUEIREDO, J.L. Manual de Peixes Marinhos do Sudoeste do Brasil I. Introdução. Cações, raias e quimeras. Mus. de Zool. da Univ. de São Paulo. 1977, 104 p.

FGUEIREDO, J. L. \& MENEZES, N.A. Manual de Peixes Marinhos do Sudeste do Brasil II. Teleostei (1). Mus. de Zool. da Univ. de São Paulo. 1980, 110p.

RQUEIREDO, J. L. \& MENEZES, N.A. Manual de Peixes Marinhos do Sudeste do Brasil III. Teleostei (2). Mus. de Zool. da Univ. de São Paulo. 1980, 90p.

FSCHER, W. (Ed.). FAO Species Identification Sheets for Fishery Purposes, Western Central Atlantic (Fishing Area 31). 1978. 1-7, Roma p. v.

FOWLER, H. W. A list of fishes Known from the Coast of Brasil. Arq. Zool. da Univ. de São Puulo III (V): 115-184p. 1941.

GREENWOOD, P. H. et alii. Phyletic studies of Teleostean Fishes, with a provisorian classification of living forms. Bull. Mus. Nat. Hist., New York, 131(4) :341-455p., 1966.

GREENWOOD, P. H. In: CLOFETA - Preliminary List of Marine Fishes. UNESCO. MARINEf 31-49p. 1980. 
JORDAN, D. A. The genera os fishes and a classification of fishes, Califórnia, Stanford University Press, $1963-800$ p.

JARDIM, L. F. A. Scienideos marinhos da Costa do Brasil Sul (Acanthopterygii - PerciformesSciaenidae). Comun. Mus. Ci. PUCRGS. Série Zool., 3 :64p. 1973.

LUCENA; C.A.S. de \& LUCENA, Z. M. S. Catálogo de Peixes Marinhos do Museu de Ciências da Pontífica Universidade Católica do Rio Grande do Sul. Elasmobronchiomosphi. Teleostomi (1a. parte). Comun. Mus. Ci. PUCRGS. $21: 1-66$ p. 1981.

Catálogo de Peixes Marinhos do Museu de Ciências da Pontífica Universidade Católica do Rio Grande do Sul. Teleostomi (final). Comun. Mus. Ci. PUCRGS. $25: 1-80$ p., 1982.

LEMA, T. de; LUCENA. C. A. S. de; SAENGER, S. \& OLIVEIRA, M. F. T. de. Primeiro Levantamento dos Tetraodontiformes do estremo sul do Brasil, Un'guai e Argentina (Teleostei: Acanthopterygii). Comun. Mus. Ci. PUCRGS. 20 : 1-84p., 1979.

ROUX, C. Poissons Teleosteans du Plateau Continental Brésilien. In: Results scientifiques des Compagnes de la Calypso. Amm. Ins. Oceanog., Paris, 1973. 49 : 23-207p.

SANTOS, E. Nossos Peixes Marinhos. F. Briguet \& Cia Edit., 1952. 265p.

SCHULTZ, L. P. et alii. Fishes of the Marshall and Marianas Islands. Smith. Inst. Unit. Stat. Mus. Bull. 202(2): 348p. 1960.

SCHULTZ, L. P. A further contribuition to the Ichthiology of Venezuela. Smith. Inst. Proc. U. S. Nat. Mus. 99 (3235):211p. 1949.

SPRINGER, S. Two New Atlantic species of dogs sharks, with key to the species of Mustelus. Proc. U. S. Nat. Museum. 86 (3058):461-468p. 1939.

TYLER, J. C. Osteology, phylogeny and higher classification os fishes of the Order Plectognathi (Tetraodontiformes). NOAA. Tech. Rep. N.M. F.S. Circ. 434:1-422p. 1980. 

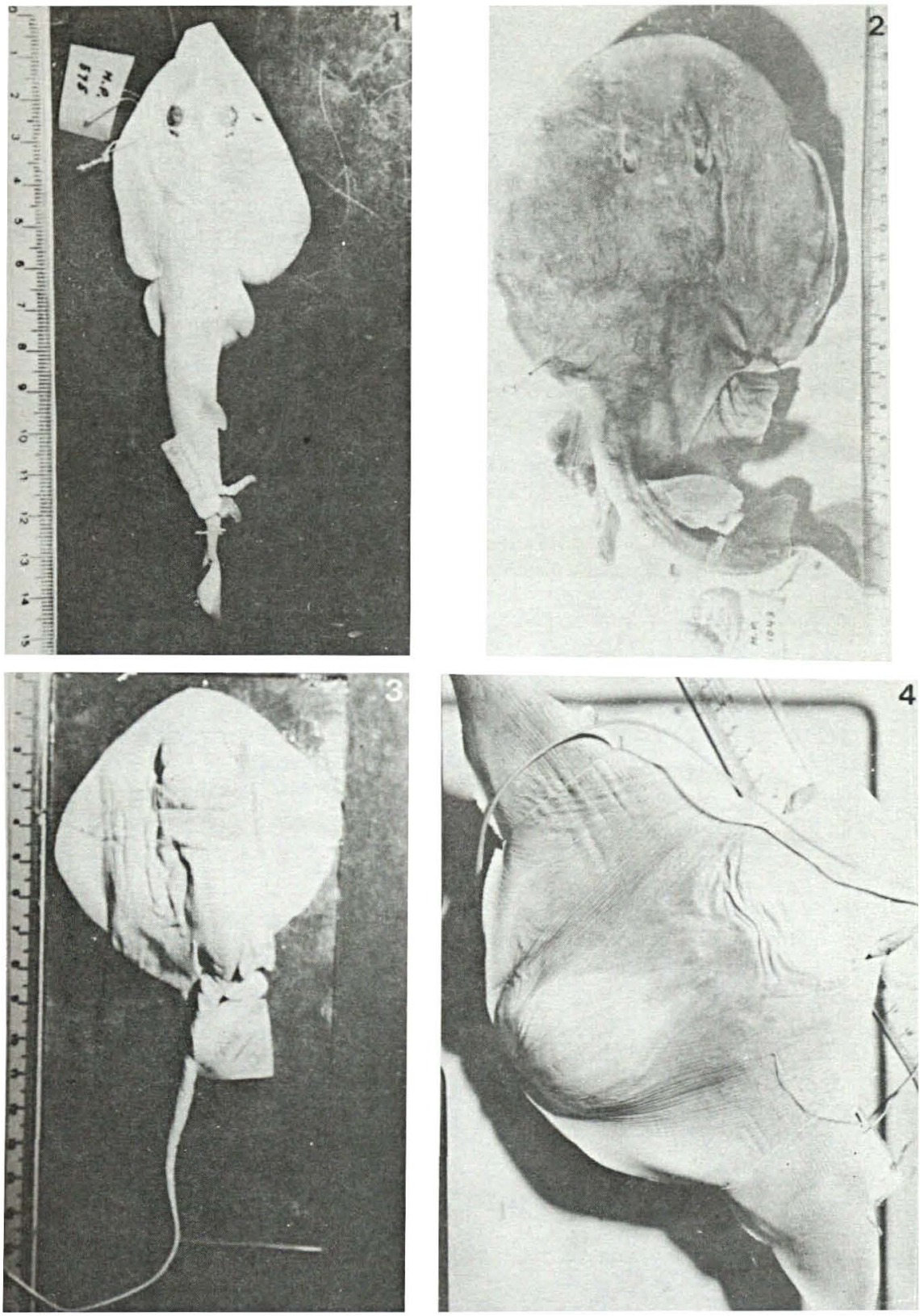

Fig. I - Classe Chondrichthyes

1. Família Rhinobatidae. Rhinobatos percellens (Walbaum, 1792)

2. Familia Narcinidae. Narcine brasiliensis (Olfers, 1831)

3. Família Dasyatidae. Dasyatis say (Lesueur, 1817)

4. Familia Rhinopteridae. Rhinoptera bonasus (Mitchill, 1815) 

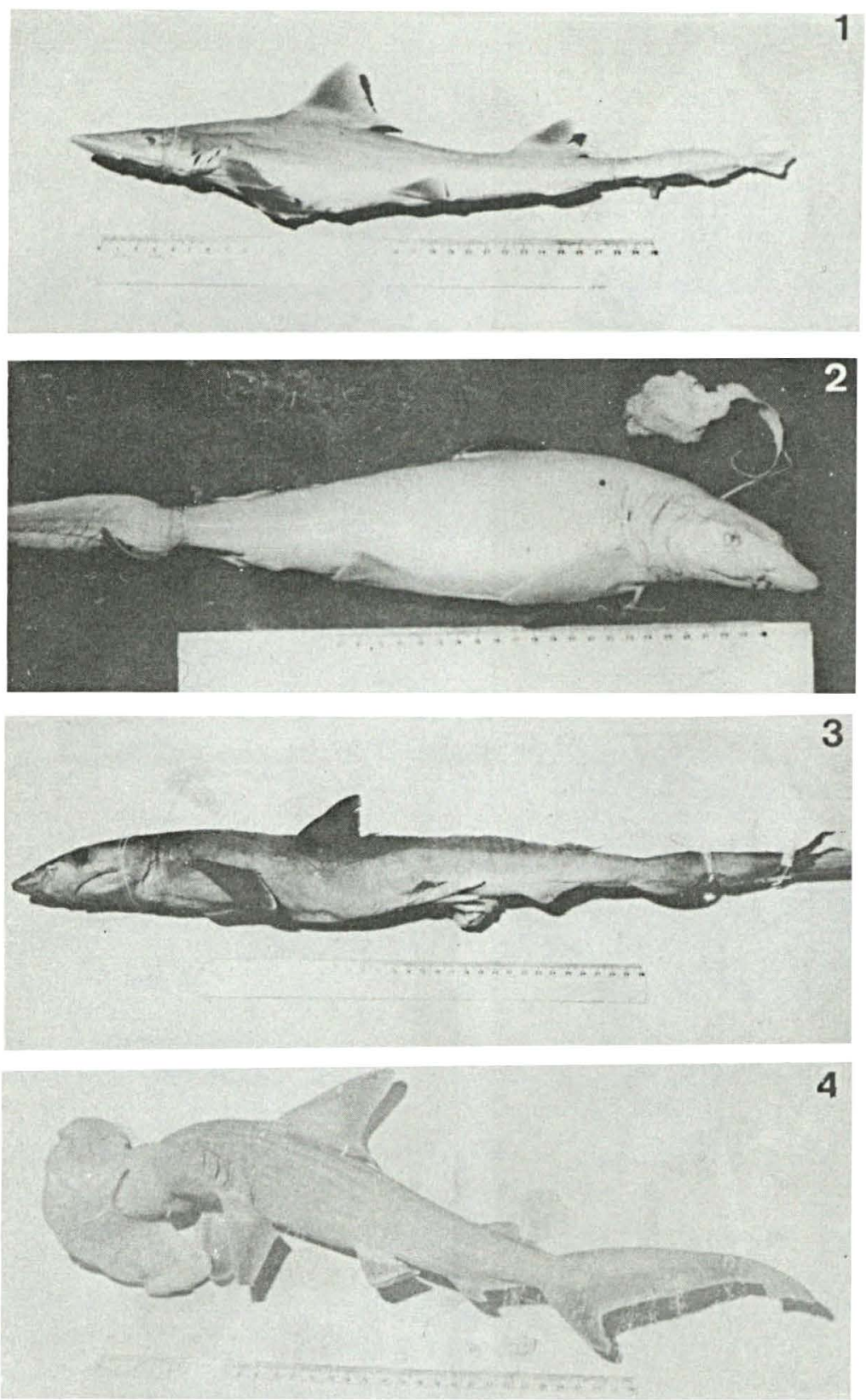

Fig. II - Classe Chondrichthyes

1. Família Triakidae. Mustelus schmitti (Springer, 1939)

2. Família Carcharhinidae. Carcharhinus porosus (Ranzani, 1839)

3. Família Carcharhinidae. Rhizoprionodon lalandei (Val. 1841)

4. Família Sphymidae. Sphyrna tudes (Val. 1822) 


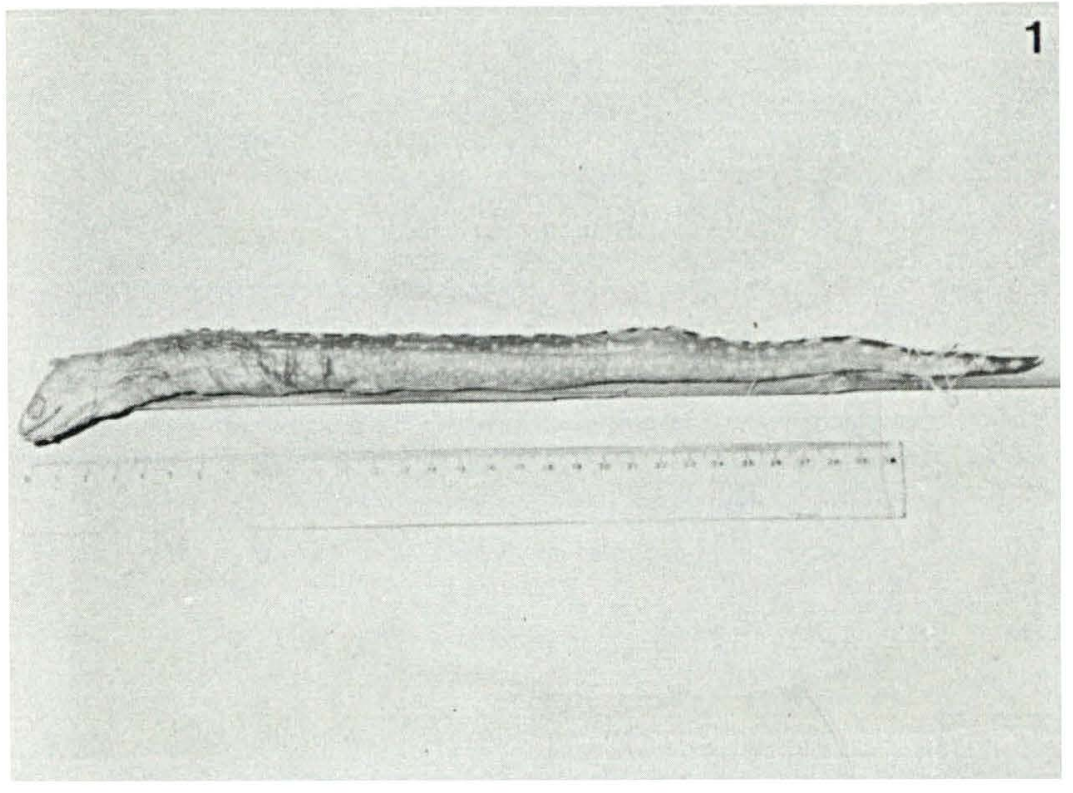

Fig. III - Classe Osteichthyes - Ordem Anguilliformes

1. Família Muraenidae. Gymnothorax ocellatus (Agassiz, 1834)

2. Familia Ophichthidae. Ophichthus gomesii (Castelnau, 1855) 

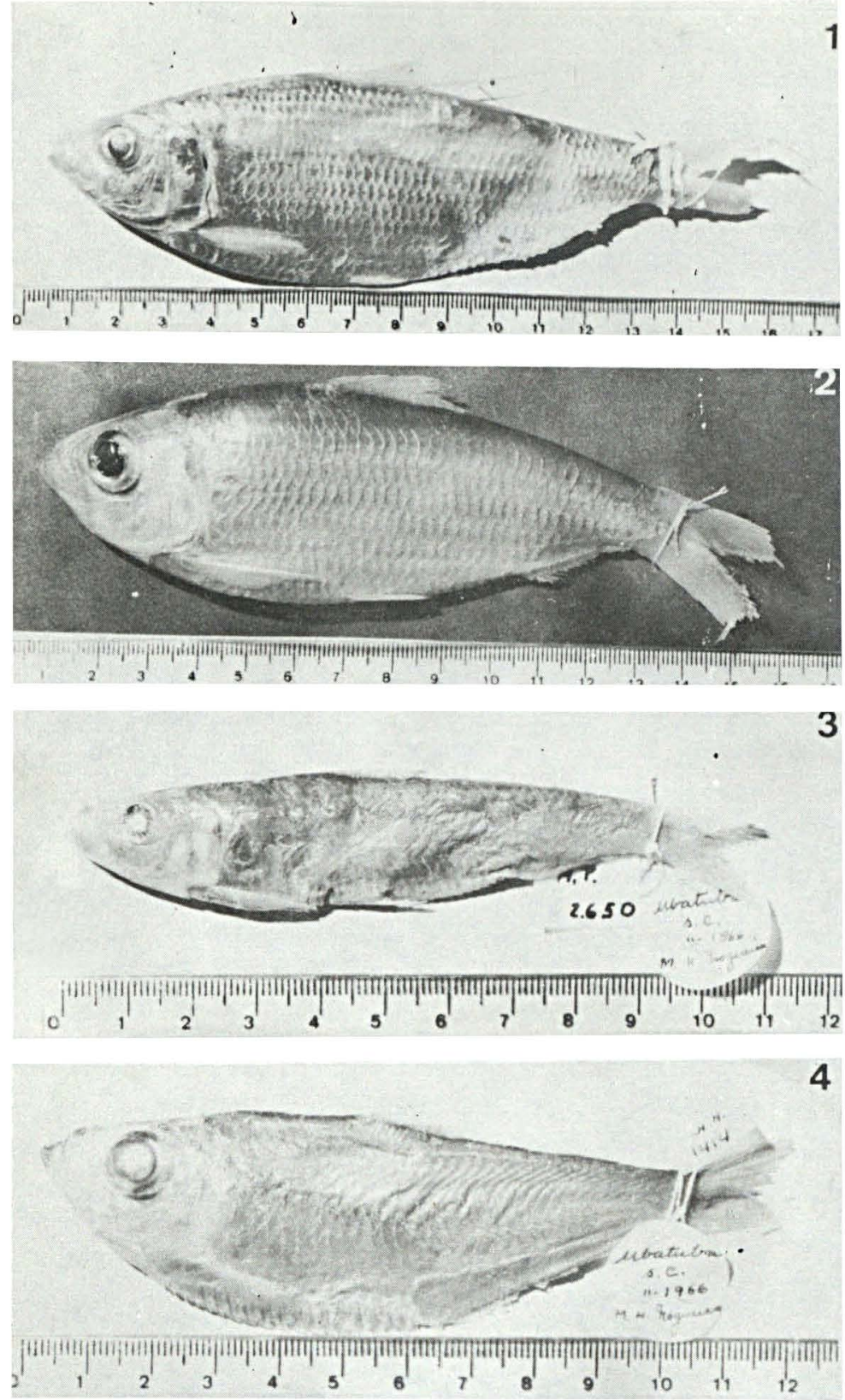

Fig. IV - Classe Osteichthves - Ordem Clupeiformes - Família Clupeidae

1. Opisthonema oglinum (Leseur, 1817)

2. Harengula clupeola (Cuvier, 1829)

3. Sardinella brasiliensis (Steindachner, 1786)

4. Pellona harroweri (Fowler, 1917) 

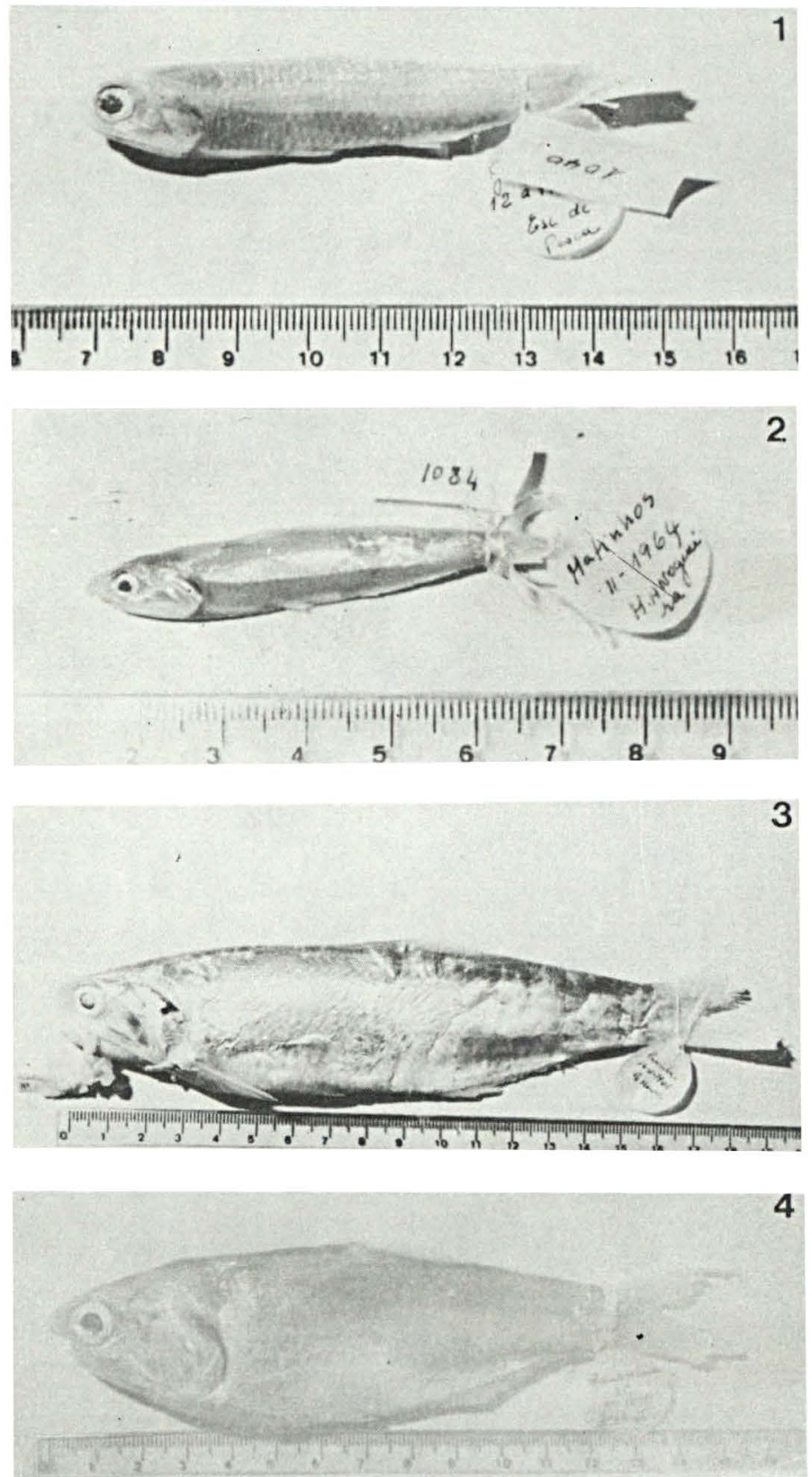

Fig. V - Classe Osteichthyes - Ordem Clupeiformes - Família Engraulidae

1. Anchoa filifera (Fowler, 1915)

2. Anchoa tricolor (Agassiz, 1829)

3. Lycengraulis grossidens (Cuvier, 1829)

4. Cetengraulis edentulus (Cuvier, 1829) 

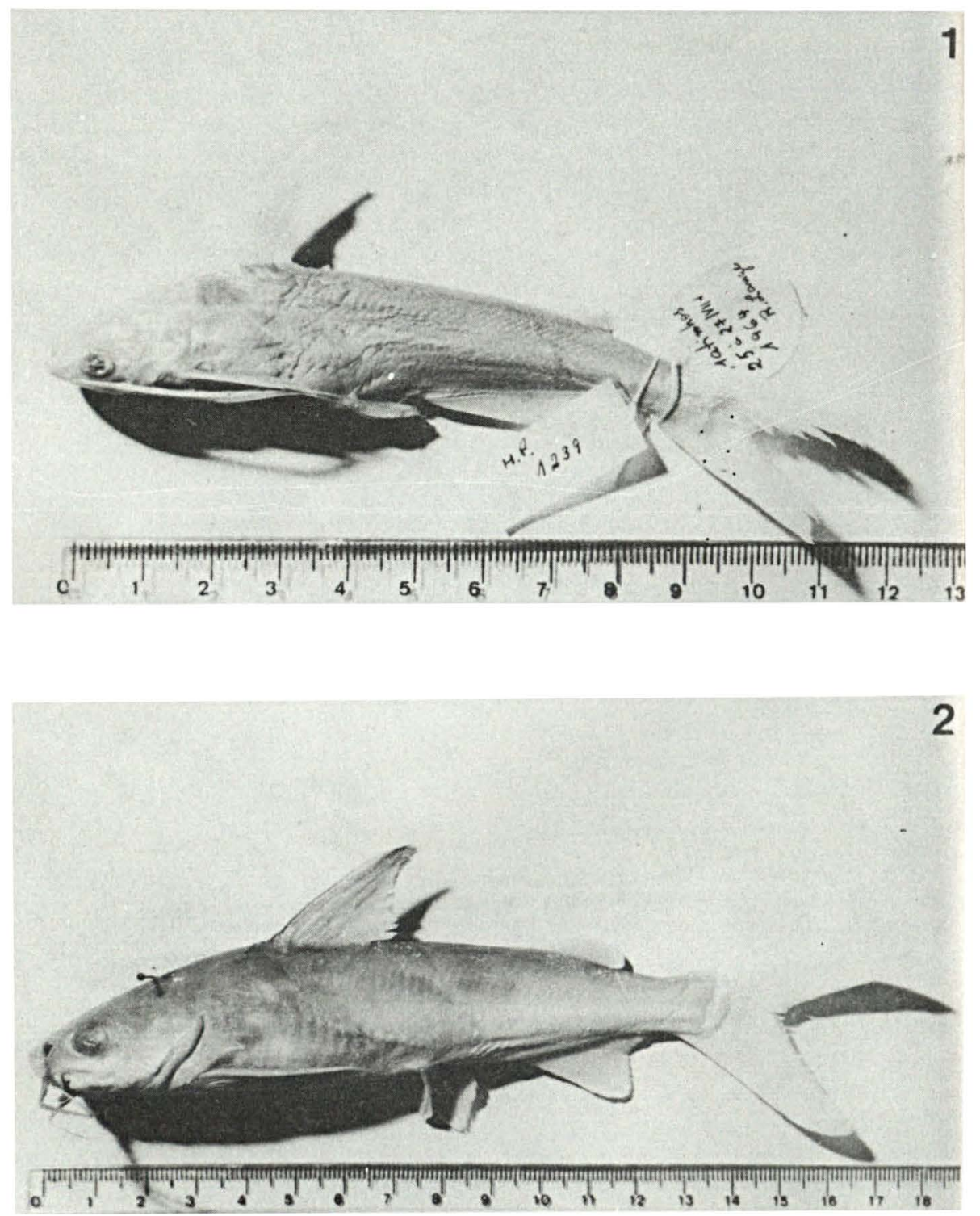

Fig. VI - Classe Osteichthyes - Ordem Siluriformes - Família Ariidae 1. Bagre bagre (Linnaeus, 1766)

2. Arius spixii (Agassiz, 1829) 


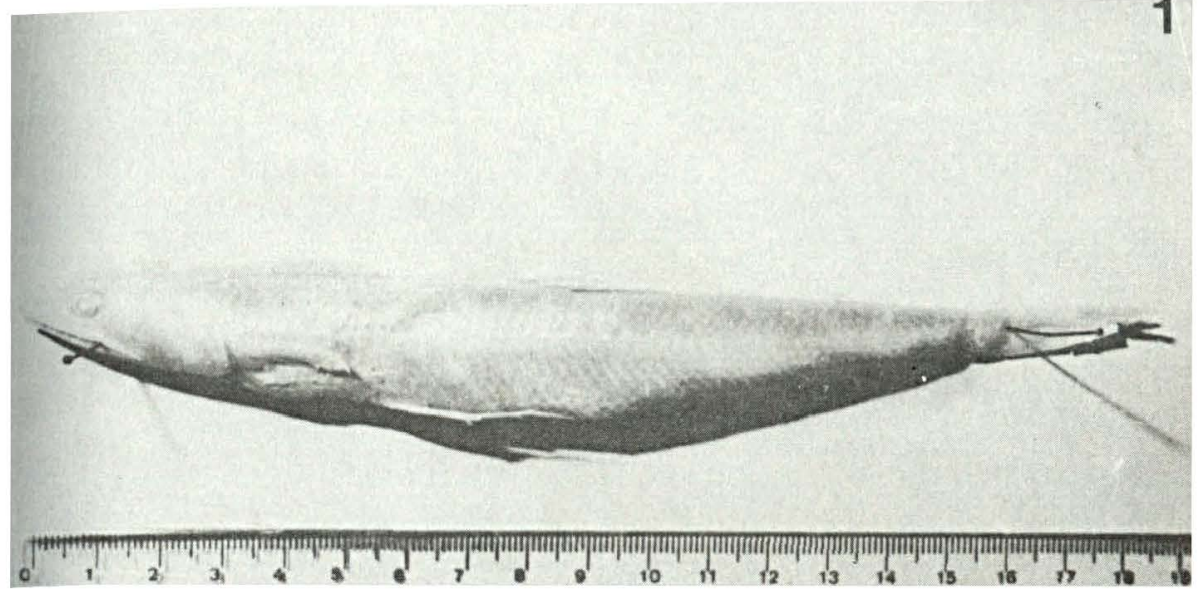

Fig. VII - Classe Osteichthyes - Ordem Aulopiformes - Família Synodontidae 1. Synodus foetens (Linnaeus, 1766)

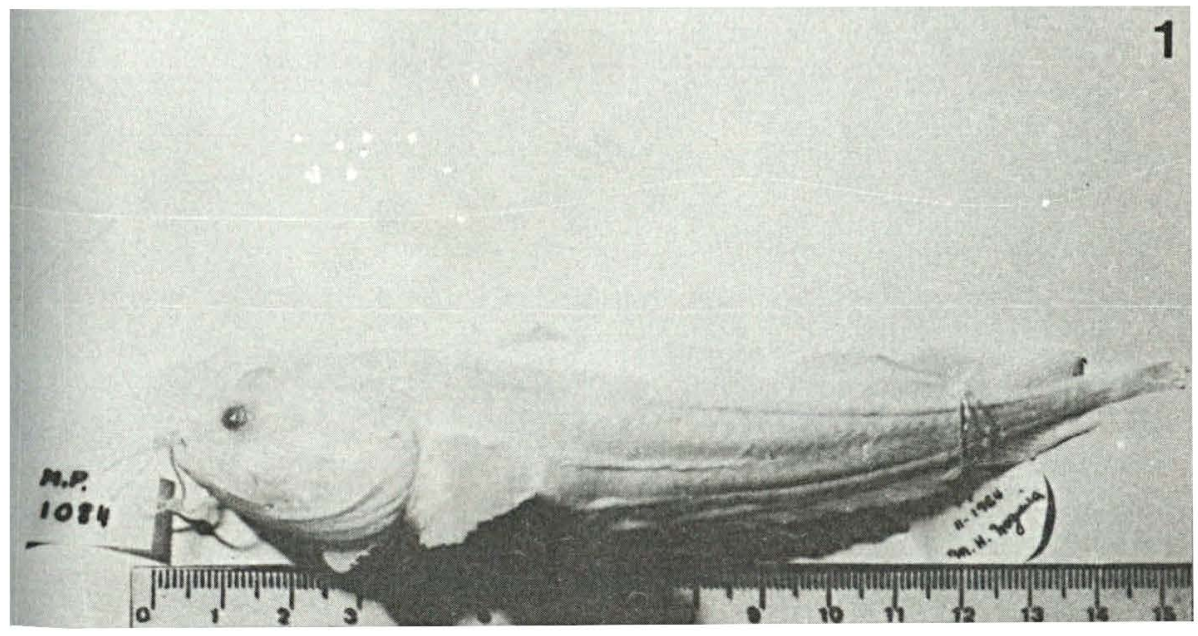

Fig. VIII - Classe Osteichthyes - Ordem Batrachoidiformes - Família Batrachoididae 1. Porichthys porosissimus (Val. 1837) 


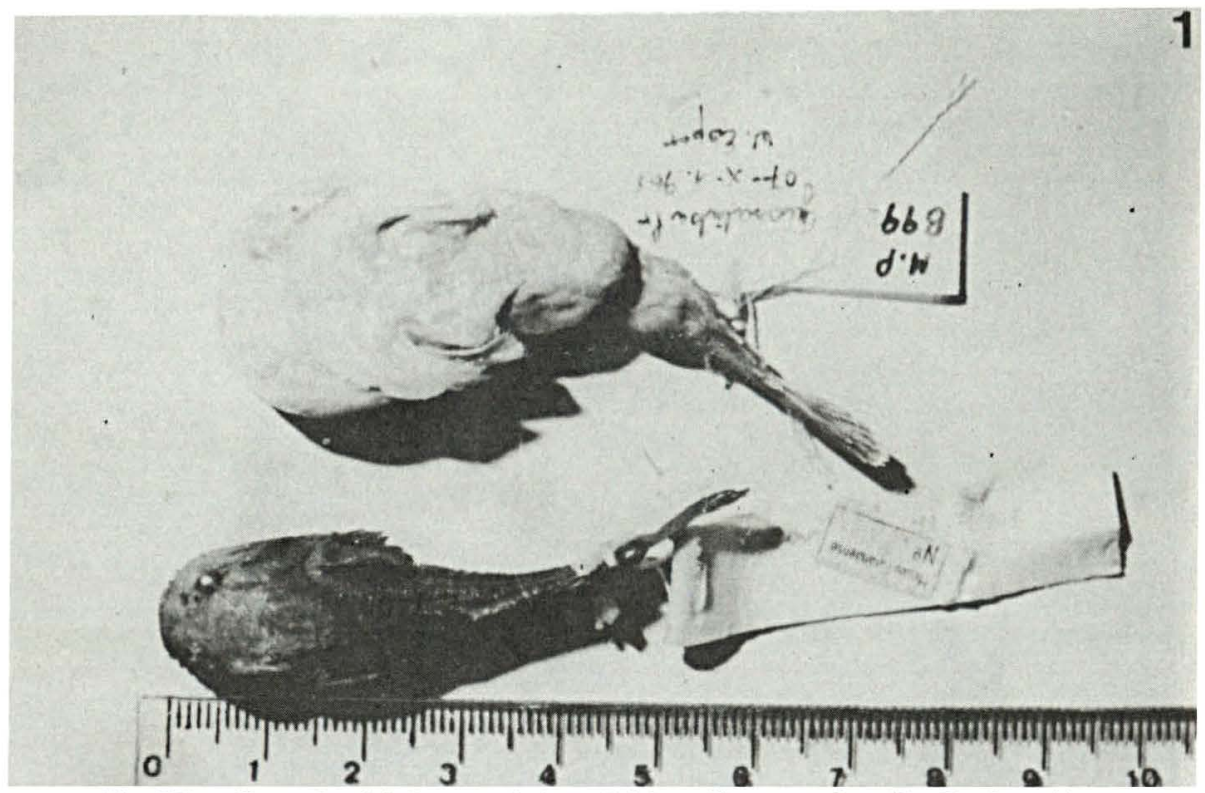

Fig. IX - Classe Osteichthyes - Ordem Gobiesociformes - Familia Gobiesocidae 1. Gobiesox strumosus (Cope, 1870)

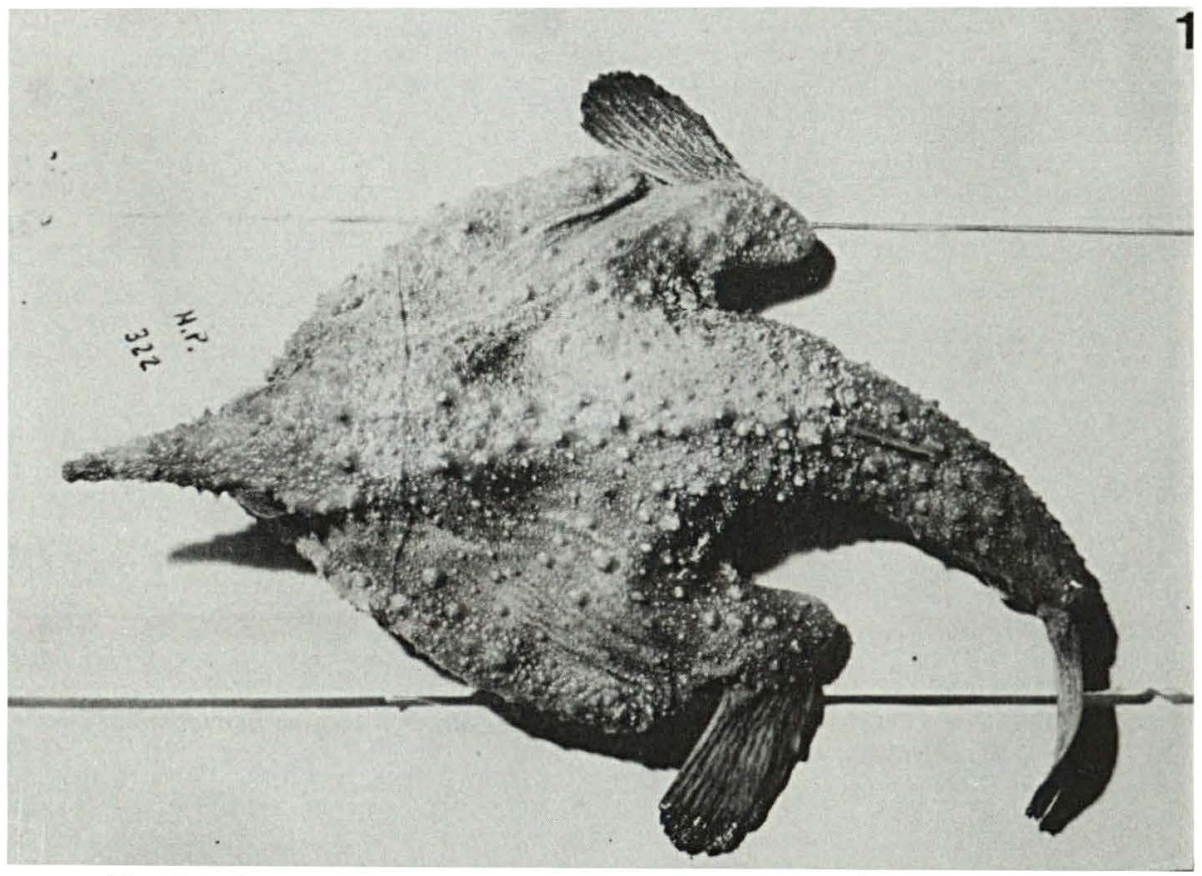

Fig. X - Classe Osteichthyes - Ordem Lophiiformes - Famillia Ogcocephalidae 1. Ogcocephalus vespertilio (Linnaeus, 1758) 


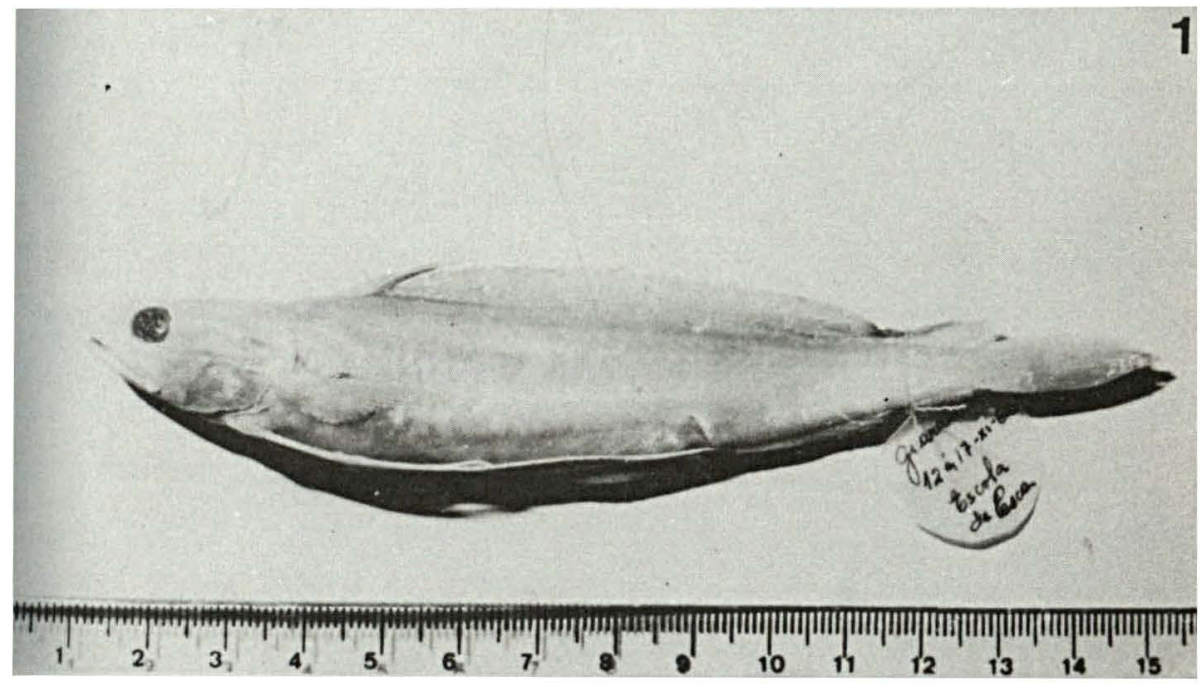

Fig. XI - Classe Osteichthyes - Ordem Gadiformes - Família Gadidae 1. Urophycis brasiliensis (Kaup, 1858) 

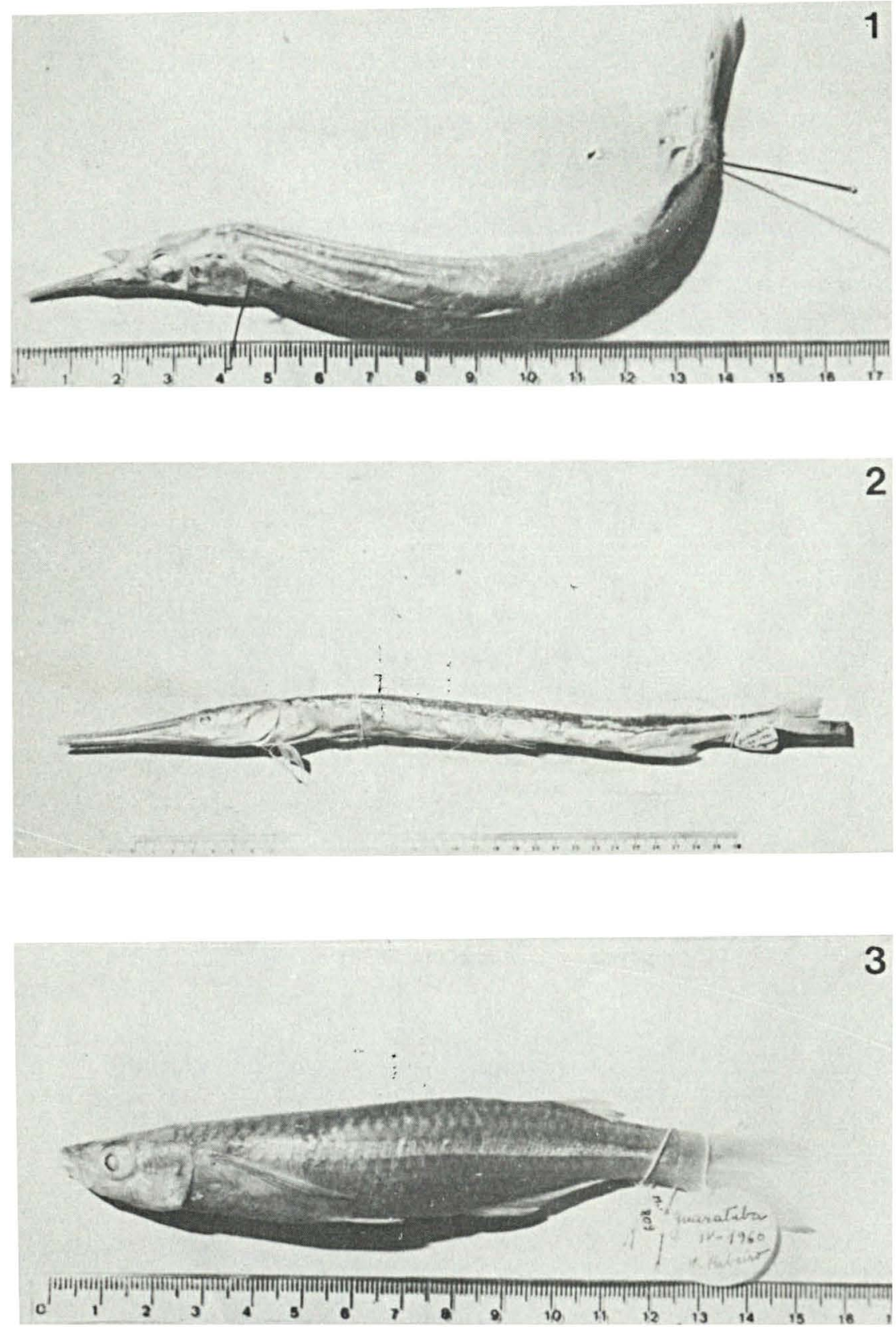

Fig. XII - Classe Osteichthyes - Ordem Atheriniformes

1. Família Hemiramphidae. Hiporhamphus unifasciatus (Ranzani, 1842)

2. Família Belonidae. Strongylura timucu (Walbaum, 1792)

3. Família Atherinidae. Xenomelaniris brasiliensis (Quoy \& Gaimard, 1824) 


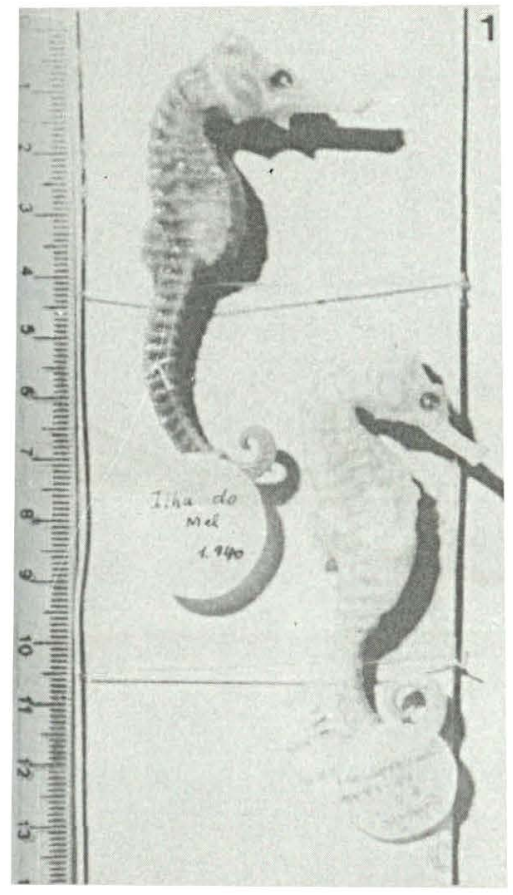

3

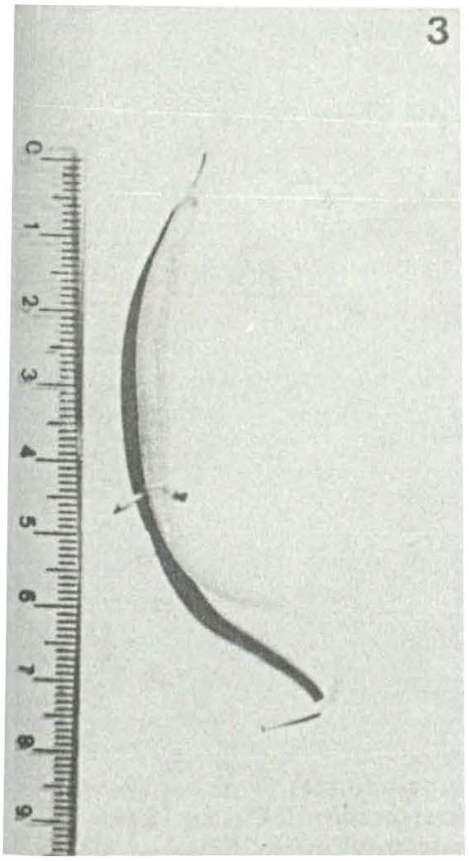

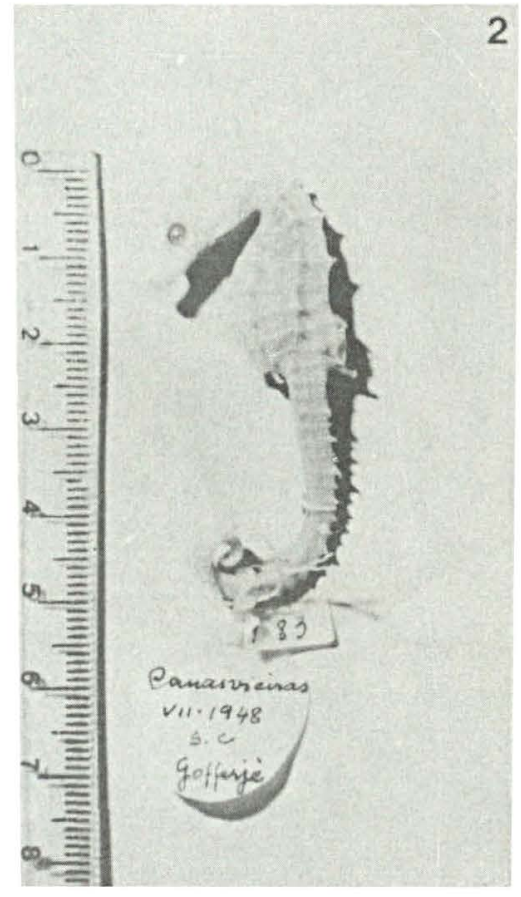

Fig. XIII -

Classe Osteichthyes.

Ordem Gasterosteiformes

Familia Syngnathidae

1. Hippocampus erectus Perry, 1810

2. Hippocampus reidi Ginsburg, 1933

3. Syngnathus folleti Herald, 1942 

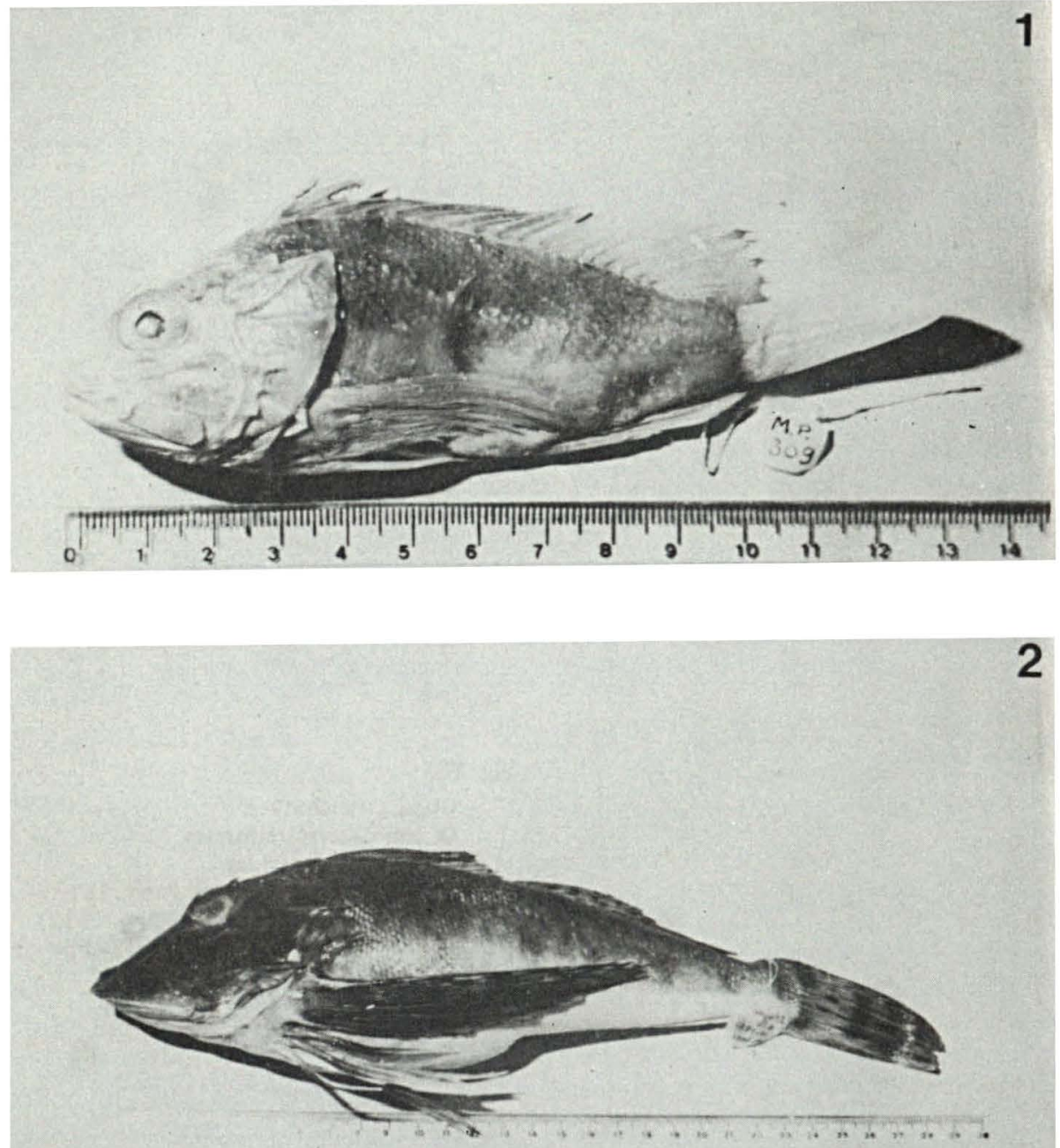

Fig. XIV - Classe Osteichthyes - Ordem Scorpaeniformes 1. Família Scorpaenidae. Scorpaena brasiliensis Cuvier, 1829

2. Família Trigfidae. Prionotus punctatus Cuvier, 1829. 


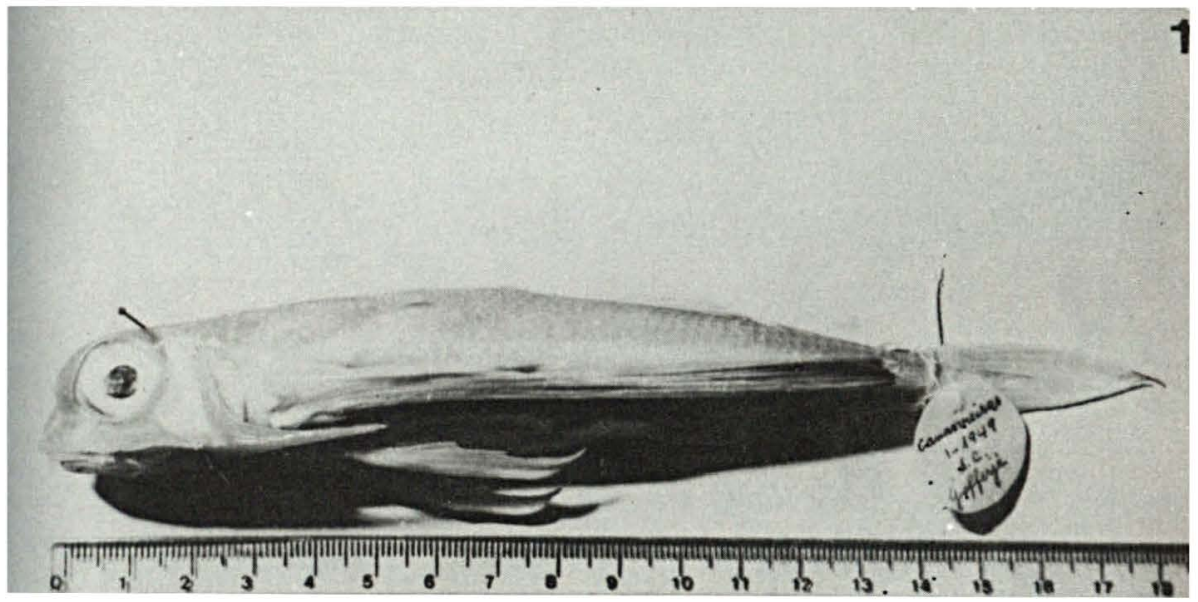

Fig. XV - Classe Osteich thyes - Ordem Dactylopteriformes - Família Dactylopteridae 1. Dactylopterus volitans (Linnaeus, 1758) 


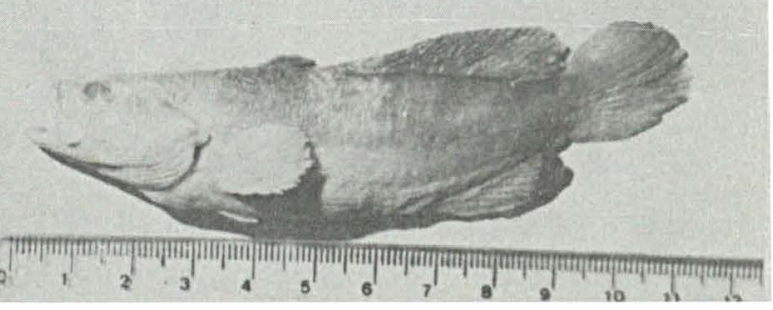

Fig. XVI - Classe Osteichthyes - Ordem Perciformes

1. Família Centropomidae. Centropomus parallelus Poey, 1860

2. Família Serranidae. Diplectrum radiale (Quoy \& Gaimard, 1824)

3. Família Serranidae. Mycteroperca tigris (Val., 1833)

4. Família Grammistidae. Rypticus randalli Courtenay, 1967 

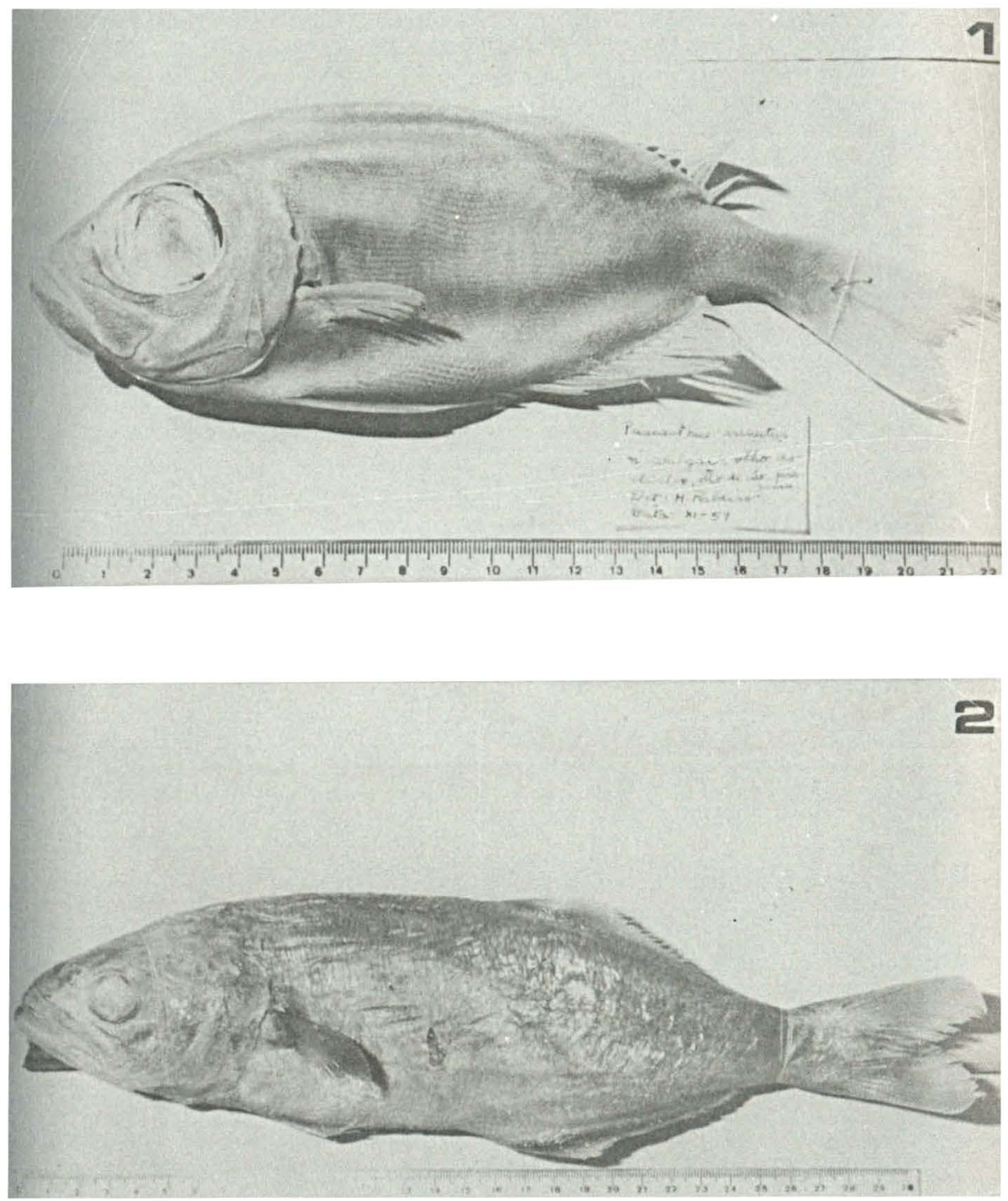

Fig. XVII - Classe Osteichthyes - Ordem Perciformes

1. Família Priacanthidae. Priacanthus arenatus Cuvier, 1829

2. Família Pomatomidae. Pomatomus saltator (Linnaeus, 1766) 

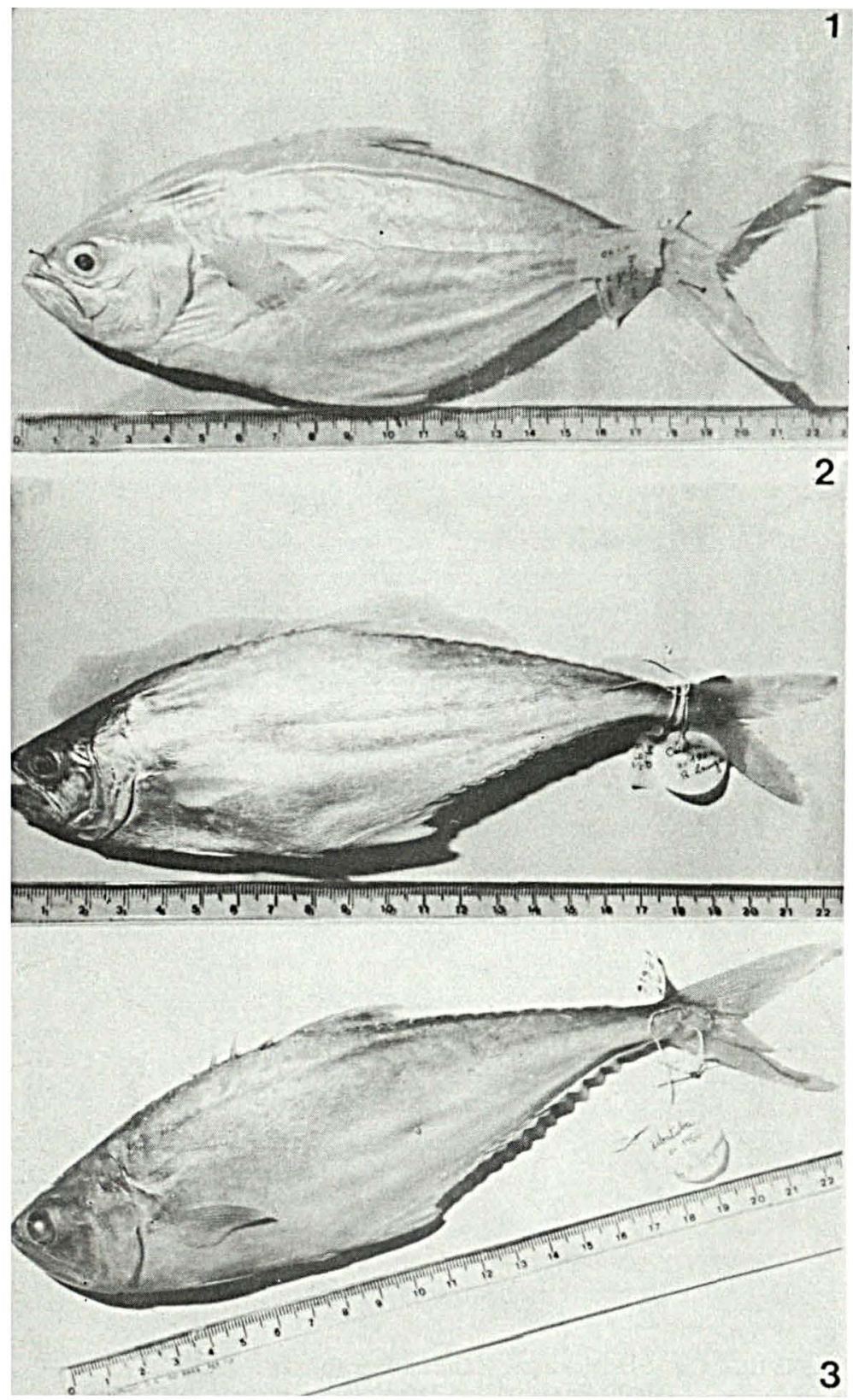

Fig. XVIII - Classe Osteichthyes - Ordem Perciformes - Famńlia Carangidae 1. Parone signate (Jenyns, 1842)

2. Oligoplites saliens (Bloch, 1793)

3. Oligoplites saurus (Bloch \& Schneider, 1801) 


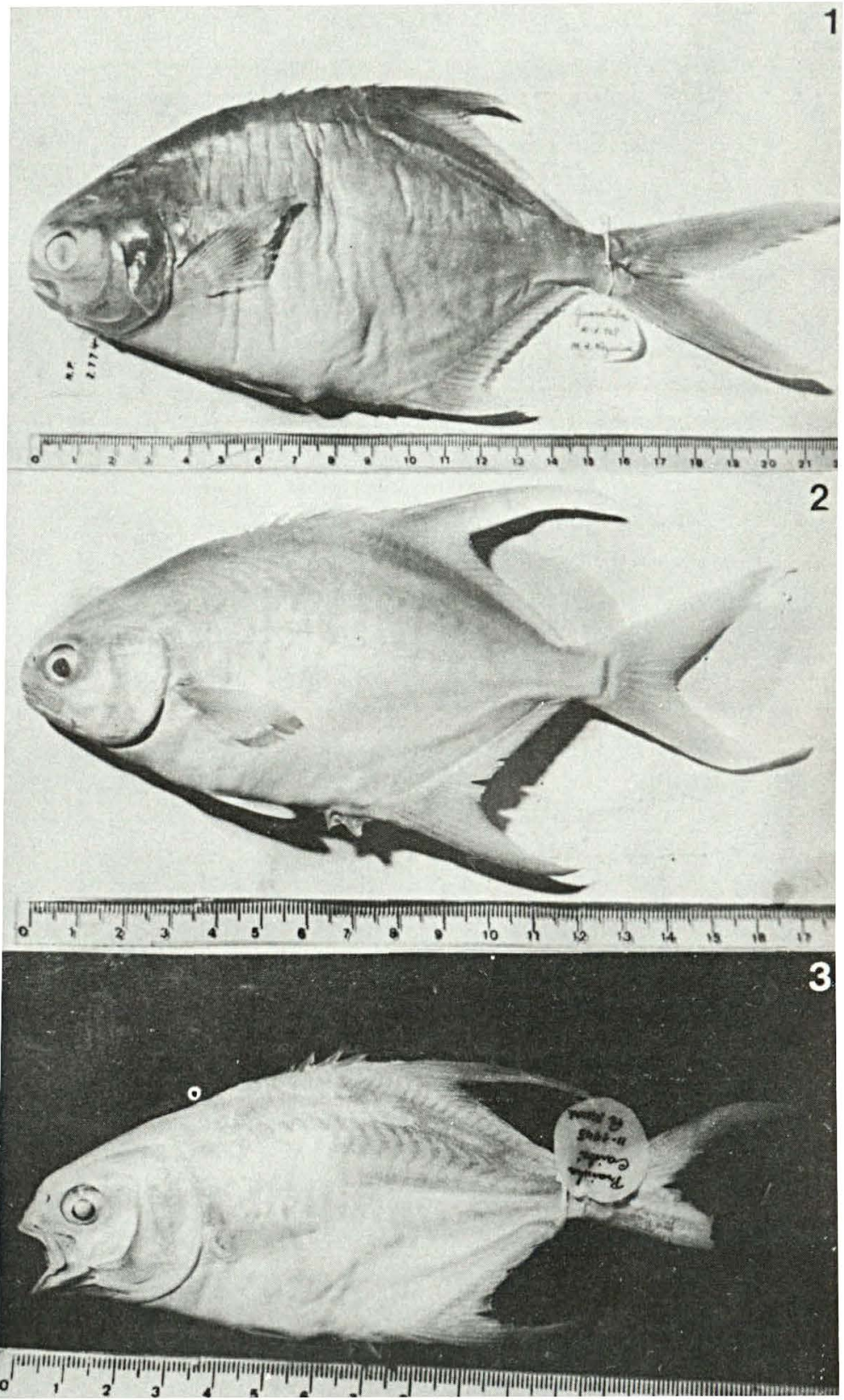

Fig. XIX - Classe Osteichthyes - Ordem Perciformes - Famúlia Carangidae 1. Trachinotus carolinus (Linnaeus, 1766)

2. Trachinotus goodel Jordan \& Evermann, 1896

3. Trachinotus falcatus (Linnaeus, 1758) 

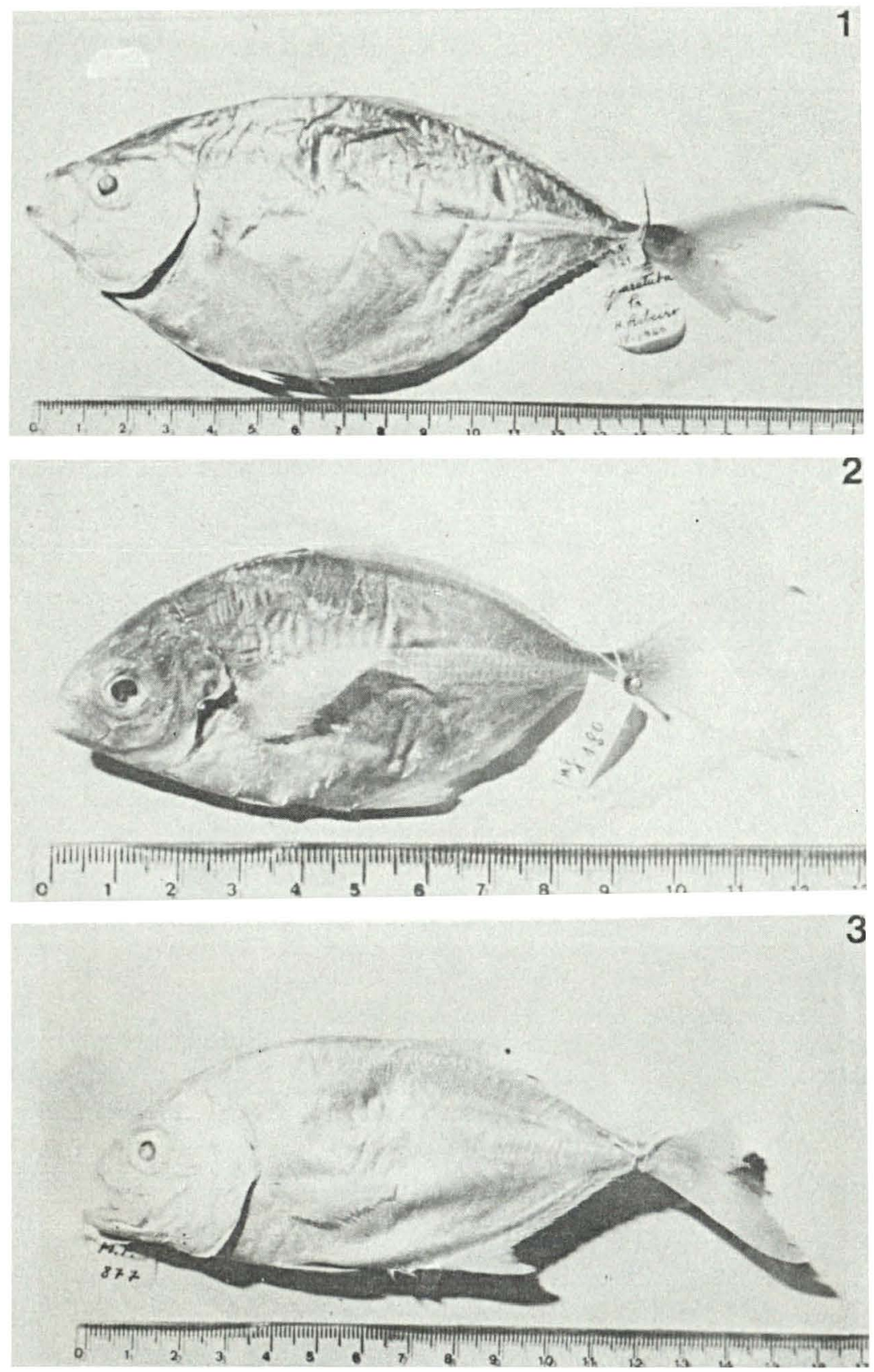

Fig. XX - Classe Osteichthyes - Ordem Perciformes - Família Carangidae 1. Chloroscombrus chrysurus (Linnaeus, 1766)

2. Hemicaranx amblirhynchus (Cuvier, 1833)

3. Caranx latus Agassiz, 1831 

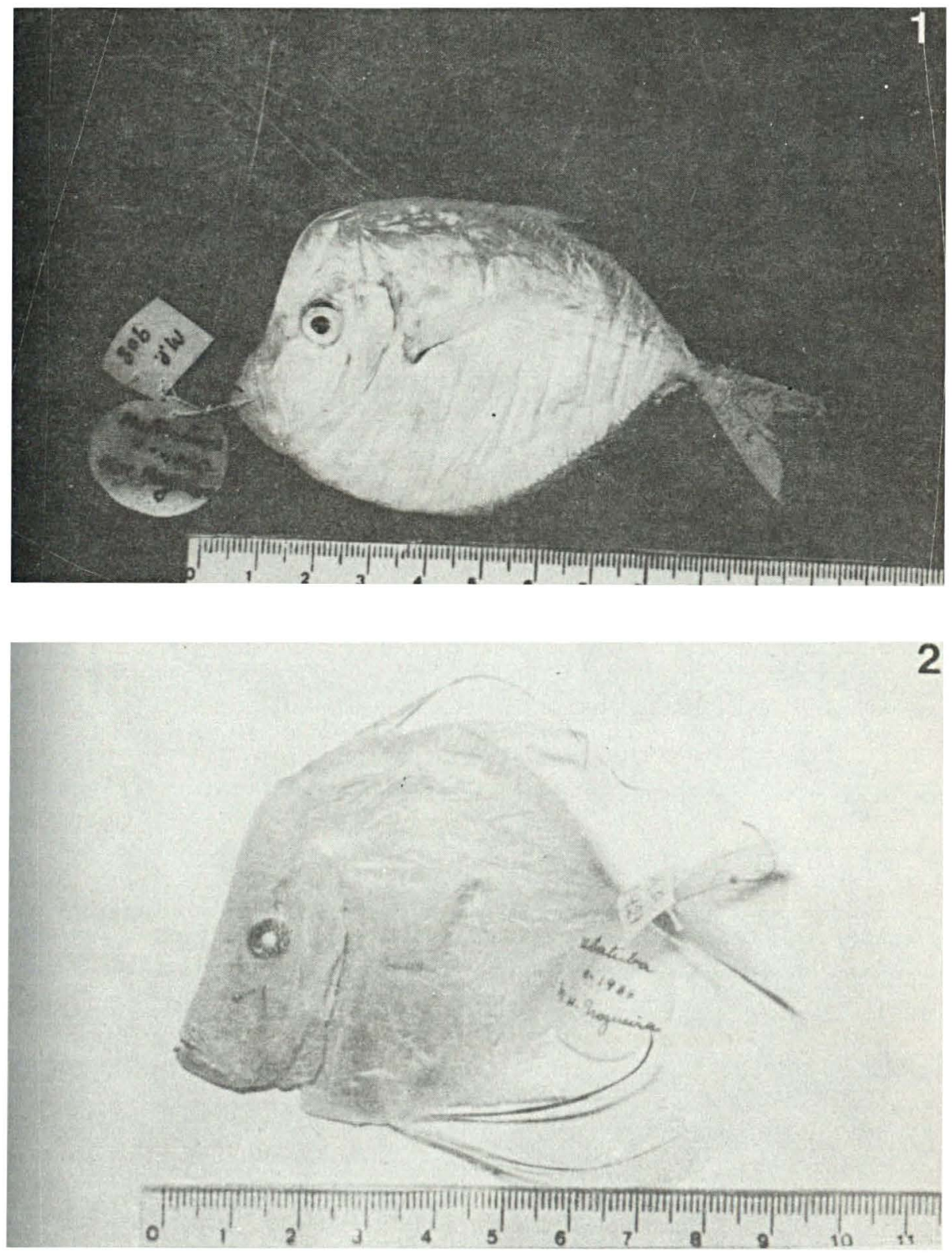

Fig. XXI - Classe Osteichthyes - Ordem Perciformes - Família Carangidae 1. Selene setapinnis (Mitchill, 1815)

2. Selene vomer (Linnaeus, 1758) 

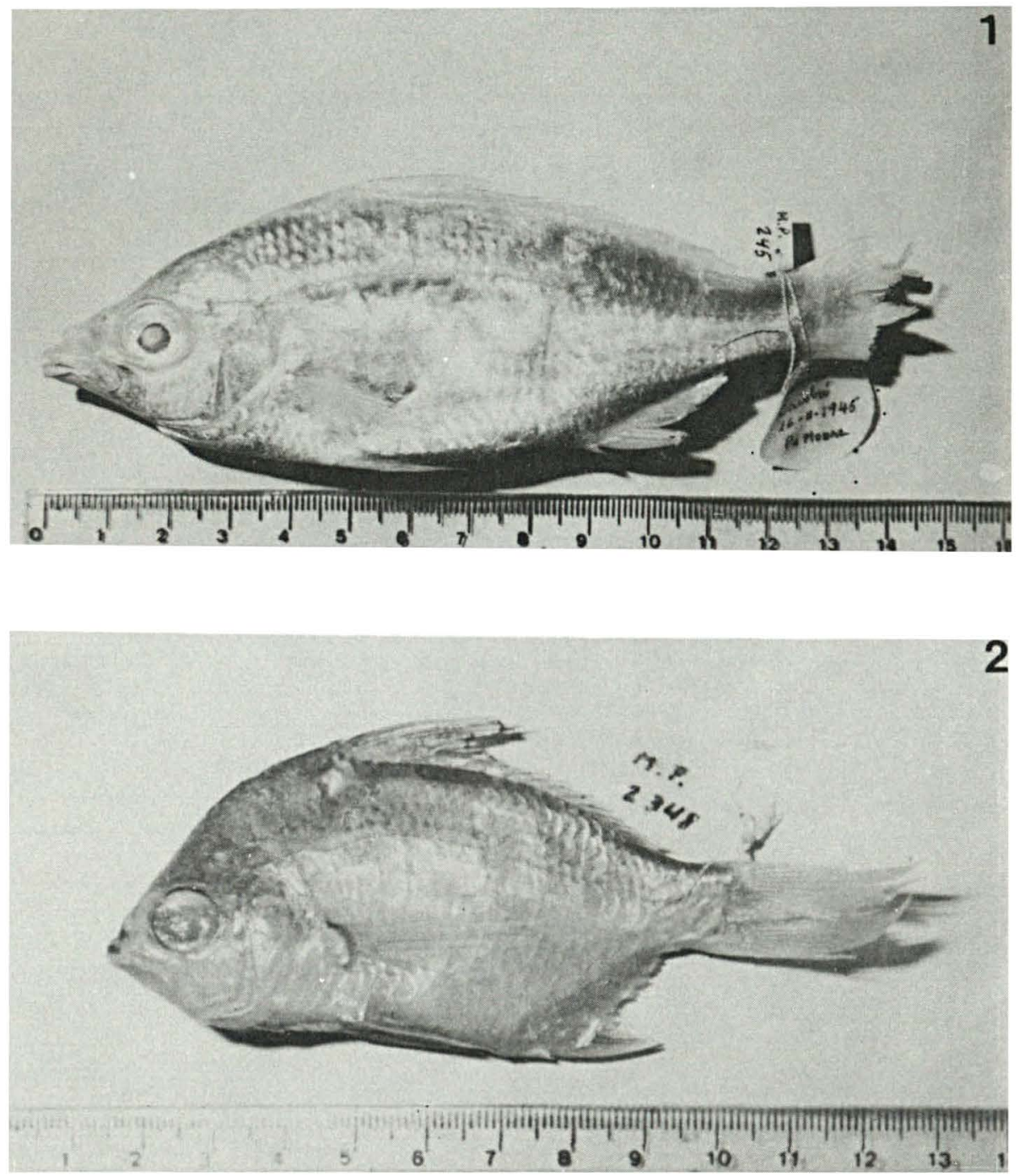

Fig. XXII - Classe Osteichthyes - Ordem Perciformes - Familia Gerreidae 1. Eucinostomus melanopterus (Bleeker, 1863)

2. Diapterus rhombeus (Cuvier, 1829) 

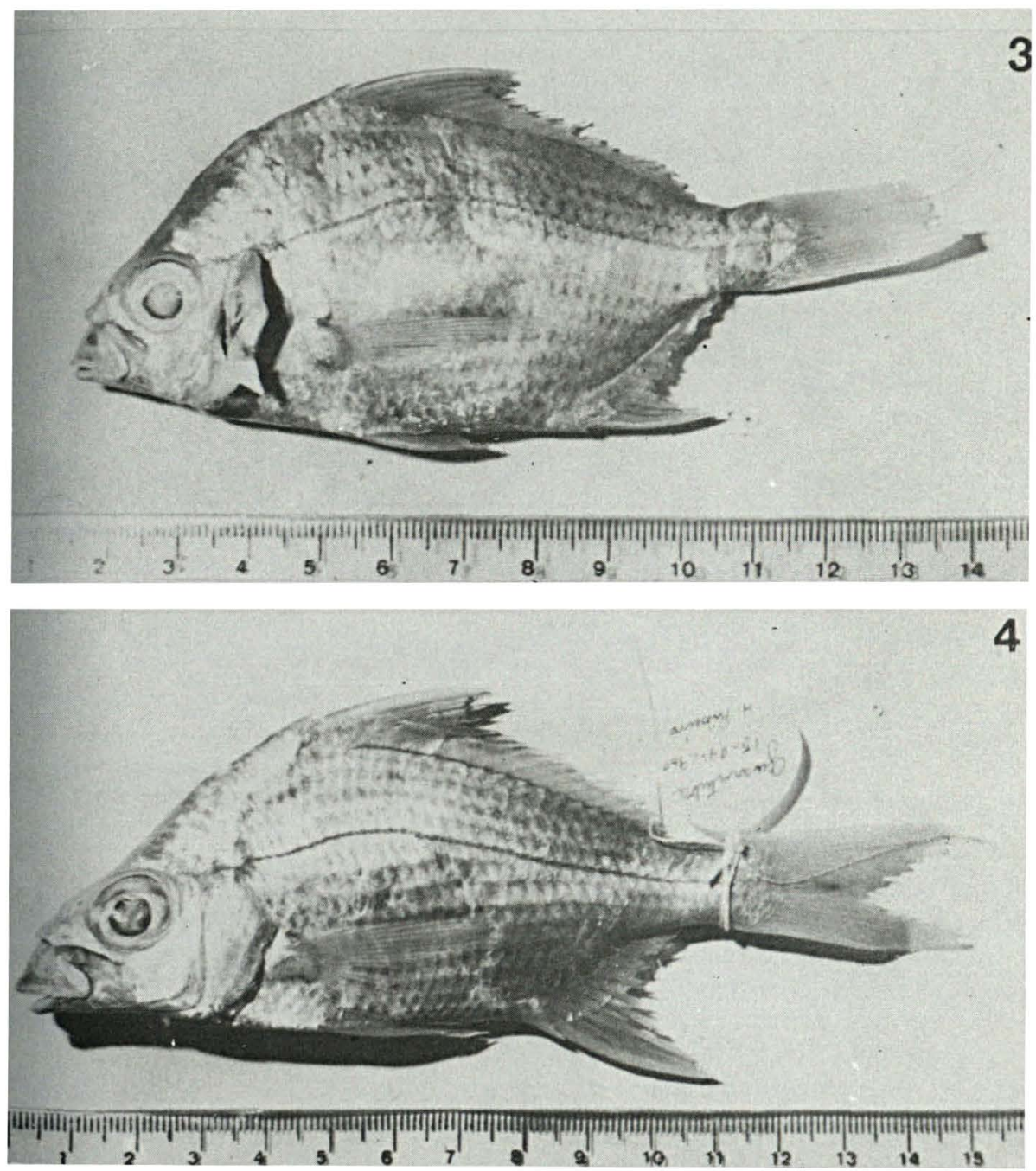

Fig. XXII - Classe Osteich thyes - Ordem Perciformes - Família Gerreidae 3. Diapterus olithostomus (Goode \& Bean, 1822)

4. Eugerres brasiliensis (Cuvier, 1830) 


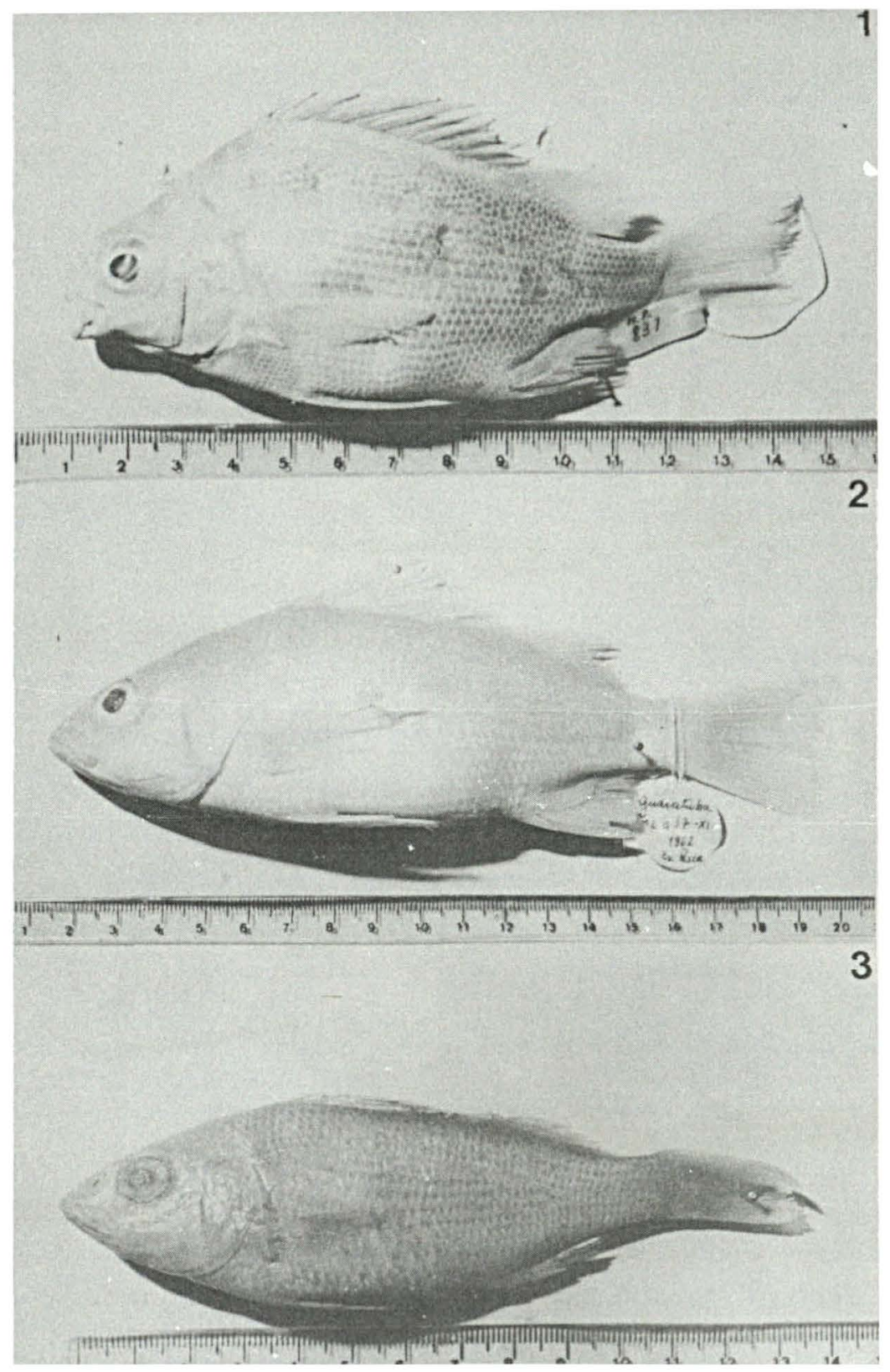

Fig. XXIII - Classe Osteichthyes - Ordem Perciformes - Família Pomadasyidae 1. Ganyatremus luteus (Bloch, 1795)

2. Boridia grossidens (Cuvier, 1830)

3. Pomadasys corvinaeformis (Steidachner, 1868) 

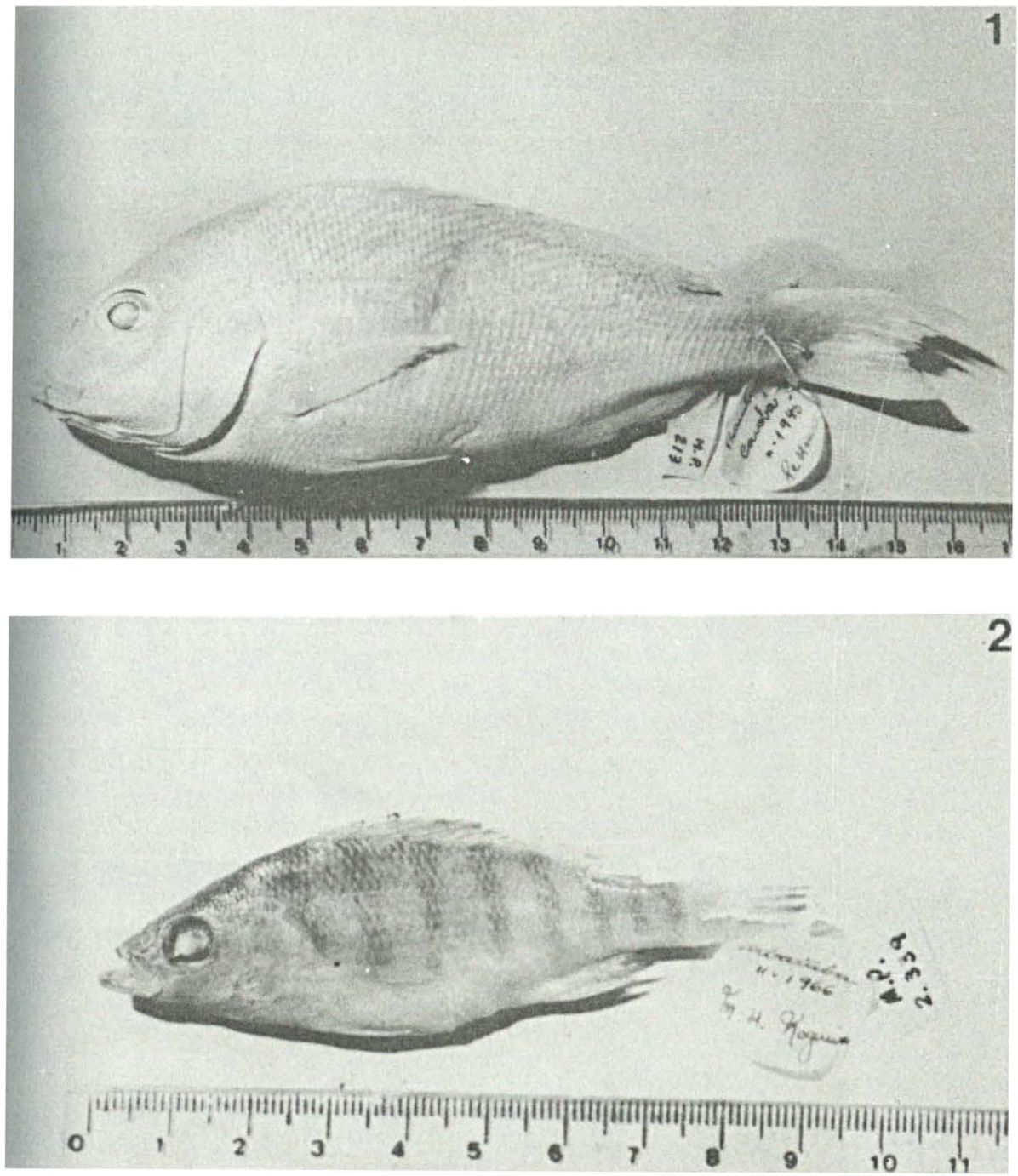

Fig. XXIV - Classe Osteichthyes - Ordem Perciformes - Família Pomadasiydae 1. Orthopristis ruber (Cuvier, 1830)

2. Conodon nobilis (Linnaeus, 1758) 

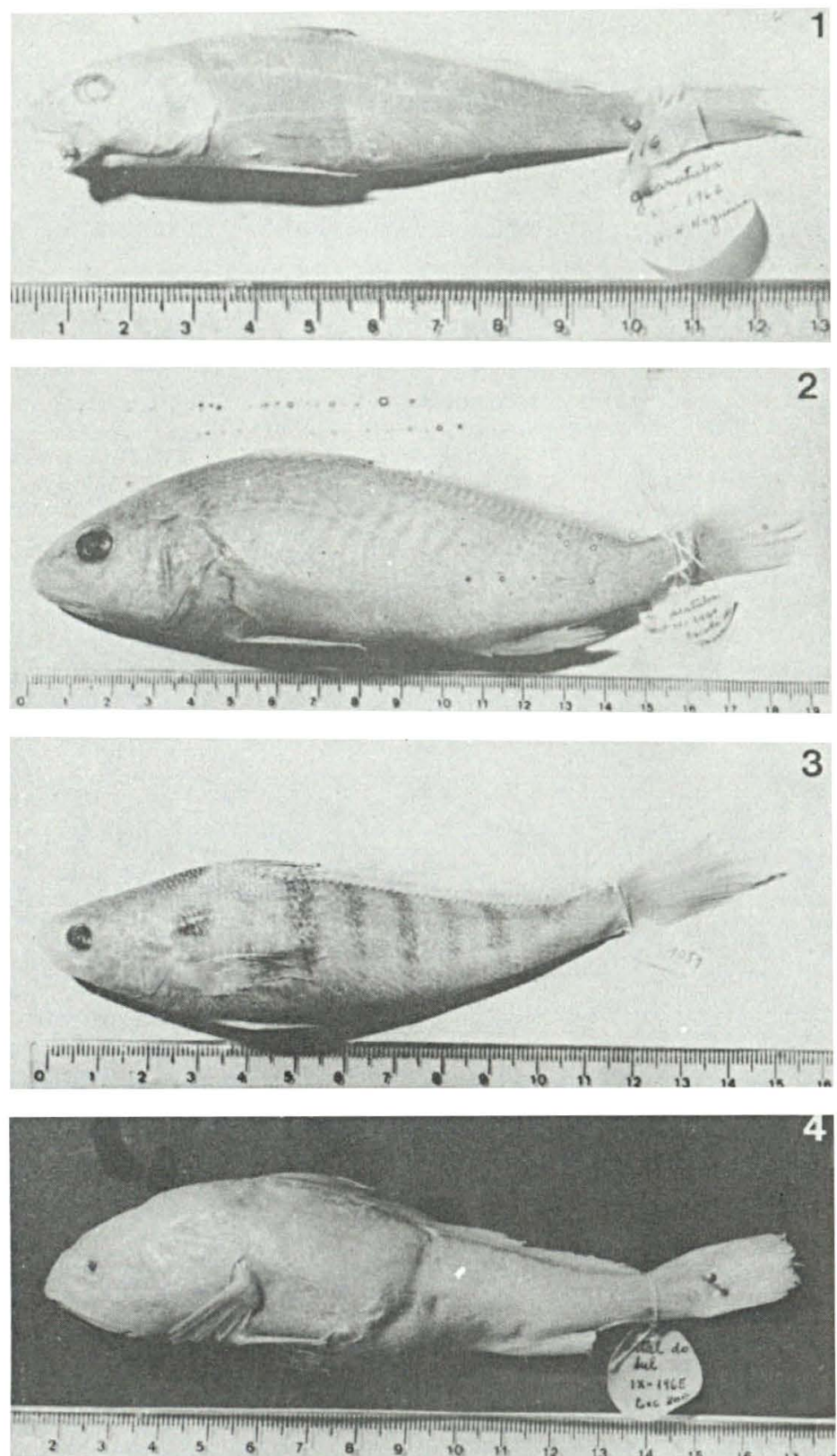

Fig. XXV - Classe Osteichthyes - Ordem Perciformes - Família Sciaenidae 1. Menticirrhus americanus (Linnaeus, 1758)

2. Micropogonias furnieri (Desmarest, 1823)

3. Paralonchurus brasiliensis (Steindachner, 1875)

4. Nebris microps Cuvier, 1830 

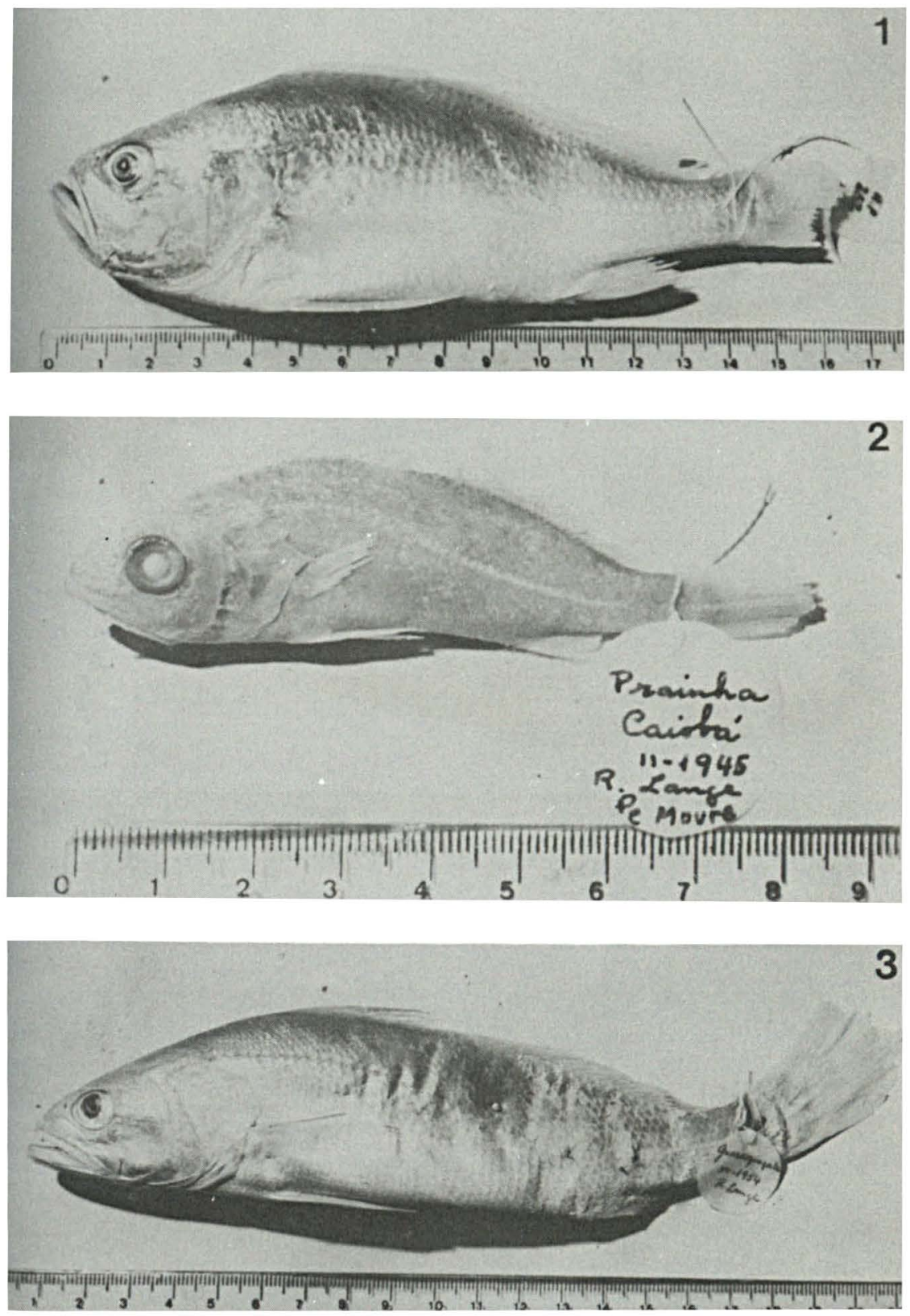

Fig. XXVI - Classe Osteichthyes - Ordem Perciformes - Família Sciaenidae 1. Larimus breviceps Cuvier, 1830

2. Isopisthus parvipinnis (Cuvier, 1830)

3. Cynoscion acoupa (Lacépède, 1802) 

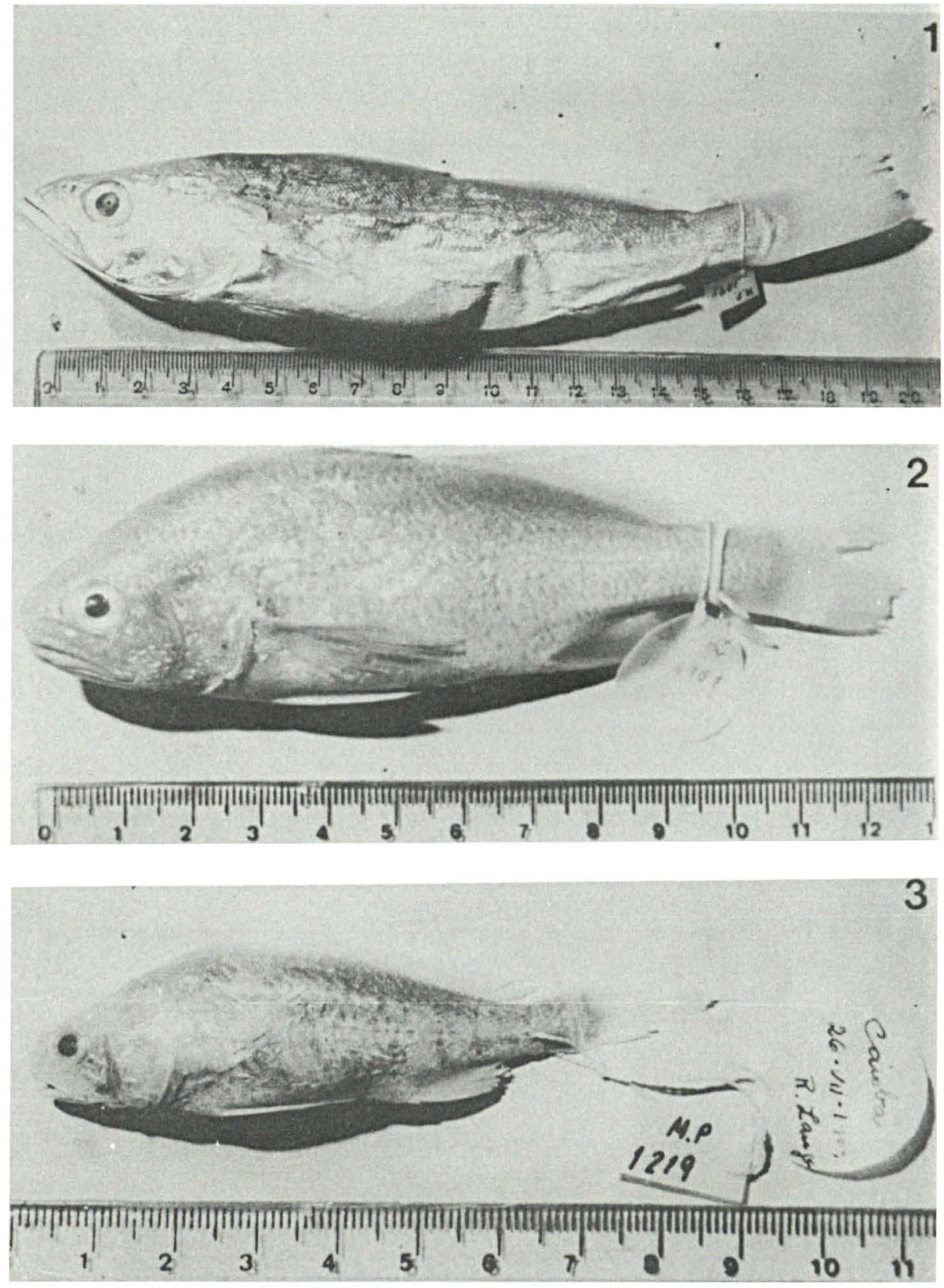

Fig. XXVII - Classe Osteich thyes - Ordem Perciformes - Família Sciaenidae 1. Cynoscion leiarchus (Cuvier, 1830)

2. Stellifer rastrifer (Jordan, 1889)

3. Stellifer brasiliensis (Schultz, 1945) 


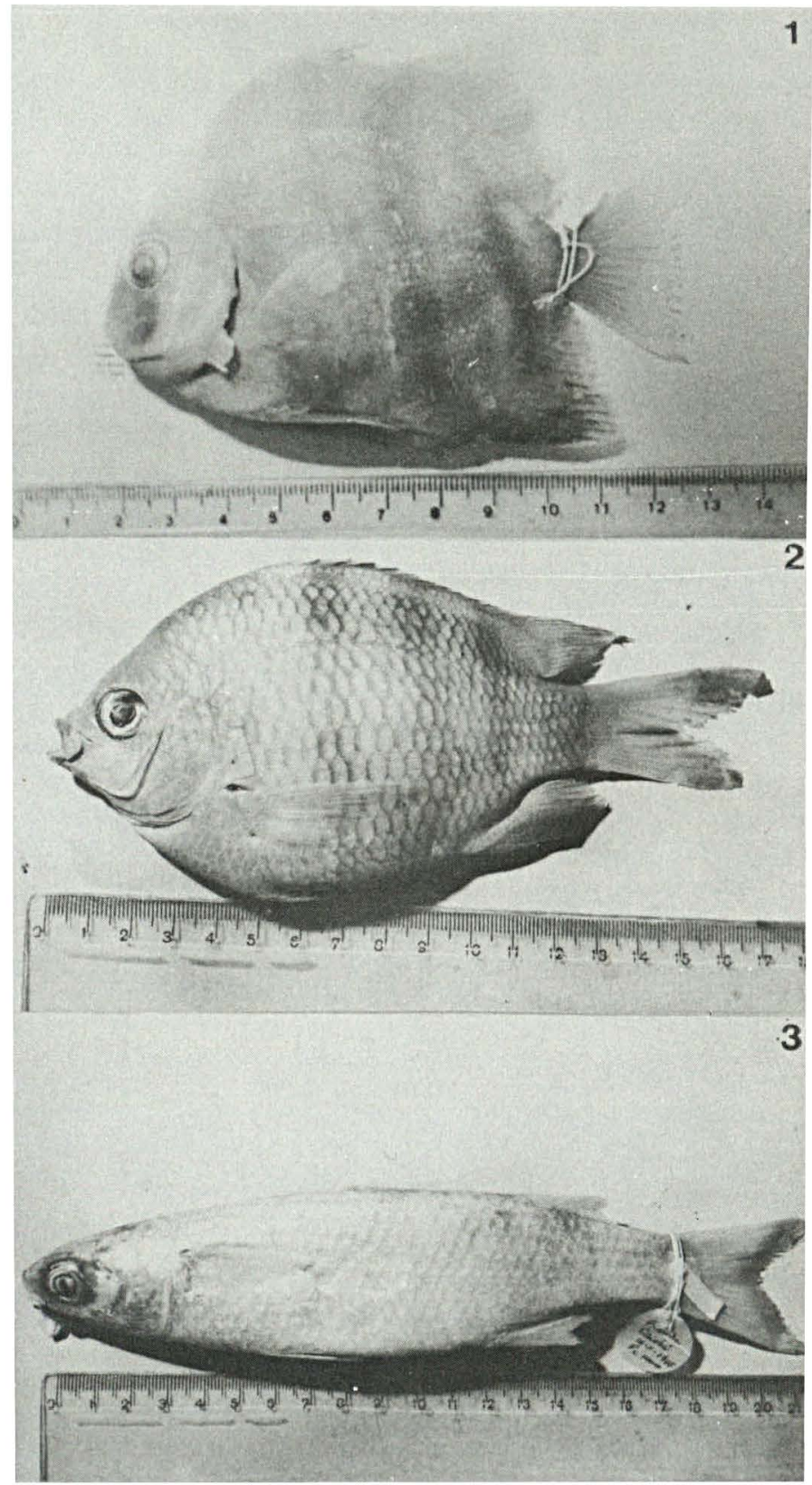

Fig. XXVIII - Classe Osteichthyes - Ordem Perciformes

1. Família Ephippidae. Chaetodipterus faber (Broussonet, 1782)

2. Família Pomacentridae. Abudefduf saxatilis Linnaeus, 1758)

3. Família Mugilidae. Mugil curema Valenciennes, 1836 

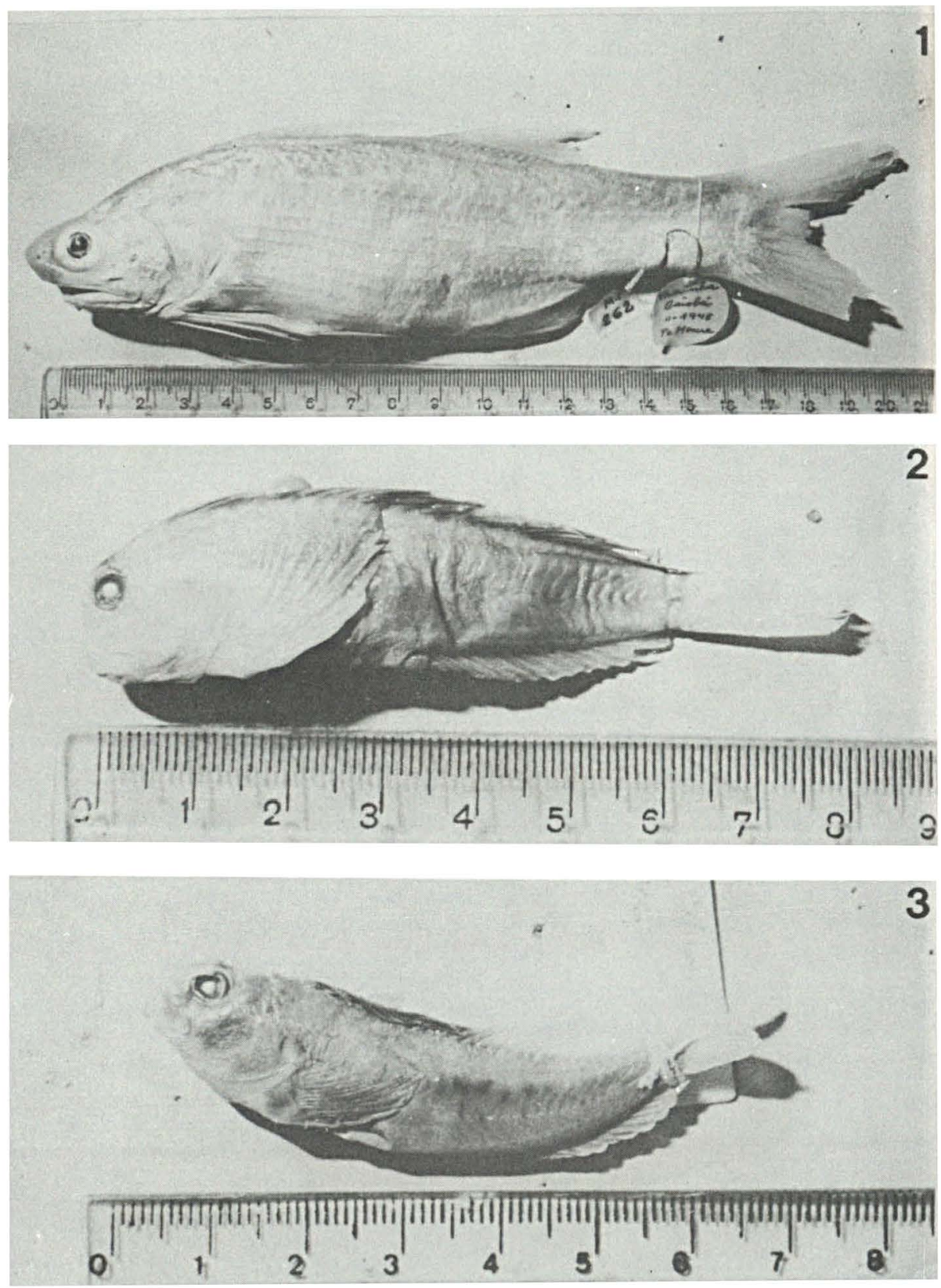

Fig. XXIX - Classe Osteichthyes - Ordem Perciformes

1. Família Polynemidae. Polidactylus virginicus (Linnaeus, 1758)

2. Família Blenniidae. Scartella cristata (Linnaeus, 1758)

3. Família Bleniidae. Hypleurochilus $s p$ 

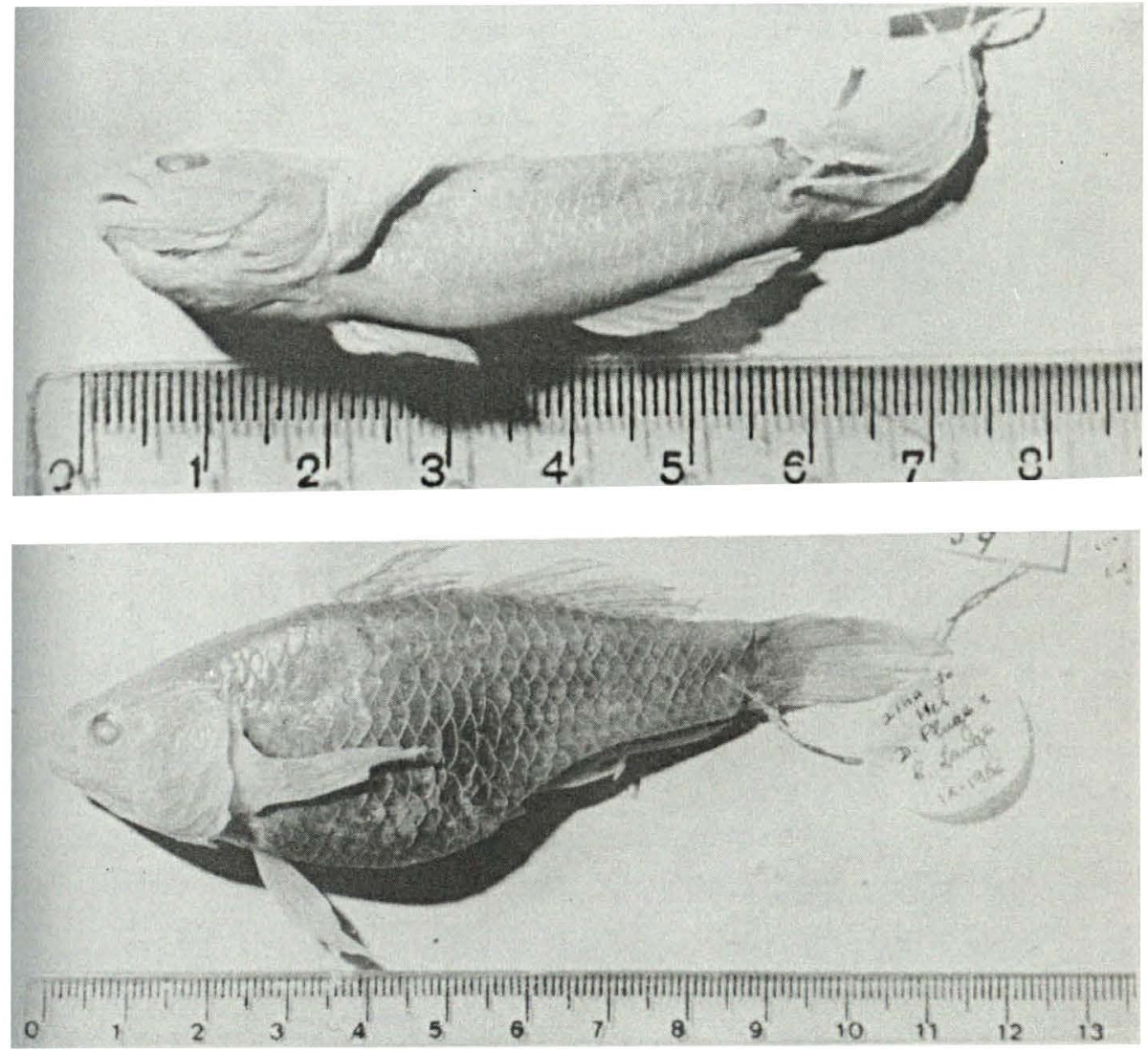

Fig. XXX - Classe Osteichthyes - Ordem Perciformes

1. Família Gobiidae. Bathygobius soporator (Val., 1837)

2. Família Eleotridae. Dormitator maculatus (Bloch, 1792) 

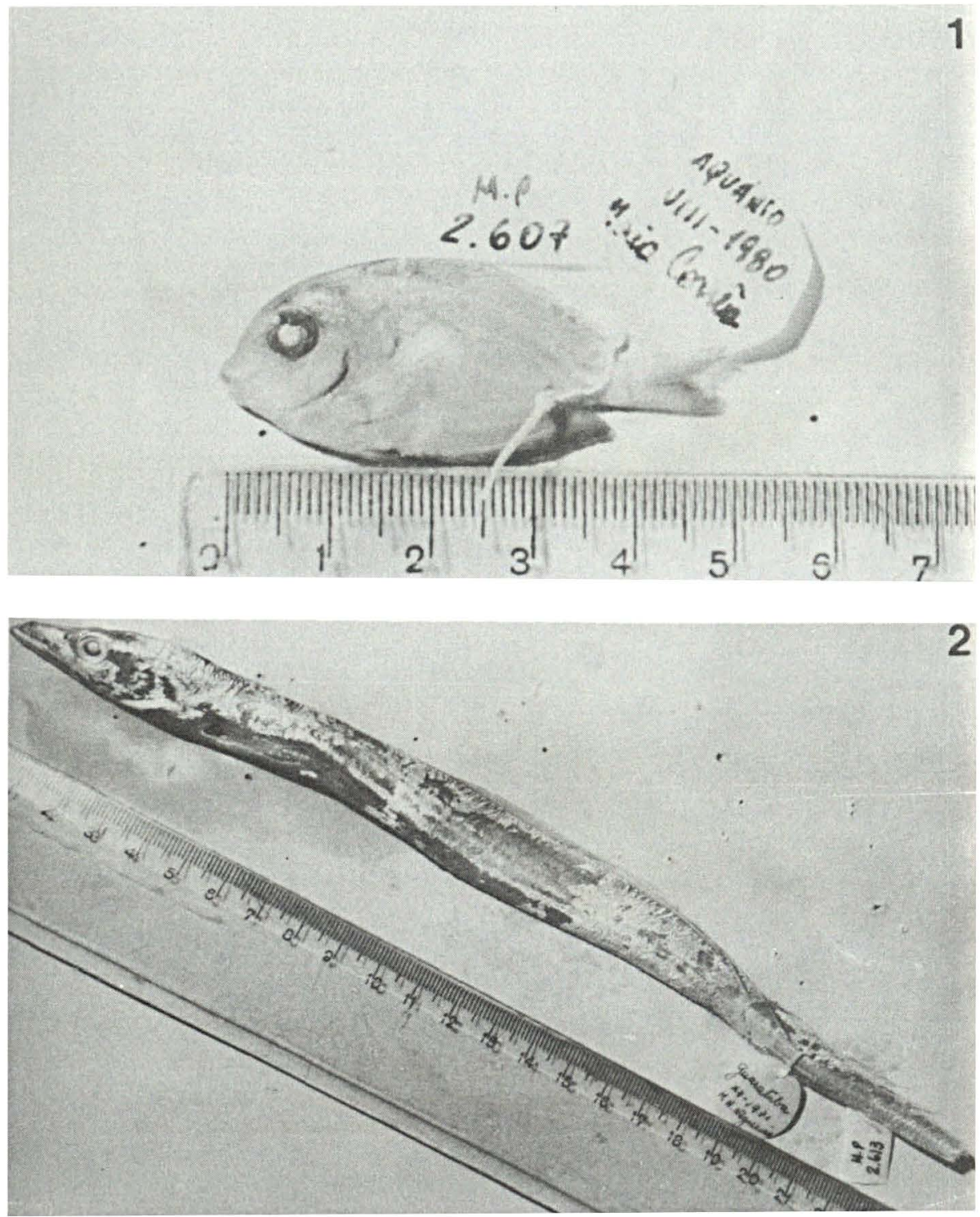

Fig. XXXI -Classe Osteichthyes - Ordem Perciformes

1. Famillia Acanthuridae. Acanthurus baianus Castelnau, 1855

2. Família Trichiuridae. Trichiurus lepturus Linnaeus, 1758 


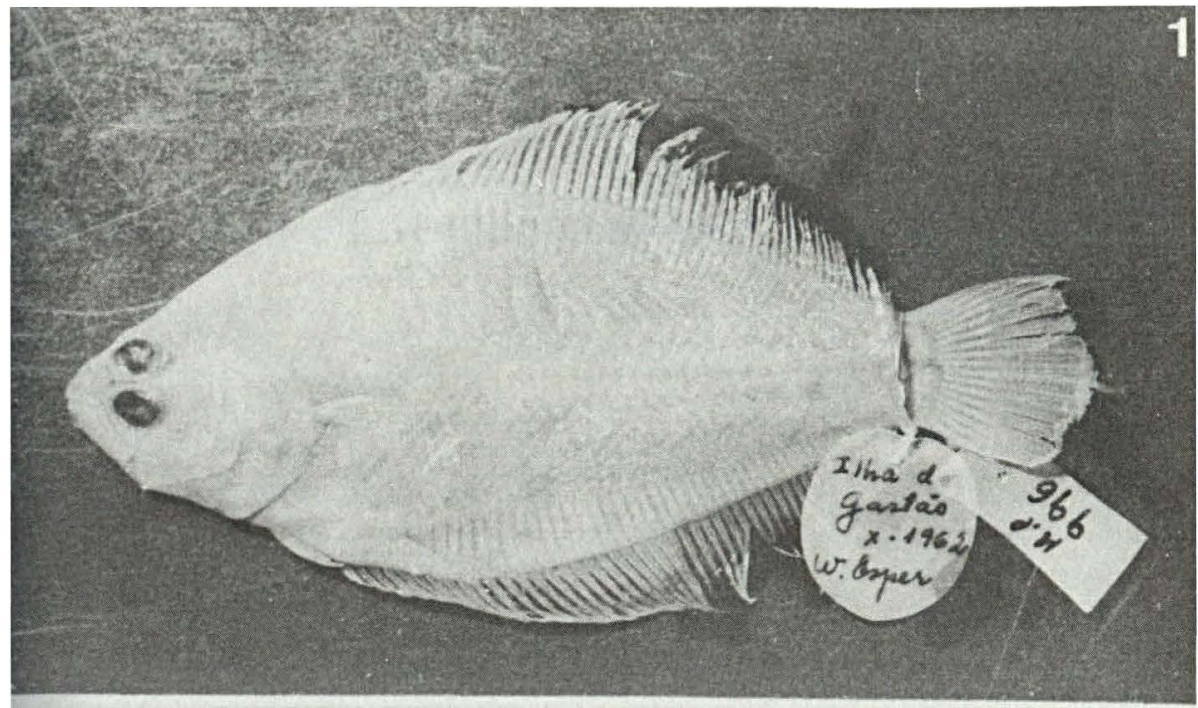

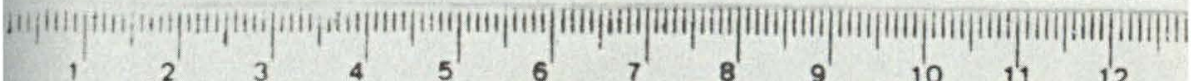

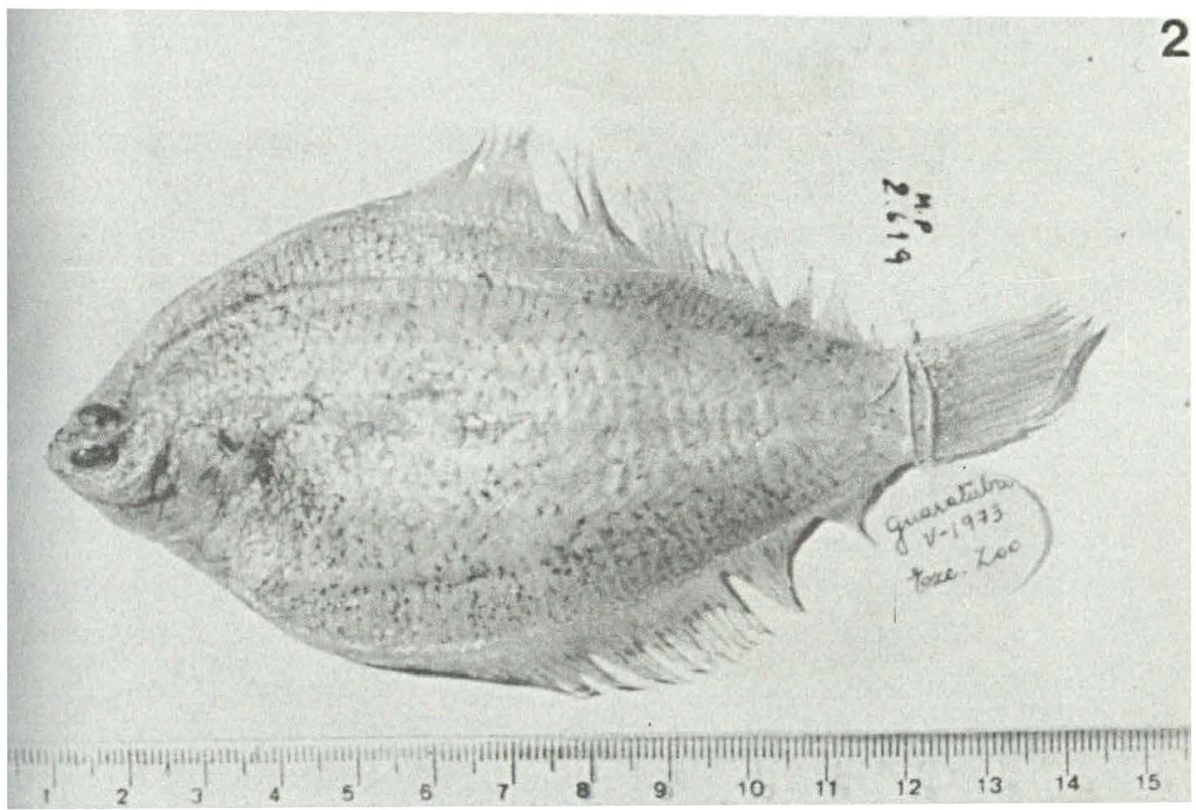

Fig. XXXII - Classe Osteichthyes - Ordem Perciformes - Família Bothidae

1. Citharichthys spilopterus Günther, 1862

2. Etropus intermedius Norman, 1933 


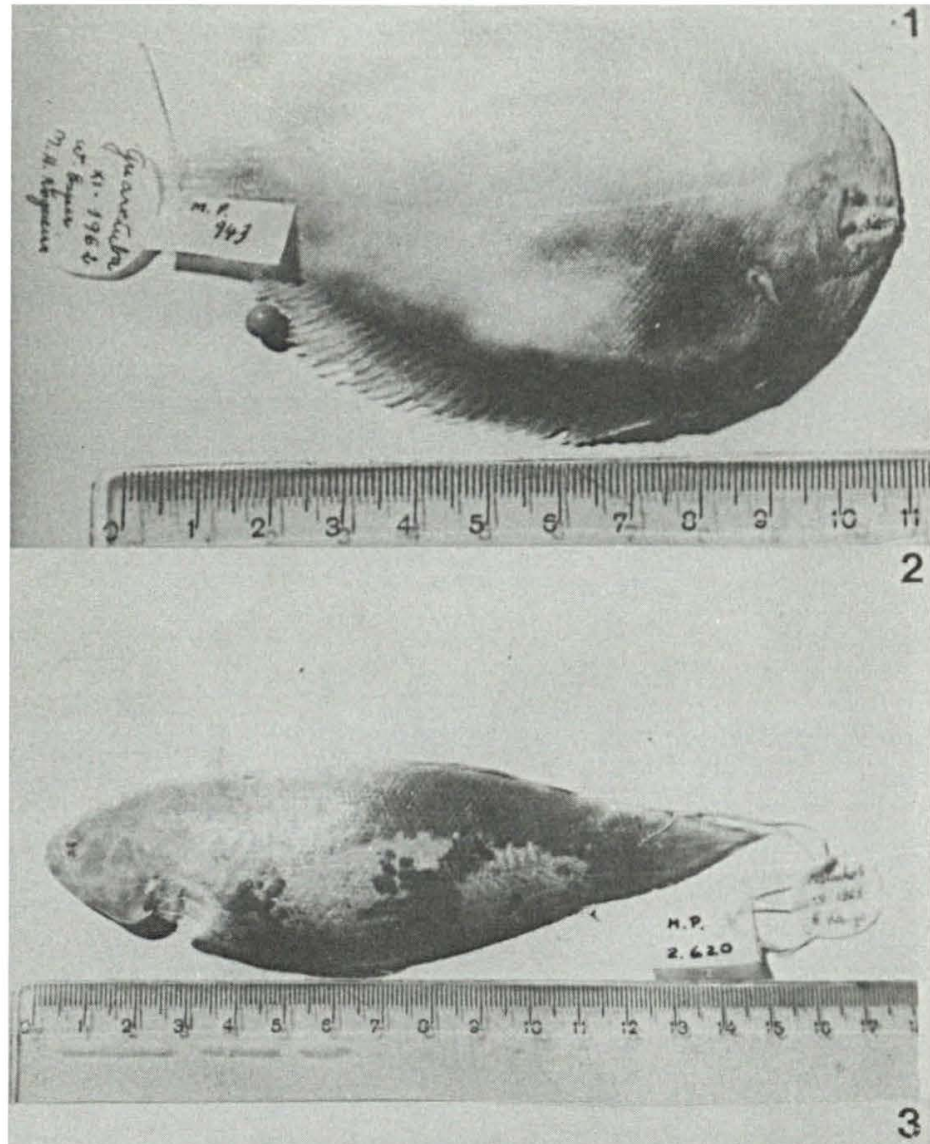

Fig. XXXIII - Classe Osteichthyes - Ordem Perciformes

1. Família Soleidae. Achirus sp. Lacépède, 1803

2. Família Cynoglossidae. Symphurus diomedanus (Goode \& Bean, 1886)

3. Família Cynoglossidae. Symphurus plagusia (Bloch \& Schenneider, 1801) 


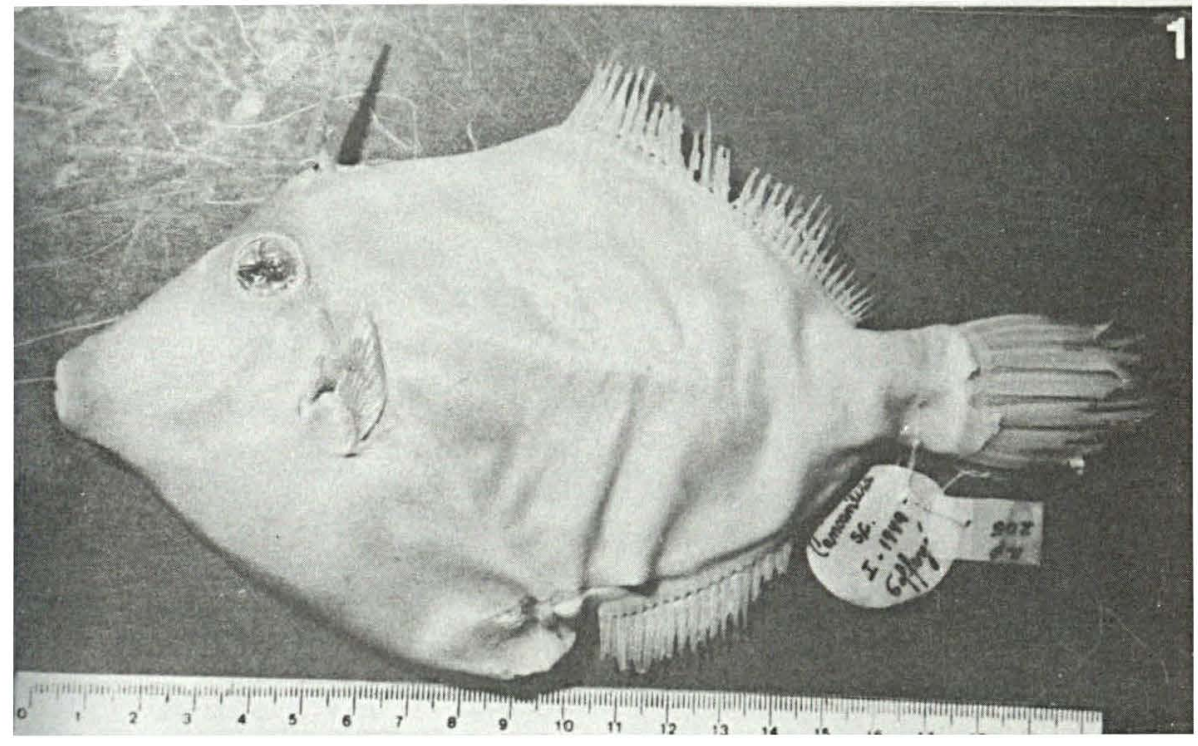

Fig. XXXIV - Classe Osteichthyes - Ordem Perciformes - Família Monoacanthidae 1. Stephanolepis hispidus (Linnaeus, 1766) 

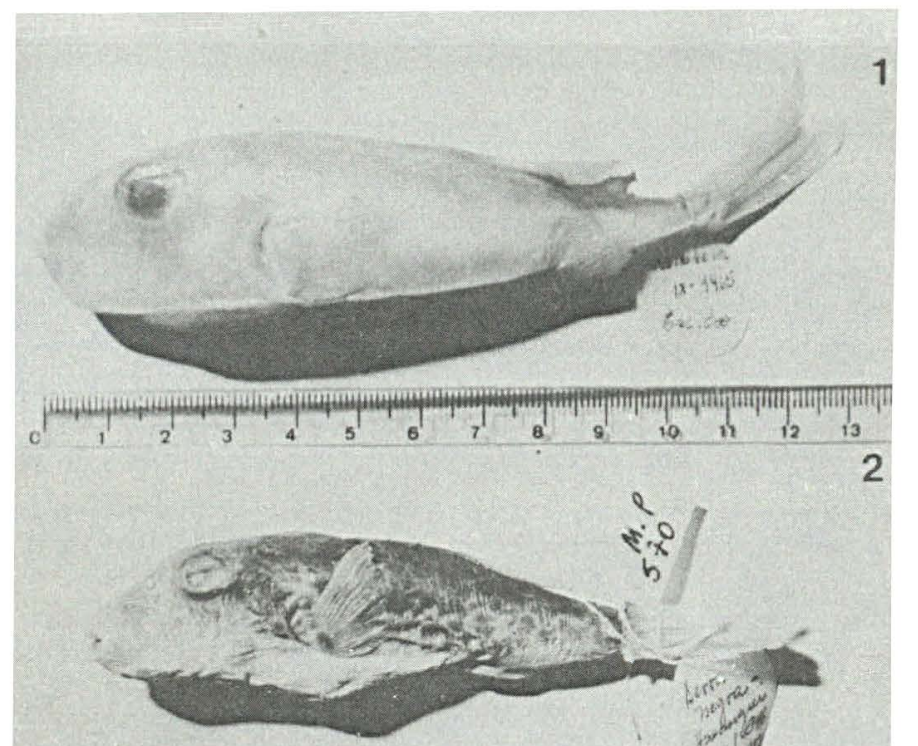

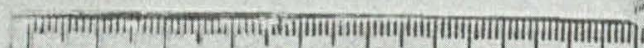

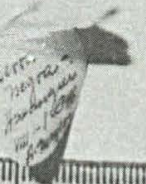

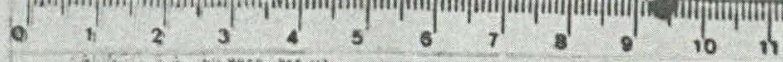

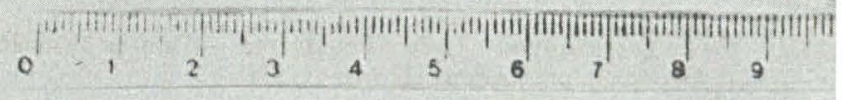

Fig. XXXV - Classe Osteichthyes - Ordem Perciformes - Família Tetraodontide

1. Lagocephalus laevigatus (Linnaeus, 1766)

2. Sphoeroides tyleri Shipp, 1972

3. Sphoeroides greeleyi Gilbert, 1900

4. Sphoeroides testudines (Linnaeus, 1758) 


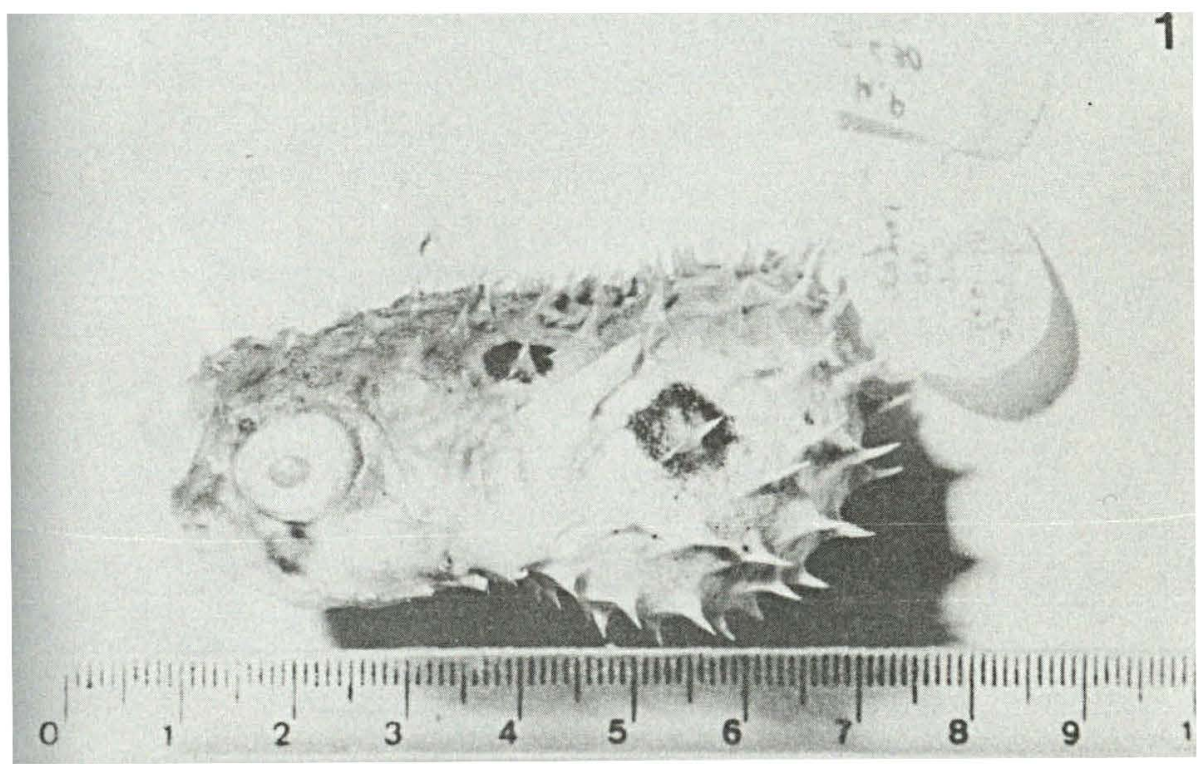

Fig. XXXVI - Classe Osteichthyes - Ordem Perciformes - Família Diodontidae 1. Chilomycterus spinosus (Linnaeus, 1758) 